\title{
Financial decision making in incomplete markets
}

Citation for published version (APA):

Floroiu, O. (2015). Financial decision making in incomplete markets. [Doctoral Thesis, Maastricht University]. Maastricht University. https://doi.org/10.26481/dis.20150409of

Document status and date:

Published: 01/01/2015

DOI:

10.26481/dis.20150409of

Document Version:

Publisher's PDF, also known as Version of record

\section{Please check the document version of this publication:}

- A submitted manuscript is the version of the article upon submission and before peer-review. There can be important differences between the submitted version and the official published version of record.

People interested in the research are advised to contact the author for the final version of the publication, or visit the DOI to the publisher's website.

- The final author version and the galley proof are versions of the publication after peer review.

- The final published version features the final layout of the paper including the volume, issue and page numbers.

Link to publication

\footnotetext{
General rights rights.

- You may freely distribute the URL identifying the publication in the public portal. please follow below link for the End User Agreement:

www.umlib.nl/taverne-license

Take down policy

If you believe that this document breaches copyright please contact us at:

repository@maastrichtuniversity.nl

providing details and we will investigate your claim.
}

Copyright and moral rights for the publications made accessible in the public portal are retained by the authors and/or other copyright owners and it is a condition of accessing publications that users recognise and abide by the legal requirements associated with these

- Users may download and print one copy of any publication from the public portal for the purpose of private study or research.

- You may not further distribute the material or use it for any profit-making activity or commercial gain

If the publication is distributed under the terms of Article $25 \mathrm{fa}$ of the Dutch Copyright Act, indicated by the "Taverne" license above, 
Financial decision making in incomplete markets 


\section{(C) 2015 Oana Floroiu}

All rights reserved. No part of this publication may be reproduced, stored in a retrieval system or transmitted, in any form or by any means, electronic, mechanical, photocopying, recording or otherwise, without the prior permission in writing from the author.

ISBN 978-90-9028877-2 


\title{
Financial decision making in incomplete markets
}

\author{
DISSERTATION \\ to obtain the degree of Doctor at Maastricht University, \\ on the authority of the Rector Magnificus, \\ Prof. dr. L.L.G. Soete, \\ in accordance with the decision of the Board of Deans, \\ to be defended in public \\ on Thursday, the $9^{\text {th }}$ of April 2015, at 16:00 hours
}

by

Oana Floroiu 
Supervisor(s):

prof. dr. Piet Eichholtz

prof. dr. Antoon Pelsser

\section{Assessment Committee:}

prof. dr. Peter Schotman (chairman)

prof. dr. Rob Bauer

prof. dr. Frank de Jong, Tilburg University

dr. Jeroen de Munnik, PGGM

This research was made possible with the financial help of the Netherlands Organization for Scientific Research (NWO). 


\section{Preface}

Thinking back to the story of how my dissertation came into being and of how I developed throughout the years while writing it, I realize that this process is not only the result of the three years of the PhD program but of a longer journey, which started in Maastricht in February 2009 when I first came to the Netherlands for my master's. Since then, I have met numerous people, who, whether they know it or not, have contributed to the story by adding different pieces and whom I would like to mention.

I always viewed the $\mathrm{PhD}$ experience as a time to learn about many different research areas and not so much as a time to specialize in a particular research area. I think my supervisors Piet Eichholtz and Antoon Pelsser understood that from the beginning, so I would like to thank them for giving me the freedom to pursue different research ideas and experiment with different types of research papers. Piet, thank you for teaching me to tell the story of a paper, in writing as well as in presentations, in such a way that the audience sees it as enthusiastically as I do. Antoon, I did not only look up to you professionally, I also saw you as a mentor. Thank you for your guidance throughout the years.

I would also like to thank Rob Bauer, Frank de Jong, Jeroen de Munnik and Peter Schotman for being part of the assessment committee and for the valuable feedback on my dissertation. Your comments and suggestions are greatly appreciated.

Few people know this, but the first person to ever introduce me to the possibility of applying for a PhD program was Frank Lutgens, my master thesis supervisor during the Financial Economics master. Frank, thank you for all your advice and help during the $\mathrm{PhD}$ application process.

Rob Bauer and Paul Smeets also played a special role. Rob, thank you for convincing me to apply for the $\mathrm{PhD}$ program and not move to Amsterdam as I had originally planned. Paul, thank you for giving me the opportunity to work as your research assistant and get to know the Finance Department better.

Jaap Bos, Paulo Rodrigues and Peter Schotman, I have learnt from you how to think about research problems and how to tackle them. I am truly grateful for your availability throughout the years to answer my numerous questions and for your enthusiasm and willingness to help me progress in my work. 
At the end of my first year of PhD, I visited the School of Banking and Finance of the University of New South Wales in Sydney. I would like to thank Thomas Post for making this visit possible. I would also like to thank Jerry Parwada for inviting me to visit UNSW and David Colwell for his valuable feedback on what is now Chapter 2 of this dissertation. It was an incredible opportunity for me, especially so early in the $\mathrm{PhD}$ program.

I would also like to thank all my fellow PhDs in the Finance Department. Regardless of the length of time we shared, we inevitably became part of each other's daily frustrations surrounding the writing of our dissertations. In particular, I will mention here Aleks, who is an invaluable source of knowledge and the voice of reason when one seeks advice, Andrea for the pragmatic attitude towards "getting the book done", Matteo, who managed to make me understand fixed and random effects, Anna, who shared office with me towards the end of my $\mathrm{PhD}$, it was a pleasure procrastinating with you, Gaby, Gildas and Mukul, my partners in crime and fellow tutors of the Risk Management course, Rogier H. and Omar, my fellow tutors of the Corporate and Venture Finance course, Judy, who proof-read my Introduction and Conclusion chapters, and Rogier Q., who is simply the go-to person whenever in doubt about econometrics.

Carina, Cecile, Els and Francien, I am grateful for all the administrative issues surrounding the dissertation that you took care of (and all the times you signed on my behalf).

My friends Gabri, Lennart, Nadine and Vera practically witnessed the manuscript being put together over the years. Thank you for brainstorming, proof-reading, giving feedback after presentations and for the technical support with various annoying software.

I would like to thank Leonard Wolk, my best friend and companion, for being a professional inspiration. 


\section{Contents}

1. Introduction

2. Closed-form solutions for options in incomplete markets …………............................................

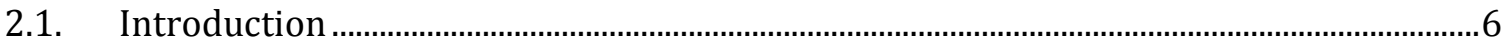

2.2. Incomplete markets - a closer look …………....................................................................... 10

2.2.1. Pricing contingent claims with model ambiguity .................................................................11

2.2.2. Good deal bounds, coherent measures of risk and model ambiguity...........................14

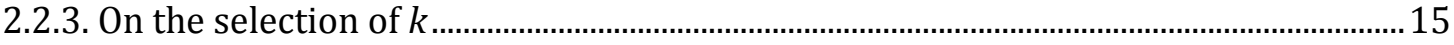

2.2.4. Interpretation of the upper and lower price bounds .................................................... 16

2.2. The European call option in incomplete markets .............................................................17

2.3.1. Upper and lower bound closed-form solutions ................................................................. 17

2.3.2. Implications for the European call option ................................................................... 18

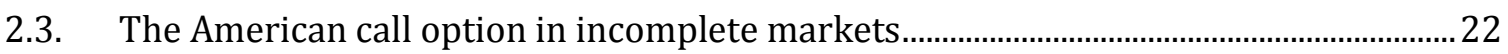

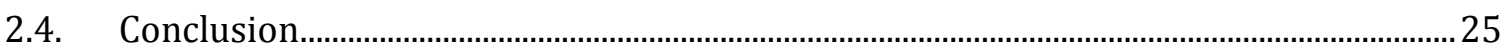

3. The informational content of infinite maturity bonds ……………......................................... 27

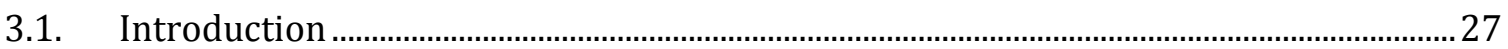

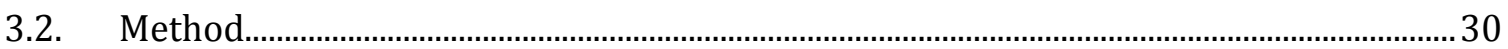

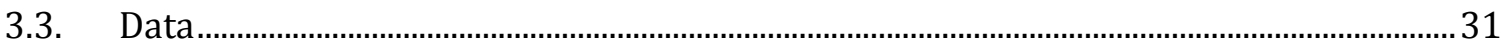

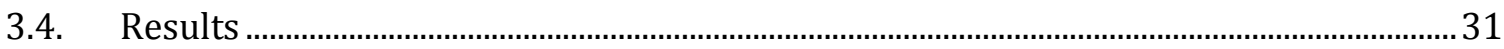

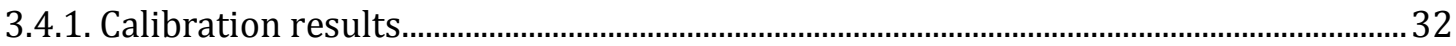

3.4.2. The determinants of the mispricing .................................................................................... 33

3.4.3. Implied long-term discount rate........................................................................................ 39

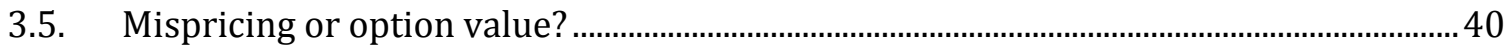

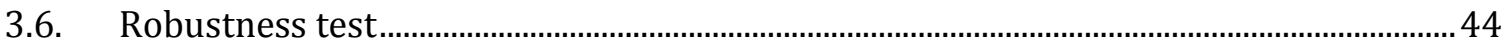

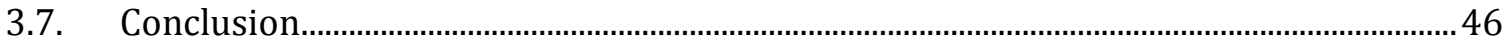

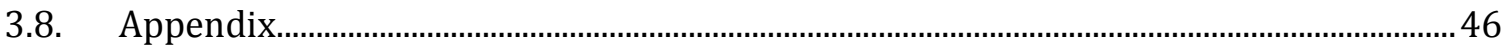

4. The role of corporate political contributions in the allocation of government

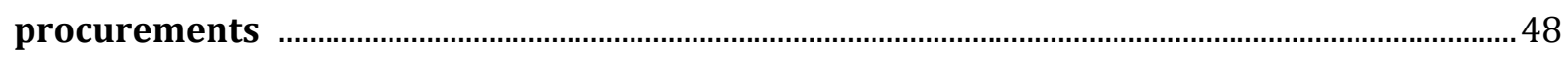

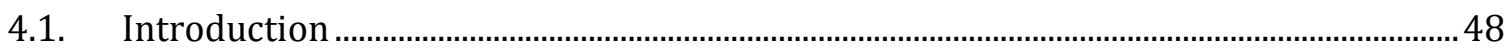

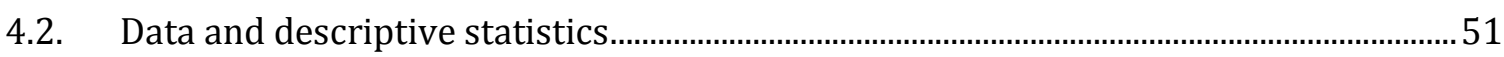

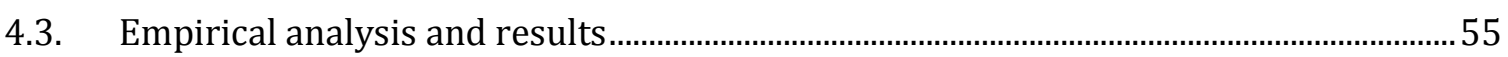

4.3.1. Corporate political contributions and subsequent procurement contracts ......... 56

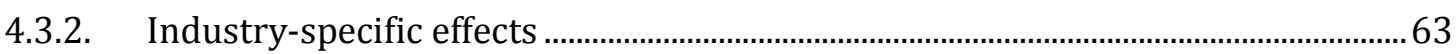

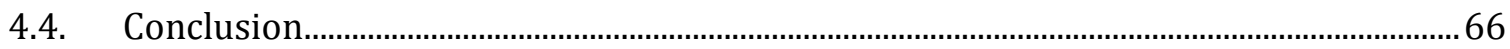

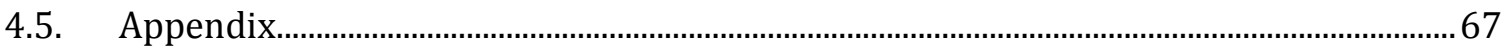




\section{CONTENTS}

5. Concluding remarks 68

References .70

Knowledge valorization 74

Biography .76 


\section{Chapter 1}

\section{Introduction}

'[A]mongst the effects [of the Black-Scholes option pricing model] was to shift patterns of option prices towards the model.' (MacKenzie, 2009, p. 3)

Most financial models are based on the assumption that markets are complete and the classical example of a complete market is the setting of the Black-Scholes (1973) option pricing model. In a complete market, the payoff of any asset can be perfectly replicated with the existing other assets without any frictions; in other words, there exists a market for every asset. The BlackScholes (1973) model is one of the most important developments of modern finance, but, despite the model's popularity and importance, the complete market assumption remains unattainable for some applications. In reality, most markets can be described as incomplete, at least at certain points in time.

My dissertation revolves around the idea of incomplete markets. Björk (2009) defines an incomplete market as a market where there are more sources of randomness than traded assets (except for the risk free asset). This means that there is a shortage of traded assets for some states of the world. Consequently, it is impossible to trade one asset for every state of the world to ensure against all future risks. There are several situations in which a market becomes incomplete: if the price of certain assets exhibits features like jumps or stochastic volatility, if we are confronted with transaction costs or portfolio constraints, or if there exist non-traded or infrequently traded assets. I focus on incompleteness which arises due to some of the assets in the market being either non-traded or infrequently traded.

There are two direct consequences of market incompleteness. First, not all risks can be perfectly traded and hedged in the financial markets. Second, the price of a generic claim is no longer unique. For a market to not have any arbitrage opportunities, the number of traded assets must be small compared to the number of sources of risk, whereas for a market to be complete, the number of traded assets must be large compared to the number of sources of risk. Consequently, the only way for a market to be complete and not present any arbitrage opportunities is if the number of traded assets is exactly equal to the number of sources of risk. This means that, in a complete market, there is only one price system for the price of a claim. Solving this system will 
lead to a unique solution, hence a unique price for the claim. However, once the market becomes incomplete and is comprised of less traded assets than sources of risk, there will be several different price systems for the price of the claim. All these systems will be consistent with absence of arbitrage, but not sufficient to arrive at a unique price.

The studies in this dissertation can be placed in the general framework of incomplete markets. The first instance of market incompleteness that I deal with is that of contingent claims, for instance options written on non-traded or infrequently traded assets. In Chapter 2, I investigate what changes must be made to the traditional pricing mechanism when the underlying asset of the option is either non-traded or infrequently traded. Traditional option pricing is represented by the Black-Scholes (1973) model, where the price of the option is established by means of a riskless replicating portfolio whose instantaneous return must be equal to the return of a riskless asset. However, the replicating portfolio exists only if the underlying asset can be continuously traded. In the current market setting, the underlying does not satisfy this condition, which means that the option valuation based on replication arguments is no longer possible.

I show in my analysis how to derive analytical formulas for European and perpetual American call options written on non-traded or infrequently traded assets. Given that the market is incomplete, the option price is not unique, but the set of possible prices can be restricted. My approach to narrowing the price interval is to restrict the volatility of the stochastic discount factor. This results in modified Black-Scholes (1973) closed-form solutions for an upper and a lower bound of the price of the call option. I find that, contrary to standard option pricing theory, the prices do not always display an increasing pattern when the volatility of the underlying asset increases. In fact, I show that the lower bound prices can decrease in response to an increase in the volatility of the underlying asset, when the underlying is either infrequently traded or nontraded.

The main contribution of Chapter 2 is to bring forward this inverse relationship between the option value and the volatility of the underlying, as well as the potential for early exercise at the lower bound even for an American call option on a non-dividend paying asset when the market is incomplete. At the lower bound, the option value decreases as the volatility of the underlying asset increases, forcing the economic agent to exercise his option early for fear that, if he continues to wait, he might lose the entire value of the claim. 
A potential application for the pricing mechanism described in Chapter 2 is the valuation of real options. Real options are investments in non-financial assets like land, buildings, even oil concessions or mines. We can think of land as a real option. Titman (1985) put forward the idea of pricing vacant land as a European call option on a building that could potentially be built on that land. The underlying asset of such an option is the building, the strike price is the construction cost and the exercise time is at the start of the development. Titman's (1985) main assumptions are that the market on which the real option exists is frictionless and that the price of the option can be calculated by means of replicating arguments. But buildings are infrequently traded assets. Even if at some point in time we observe a trade for a particular property, the same property might never be traded again or, at best, it will be traded at large intervals of time. Furthermore, each property is unique and it is therefore impossible to trade multiple homogeneous units of a building the way we do with liquid assets like stocks. Within this framework, we do not have the possibility to price the real option with the Black-Scholes (1973) option pricing formula. However, the good-deal bounds valuation technique can price this real option, provided that there exists a traded asset correlated with the underlying, for instance a REIT (Real Estate Investment Trust).

It is often the case that real options theory is used to turn a negative NPV project into a positive NPV project, where the total NPV of a project is the sum of the traditional NPV value and the real option value. This can indeed happen if we apply the Black-Scholes (1973) formula in any setting disregarding whether or not the main assumptions are satisfied, given that higher volatility of the underlying asset in the formula automatically leads to a higher price. Chapter 2 shows that in an incomplete market setting, the price of the real option can actually decrease with an increase in the volatility of the underlying asset, meaning that investors can take a more conservative approach to pricing and avoid overestimating the value of an asset.

The second case of market incompleteness that I explore in my dissertation is the problem of pricing very long-dated cash flows. The longest maturities for government bonds traded in the market are usually 25 or 30 years, meaning that if we want to value cash flows with maturities longer than 30 years we are again in an incomplete market situation due to the presence of nontraded assets.

In Chapter 3, I investigate how the market implicitly prices very long-dated cash-flows. I look at the prices of UK infinite maturity bonds, which were first issued in the $18^{\text {th }}$ century. Some of them are still traded today. I compute theoretical prices for these bonds and show that they are a cheap investment, because they are generally underpriced. The results show that the mispricing 
is mainly driven by volatility in financial markets and not by expectations of the economic outlook as one might think.

Such problems are important to investigate, because they could reveal valuable information about what the term structure of interest rates should look like beyond traded maturities. The market prices of the UK infinite maturity bonds imply a constant discount rate beyond traded maturities that is higher than the last observed rate, suggesting a slightly upward sloping yield curve.

The research in this chapter has implications for pension funds all over the world as they are increasingly more affected by changing demographics. The ratio of workers per retiree is decreasing at an alarming rate, making pension funds fear that they will soon not be able to honor their obligations anymore. This problem can be addressed not only through social policies, but also in terms of how the pension system as a whole is set up. In order to assess the magnitude of the problem, one must be able quantify how underfunded the pension funds are. Consequently, one must be certain they are discounting the obligations with the correct discount rate, otherwise the value we calculate to be put aside in order to meet later obligations might not be the true value of the obligations. Chapter 3 discusses the need to devise a way to discount very distant cash flows and points towards potential financial instruments that could provide a solution, like the UK infinite maturity bonds.

The last incomplete-market setting that I study is related to the market for political contributions. The activity of companies is affected by the political decisions made in the country they operate in. However, one cannot trade in political decisions hence the market for political risk can be considered incomplete. It is natural though for companies to want to hedge against the risk of political decisions. In Chapter 4, I gather extensive information on all S\&P500 companies in a time span of 18 years (i.e., between 1993 and 2010). In particular, I focus on the political contributions they make to US Congressional election campaigns and the government procurements they receive following these contributions. What I observe in the data is that the vast majority of S\&P500 companies contribute to election campaigns of candidates from both the Democratic and the Republican Party, which could be assimilated to a partial hedge against this type of risk.

The results of this last study show that, in order to maximize the procurement value in the next period, companies should contribute to a large number of candidates taking part in Congressional races and preferably to candidates of the Republican Party. The effect of 
contributions on the subsequent procurement value is positive and statistically significant not only in the whole sample analysis, but also in sub-sample analysis. There appears to be a reciprocal relationship between contributing S\&P500 companies and the government in all election cycles, where an election cycle is defined as the two-year period between US Congressional elections in which an elected candidate exerts his term and contributions can be made for the next election.

Election campaigns are something that everyone is familiar with and can relate to. The way these campaigns are funded and whether or not there is a connection between their outcome and public sector expenditures in the form of procurements is of importance to all tax payers. Chapter 4 opens the door for a discussion on a principal-agent type of problem (check this again). The agent in this case is the politician and the principal is the constituency. The politician is elected by the constituency and hence is expected to act in the best interests of this constituency. However, the politician's decisions can be influenced by a third party - the highest paying interest group. The politician's interest is to remain in power for as long as possible, thus he seeks reelection and collects political contributions in order to fund his election campaigns. If the politician promises political favors after reelection in return for generous contributions from high paying interest groups, this could be done at the expense of the interests of the constituency. In the end, it all boils down to how well government money is spent and whether or not it is actually spent in the interest of the tax payers.

Overall, this dissertation brings together three different studies within the framework of incomplete markets and touches upon pricing and hedging issues in this particular framework. Its goal is not to give an exhaustive treatment of incomplete markets, but to show the importance of this concept and the various situations in which it can appear and how it can alter established results based on complete market arguments. 


\section{Chapter 2}

\section{Closed-form solutions for options in incomplete markets ${ }^{1}$}

\subsection{Introduction}

The purpose of this paper is to show how call options written on infrequently traded or nontraded assets can be priced in the setting of incomplete markets. Specifically, we assume that the underlying asset of the option carries both hedgeable and unhedgeable risk and apply the principles of model ambiguity to value the option and bring new insights into the predictions of standard option pricing models. The result is a modified Black-Scholes (1973) closed-form solution. We derive an upper and a lower bound for the price of the option and find that, contrary to standard option pricing theory, the incomplete market option prices do not always display an increasing pattern when the volatility of the underlying asset increases. In fact, we show that the lower bound prices can decrease in response to an increase in the volatility of the underlying asset, when the underlying is either infrequently traded or non-traded.

The main contribution of our paper is to highlight the existence of the inverse relationship between the option value and the volatility of the underlying asset and the potential for early exercise even for an American call option on a non-dividend paying asset. These features appear in an incomplete market as direct consequences of unhedgeable risk coming from an infrequently traded or even non-traded underlying asset. However, they are overlooked by complete market models, because such models take into account only hedgeable sources of risk.

Standard option pricing models are complete market models, which assume that all sources of risk can be perfectly hedged against and that options can be priced based on replication arguments. The main prediction of such models is that option value increases with an increase in the volatility of the underlying asset. The problem is that, if the underlying asset of an option is an infrequently traded asset or even a non-traded one, the replication arguments fall apart, because we can no longer construct a riskless replicating portfolio out of a risk-free asset and

\footnotetext{
1 This is joint work with prof. dr. Antoon Pelsser. We are grateful for all the helpful comments we received from our colleagues at Maastricht University and the audiences at the 2013 ASTIN Colloquium of the International Actuarial Association in the Hague, the 2012 World Congress of the Bachelier Finance Society in Sydney, the School of Banking and Finance of University of New South Wales in Sydney, whose hospitality is highly appreciated, and the 2012 AsRES - AREUEA Joint International Conference in Singapore. The authors also thank NWO (the Dutch Organization for
} 
the underlying asset and equate the price of the option with the cost of this replicating portfolio as in the Black-Scholes (1973) option pricing model.

This problem has been considered before. There are three strands of literature which try to tackle the problem: utility indifference pricing, pricing via coherent risk measures and pricing via a Sharpe ratio criterion.

Utility indifference pricing assumes a utility function for a representative agent who maximizes his utility of wealth, where wealth is influenced by an investment in the option. Duffie et al. (1997) derive optimal consumption and portfolio allocations in the context of incomplete markets. Davis (2006) focuses on the optimal hedging strategy in an incomplete market where an option is written on a non-traded asset and shows that the difference between complete and incomplete market prices is substantial.

Henderson (2007) and Miao and Wang (2007) restrict their analyses to real estate projects and derive semi-closed form solutions for options written on real estate assets using the utility indifference pricing technique. Both Henderson (2007) and Miao and Wang (2007) show that market incompleteness, in particular the degree of risk aversion, can actually reduce the option value.

The utility indifference pricing approach is a promising candidate for a pricing mechanism. It is a convenient method to derive a partial differential equation that the option price must satisfy. However, results have been obtained mainly for exponential utility and power utility. Furthermore, exponential utility cannot price short call positions, because the prices converge to infinity (Henderson and Hobson, 2004), and power utility cannot price any short positions (Henderson (2002) and Henderson and Hobson (2002)).

Pricing via a coherent risk measure was first introduced by Artzner et al. (1999) and it is defined as the supremum of the expected negative of final net worth for a set of probability measures. Carr et al. (2001) refine this idea. They argue that economic agents will not only invest in any arbitrage opportunity, but also in any opportunity that seems acceptable given their level of risk aversion. The problem is that the concept of 'acceptable opportunity' is a subjective one and it cannot be easily generalized to a market, but it rather characterizes a particular economic agent.

Scientific Research) for the generous support in the form of a three-year grant via the Graduate Programme 2011 (correspondence number 2011/08865/BOO). 
Hansen and Jagannathan (1991) and later Cochrane and Saa-Requejo (2000) put forward the idea of pricing via a Sharpe ratio criterion, by exploiting the fact that investors would always trade in assets with very high Sharpe ratios and pure arbitrage opportunities. Whenever we want to price a general claim, we calculate the expectation of a stochastic discount factor times the payoff of that claim (Cochrane, 2005). This is straightforward in a complete market, where all assets are assumed to be traded which means that we can observe their market price of risk. The volatility term of the stochastic discount factor is nothing else than the Sharpe ratio of the asset we are trying to price (Cochrane, 2005). Unfortunately, in an incomplete market, we cannot observe the market price of risk, because here there are also infrequently traded or even non-traded assets. We can however distinguish between hedgeable and unhedgeable risk and express the market price of risk for the unhedgeable component in terms of what we already know: the Sharpe ratio of a traded asset. This Sharpe ratio is an essential tool in determining the expression for the overall volatility of the stochastic discount factor, such that we can restrict the set of all possible discount factors to obtain the option price.

The methodology we propose takes the model ambiguity framework of Hansen and Sargent (2001) and Andersen et al. (2003) and applies it to the pricing of contingent claims. Model ambiguity starts from the idea that the model used might be misspecified and allows for parameter uncertainty by specifying a confidence interval around the drift and diffusion terms of a stochastic process. We assume that the diffusion is known with certainty, but that there is uncertainty regarding the drift term. Furthermore, we restrict the total volatility of the stochastic discount factor to be lower than or equal to an exogenous $k$ and show that imposing this restriction is equivalent to setting a confidence interval around the drift term of a stochastic process. The result is a finite set of stochastic discount factors, leading to an interval for the option price. We study the upper and lower bound prices and document the different properties comparing to the complete market prices of the Black-Scholes (1973) model.

The parameters which ultimately determine the incomplete market value of the option are the volatility of the underlying asset, the restriction on the volatility of the stochastic discount factor, the correlation coefficient between the underlying and a traded risky asset and the expected return of the investment. Interestingly, unlike in the standard option pricing models, the incomplete market option prices do not always increase as the volatility of the underlying asset increases. In fact, the lower bound prices are decreasing with increasing volatility of the underlying. This is a reflection of the additional uncertainty coming from the presence of unhedgeable risk, a feature of an incomplete market but not of the Black-Scholes (1973) complete-market setting. 
The negative relationship between option value and the volatility of the underlying gives rise to another phenomenon: the early exercise of an American call option even for a non-dividend paying asset. At the lower bound, the option value is decreasing with increasing volatility of the underlying asset, forcing the economic agent to exercise his option early for fear that, if he continues to wait, he will lose the entire value of the claim.

The advantage of our pricing mechanism over other incomplete market techniques is that the resulting option prices do not depend on a risk aversion parameter. However, even though one need not make any assumptions about the utility function of a representative economic agent and implicitly about this agent's level of risk aversion, one is still required to impose a restriction on the total volatility of the stochastic discount factor. This restriction is an exogenous parameter in our framework.

Our closed-form solutions are comparable to the Black-Scholes (1973) option price. For very low values of the volatility of the underlying, the only source of uncertainty comes from the traded asset and we are back in the Black-Scholes (1973) framework. Similarly, for very high values of the correlation coefficient $\rho$, the upper and lower bound prices approach the Black-Scholes (1973) price by $\sqrt{1-\rho^{2}}$, meaning that there is a large gap between the prices on an almost complete market and the Black-Scholes price at $\rho=1$. Even at a $\rho=0.99, \sqrt{1-\rho^{2}}$ is already equal to 0.14 . This is also documented by Davis (2006) via a utility indifference approach. Furthermore, when the restriction on the volatility of the stochastic discount factor is exactly equal to the Sharpe ratio of the traded asset, we again exit the incomplete market setting and the incomplete market prices converge to the Black-Scholes (1973) price. In other words, we generalize the market setting to the incomplete market and bring it closer to real life, yet, at the same time, maintain a reference point, which is the Black-Scholes (1973) result.

The remainder of this chapter is organized as follows: Section 2.2 develops an incomplete market pricing mechanism by applying model ambiguity concepts to the pricing of general claims, Section 2.3 derives closed-form solutions for a European call option in incomplete markets and analyzes the behavior of these prices for different parameter values, Section 2.4 presents closedform solutions for a perpetual American call option in incomplete markets, and Section 2.5 concludes. 


\subsection{Incomplete markets - a closer look}

The classical complete market model, the Black-Scholes (1973) option pricing model, relies on the following assumptions: the price process for the underlying asset follows a geometric Brownian motion, the underlying asset is continuously traded and it pays no dividends, short selling is allowed, there are no transaction costs or taxes and there are no riskless arbitrage opportunities (Hull, 2012). In reality though, economic agents are confronted with a series of imperfections. For instance, whenever non-traded or infrequently traded assets are present in a market, that market becomes incomplete, because there are more sources of randomness than traded assets to span them (Björk, 2009).

The continuous trading assumption is the one that makes our case. The underlying idea of the Black-Scholes (1973) model is that we can construct a riskless replicating portfolio, by selling the option and buying delta units of the underlying asset. To satisfy the no-arbitrage condition, we then equate the instantaneous return of this portfolio with the return of a riskless asset. However, this is only possible because we can continuously trade in the underlying asset of the option. But, in a market that is incomplete due to the presence of infrequently traded or even non-traded assets, if the underlying happens to be one of these problematic assets, then we can no longer perform the option valuation based on replication arguments.

As Duffie (1987) shows, the problem with pricing in incomplete markets is that imposing the noarbitrage condition is no longer sufficient to arrive at a unique price for a general contingent claim (i.e., for a financial derivative). Take for example a non-traded underlying asset. It is impossible to exactly replicate a claim on such an asset, so we can expect to be confronted with more than one price system consistent with absence of arbitrage for this claim. In fact, if we just impose the no-arbitrage condition, the price will be situated within the arbitrage bounds (i.e., the interval given by all the possible values for the option price that satisfy the no-arbitrage condition). For a call option, the lower arbitrage bound is zero and the upper arbitrage bound is the price of the underlying. Such an interval is not very informative, because it is too wide to be useful. The solution is to make additional assumptions about the choice of the pricing kernel (Duffie et al., 1997).

The solution we propose applies the idea of model ambiguity of Hansen and Sargent (2001) and Anderson et al. (2003) to the pricing of contingent claims. Model ambiguity acknowledges the fact that the model used might be misspecified and assumes a confidence interval around the drift and diffusion terms of a stochastic process. We make the assumption that there is 
uncertainty only around the drift term of a stochastic process and that this process is the underlying of a contingent claim. We show that this uncertainty in the drift term is equivalent to restricting the volatility of the stochastic discount factor to be at most $k$, where $k$ is exogenously determined, and that we can establish an upper and a lower bound price for the contingent claim.

\subsubsection{Pricing contingent claims with model ambiguity}

We analyze pricing in incomplete markets for the special case of a monotonically increasing payoff - the call option - and we derive upper and lower bound prices for this special case. We assume partly hedgeable and partly unhedgeable risk and that we can find on the market a traded risky asset, correlated with the illiquid underlying asset, with which we can hedge the underlying at least partly.

We have a call option written on an infrequently traded asset $V$. There exists a traded riskless asset $B$, a traded risky asset $S$, for instance a stock, which is correlated with $V$ and which we can use as a partial hedge for $V$. The dynamics of the assets are:

$$
\begin{gathered}
d S_{t}=\mu_{S} S_{t} d t+\sigma_{S} S_{t} d W_{1} \\
d V_{t}=\mu_{V} V_{t} d t+\sigma_{V} V_{t}\left(\rho d W_{1}+\sqrt{1-\rho^{2}} d W_{2}\right) \\
d B_{t}=r B_{t} d t
\end{gathered}
$$

where $\rho$ is the correlation coefficient between assets $V$ and $S,\left(W_{1}, W_{2}\right)$ is a two-dimensional standard Brownian motion and $r$ is a deterministic short interest rate.

Like any other contingent claim, our call option can be priced as the expectation of a stochastic discount factor times the payoff of the option (Björk, 2009):

$$
C_{t}=E_{t}^{P}\left[\frac{\Lambda_{T}}{\Lambda_{t}}\left(V_{T}-K\right)^{+}\right]
$$

where $\quad C$ - the price of the call option

$\Lambda$ - a stochastic discount factor

$E^{P}$ - the expectation under the probability measure $P$

$V_{T}$ - the value of the infrequently traded asset at maturity time $T$

$K$ - the constant strike price of the option 
In order to price the option, we need a change of probability measure from the physical (or realworld) measure $P$, to an equivalent measure, which we generically call $Q_{A}$. We search for any probability measure $Q_{A}$ equivalent to the physical measure $P$. The stochastic discount factor $\Lambda$ is then the product of a risk-free discount factor and the Radon-Nikodym derivative $d Q_{A} / d P(B j o ̈ r k$, 2009). The price of the option under the probability measure $Q_{A}$ is given by:

$$
C_{t}=e^{-r(T-t)} E_{t}^{Q_{A}}\left[\left(V_{T}-K\right)^{+}\right]
$$

The process for the stochastic discount factor must price both hedgeable and unhedgeable sources of risks:

$$
d \Lambda_{t}=-r \Lambda_{t} d t-\kappa_{1} \Lambda_{t} d W_{1}-\kappa_{2} \Lambda_{t} d W_{2}
$$

where: $\quad \kappa_{1}$-market price of hedgeable risk

$\kappa_{2}$ - market price of unhedgeable risk

In a complete market, the volatility of the stochastic discount factor can be interpreted as the market price of risk or the Sharpe ratio of a traded risky asset. Furthermore, the martingale measure can be uniquely identified as the risk-neutral measure, leading to a unique price. In fact, it was Hansen and Jagannathan (1991) who first put forward the idea that in a complete market restricting the volatility of the stochastic discount factor is equivalent to restricting the Sharpe ratio of a traded risky asset. In an incomplete market, we can no longer uniquely identify the martingale measure. We can however restrict the set of possible stochastic discount factors.

First, following Hansen and Jagannathan (1991), we fix the market price of hedgeable risk $\kappa_{1}$ to be equal to the Sharpe ratio $\frac{\mu_{S}-r}{\sigma_{S}}$ of asset $S$, which is an observable quantity. The stochastic discount factor in this context becomes:

$$
d \Lambda_{t}=-r \Lambda_{t} d t-\frac{\mu_{S}-r}{\sigma_{S}} \Lambda_{t} d W_{1}-\kappa_{2} \Lambda_{t} d W_{2}
$$

Next, we restrict the total volatility of the stochastic discount factor to be at most $k$ :

$$
|\kappa|=\sqrt{\kappa_{1}^{2}+\kappa_{2}^{2}} \leq k
$$

After substituting $\kappa_{1}=\frac{\mu_{S}-r}{\sigma_{S}}$ and solving for $\kappa_{2}$, we find: 


$$
\kappa_{2} \in\left[-\sqrt{k^{2}-\left(\frac{\mu_{S}-r}{\sigma_{S}}\right)^{2}}, \sqrt{k^{2}-\left(\frac{\mu_{S}-r}{\sigma_{S}}\right)^{2}}\right]
$$

Even though $\kappa_{2}$ cannot be observed, because it is the market price of unhedgeable risk, it can be expressed in terms of the exogenous restriction $k$ and the observable market price of hedgeable risk. The interval for $\kappa_{2}$ leads to an interval for the option price with an upper and a lower bound.

The change of probability measure from measure $P$ to measure $Q_{A}$ implies a two-dimensional Girsanov transformation on process $V$ :

$$
\begin{gathered}
d W_{1}=d \widehat{W}_{1}-\frac{\mu_{S}-r}{\sigma_{S}} d t \\
d W_{2}=d \widehat{W}_{2}-\kappa_{2} d t
\end{gathered}
$$

leading to a new stochastic process for $V$ with a modified drift term:

$$
d V_{t}=\left(\mu_{V}-\sigma_{V} \rho \frac{\mu_{S}-r}{\sigma_{S}}-\sigma_{V} \sqrt{1-\rho^{2}} \kappa_{2}\right) V_{t} d t+\sigma_{V} V_{t}\left(\rho d \widehat{W_{1}}+\sqrt{1-\rho^{2}} d \widehat{W}_{2}\right)
$$

Notice that the Girsanov transformation affects only the drift term of process $V$ and the adjustment it makes is equal to the volatility of the stochastic discount factor. The expected return $\mu_{V}$ is now lower by the market price of each type of risk, but proportionately to how much can be hedged and how much is left unhedged ( $\rho$ and $\sqrt{1-\rho^{2}}$, respectively).

It can be shown that at the upper bound $\kappa_{2}=-\sqrt{k^{2}-\left(\frac{\mu_{S}-r}{\sigma_{S}}\right)^{2}}$ and at the lower bound $\kappa_{2}=\sqrt{k^{2}-\left(\frac{\mu_{S}-r}{\sigma_{S}}\right)^{2}}$. Using the Feynman-Kac formula, it follows that the option price $C$ must satisfy a PDE of the form:

$$
\frac{\partial C}{\partial t}+\left(\mu_{V}-\sigma_{V} \rho \frac{\mu_{S}-r}{\sigma_{S}}-\sigma_{V} \sqrt{1-\rho^{2}} \kappa_{2}\right) V_{t} \frac{\partial C}{\partial V}+\frac{1}{2} \sigma_{V}^{2} V_{t}^{2} \frac{\partial^{2} C}{\partial V^{2}}-r C=0
$$

The call price is monotonically increasing in the price of the underlying (i.e., $\frac{\partial C}{\partial V}>0$ ), which means that the value of $\kappa_{2}$ which maximizes the call value and leads to the upper bound price is $-\sqrt{k^{2}-\left(\frac{\mu_{S}-r}{\sigma_{S}}\right)^{2}}$ and the value of $\kappa_{2}$ which minimizes the call value to yield the lower bound price is $\sqrt{k^{2}-\left(\frac{\mu_{S}-r}{\sigma_{S}}\right)^{2}}$. 
The difficult step of pricing with model ambiguity is specifying the volatility restriction $k$. Once we have found a traded risky asset correlated with the non-traded (or infrequently traded) underlying asset of the option, we can express the restriction $k$ on the volatility of the stochastic discount factor in terms of the Sharpe ratio of this traded asset. Mathematically, $k$ must be at least equal to the Sharpe ratio of the risky traded asset $S$ in order for $\kappa_{2}=\left[-\sqrt{k^{2}-\left(\frac{\mu_{S}-r}{\sigma_{S}}\right)^{2}}, \sqrt{k^{2}-\left(\frac{\mu_{S}-r}{\sigma_{S}}\right)^{2}}\right]$ to be defined. The larger the difference between the restriction $k$ and the Sharpe ratio of the traded risky asset is the wider the option price bounds become. Furthermore, these particular choices of $\kappa_{2}$ are designed for monotone payoffs only.

\subsubsection{Good deal bounds, coherent measures of risk and model ambiguity}

Mathematically, the concepts of good deal bounds pricing, coherent measures of risk and model ambiguity are equivalent.

Restriction (2.8) is inspired by the model ambiguity framework of Hansen and Sargent (2001) and Anderson et al. (2003). Model ambiguity acknowledges the fact that the model used might be misspecified and assumes a confidence interval around the drift and diffusion terms of a stochastic process. Imagine that we specify a confidence interval around the drift term $\mu_{V} V_{t}$ in equation (2.2) and that we know the diffusion term with certainty. Furthermore, assume that the width of the confidence interval is $2 k$ times the standard deviation $\sigma_{V} V_{t}$. The confidence interval around the drift term is then $\left[\mu_{V} V_{t}-k \sigma_{V} V_{t}, \mu_{V} V_{t}+k \sigma_{V} V_{t}\right]$, which is exactly the representation in equation (2.12), i.e., $\left[\mu_{V} V_{t}-\left(\kappa_{1} \rho \sigma_{V}+\kappa_{2} \sqrt{1-\rho^{2}} \sigma_{V}\right) V_{t}, \mu_{V} V_{t}+\left(-\kappa_{1} \rho \sigma_{V}-\kappa_{2} \sqrt{1-\rho^{2}} \sigma_{V}\right) V_{t}\right]$ and $\sqrt{\kappa_{1}^{2}+\kappa_{2}^{2}} \leq k$.

Good-deal bounds pricing is another incomplete market pricing mechanism, which uses a restriction on the total volatility of the stochastic discount factor as an additional restriction to arrive at tighter and more informative bounds for the option price. Hansen and Jagannathan (1991) and later Cochrane and Saa-Requejo (2000) exploit the fact that investors would always trade in assets with very high Sharpe ratios and pure arbitrage opportunities. Consequently, such investments would immediately disappear from the market, so we should only be interested in a Sharpe ratio that is high enough to induce trade, but not too high to include the deals which are too good to be true. The good-deal bounds pricing mechanism is simply a tool to rule out these too good deals and the arbitrage opportunities (which Björk and Slinko (2006) call "ridiculously good deals"), such that the result is an option price within a tight and informative interval. Hodges (1998), Černý (2003) and Björk and Slinko (2006) even extend the 
Cochrane and Saa-Requejo (2000) setting to generalized Sharpe ratios for pricing in incomplete markets. If the total volatility of the stochastic discount factor $k$ is simply set equal to the Sharpe ratio of a traded risky asset, then the approach in Section 2.2.1 reduces to good-deal bounds pricing.

The representation in equation (2.8) is also a coherent measure of risk. What we search for are all measures $Q_{A}$ lower than or equal to $k$, such that we can place an upper bound $k$ on the total volatility of the stochastic discount factor. This translates into a minimization over the set of all the risk measures $Q_{A}$ and equation (2.5) can be re-written as:

$$
C_{t}=\min _{Q_{A} \leq k} e^{-r(T-t)} E_{t}^{Q_{A}}\left[\left(V_{T}-K\right)^{+}\right]
$$

In this case, the minimum of the payoff leads to the lower bound and the maximum (i.e., the minimum of the negative payoff) leads to the upper bound of the price of the call option. Under the notation in equation (2.14), our ambiguity approach to contingent claim pricing is a coherent risk measure as defined by Artzner et al. (1999). Any risk measure that is coherent satisfies the following four properties: translational invariance, subadditivity, positive homogeneity and monotonicity, and it is defined as the supremum of the expected negative of final net worth for a set of probability measures. Delbaen (2002) further shows that any coherent risk measure can be expressed as a worst expected loss over a given set of probabilities and Jaschke and Küchler (2001) link the good-deal bounds to coherent risk measures as well by showing that the gooddeal bounds are coherent valuation bounds.

\subsubsection{On the selection of $k$}

Cochrane and Saa-Requejo (2000) suggest that the bound $k$ be set equal to twice the market price of risk on the stock market. In other words, we relate the unknown $k$ to something that we can find out, the Sharpe ratio of a traded asset. Similarly, we could set $k$ equal to the highest Sharpe ratio ever documented on the equity market. It is even possible to imply the value of $k$ from market data, with a procedure similar to the one used to imply volatilities from option prices.

The best way to determine $k$ is probably the model ambiguity framework of Hansen and Sargent (2001): specify a confidence interval around the drift term of $V$ and assume that the diffusion term is known with certainty. An estimate for $k$ can be easily obtained using historical data on $V$. For a 95\% confidence interval, 
$\left[\mu_{V} V_{t}-\left(\kappa_{1} \rho \sigma_{V}+\kappa_{2} \sqrt{1-\rho^{2}} \sigma_{V}\right) V_{t}, \mu_{V} V_{t}+\left(-\kappa_{1} \rho \sigma_{V}-\kappa_{2} \sqrt{1-\rho^{2}} \sigma_{V}\right) V_{t}\right]=\left[\mu_{V} V_{t}-1.96 * S E, \mu_{V} V_{t}+\right.$ $1.96 * S E]=\left[\mu_{V} V_{t}-1.96 * \frac{\sigma_{V} V_{t}}{\sqrt{n}}, \mu_{V} V_{t}+1.96 * \frac{\sigma_{V} V_{t}}{\sqrt{n}}\right]$, meaning that $\kappa_{2}$ reduces to $\kappa_{2}=\frac{1.96-\kappa_{1} \rho \sqrt{n}}{\sqrt{n\left(1-\rho^{2}\right)}}$ and $k=\sqrt{\frac{\left(1.96-\kappa_{1} \rho \sqrt{n}\right)^{2}+\kappa_{1}^{2} n\left(1-\rho^{2}\right)}{n\left(1-\rho^{2}\right)}}$, where $\kappa_{1}=\frac{\mu_{S}-r}{\sigma_{S}}$ and $n$ is the number of years of historical data. The higher $n$ is, the lower the uncertainty around the drift term is and the tighter the price bounds are. For instance, if we assume that $\rho=0.8$ and $\kappa_{1}=0.25$, then an increase in the number of years of historical data from $n=25$ to $n=50$ determines a decrease in $k$ from 0.4 to 0.28 and implicitly a considerable tightening of the price bounds.

\subsubsection{Interpretation of the upper and lower price bounds}

Cochrane and Saa-Requejo (2000) point towards a nice interpretation of the price bounds as a bid-ask spread. The lower bound would correspond to the bid price and the upper bound, to the ask price. The bid and ask prices also relate to reservation prices. The buyer's reservation price shows the buyer's maximum valuation of an asset and the seller's reservation price his minimum valuation of that asset. For any price lower than his maximum valuation, the buyer will agree to buy and, for any price higher than his minimum valuation, the seller will want to sell. Otherwise, no transaction occurs.

The bid-ask spread idea is reiterated by Carr et al. (2001), who argue that economic agents will not only invest in any arbitrage opportunity, but also invest in any acceptable opportunity. Acceptable opportunities are defined as claims for which the difference between their payoff and their hedge is not necessarily non-negative, but simply acceptable according to the level of risk aversion of the economic agent. An arbitrage opportunity is a special case of an acceptable opportunity.

Inspired by, among others, Cochrane and Saa-Requejo (2000) and Carr et al. (2001), Cherny and Madan (2010) introduce the concepts of 'conic finance' and 'two price markets'. Essentially, they argue that every asset should be characterized by a bid and an ask price, not by one price, and derive closed-form solutions for both put and call options. The presence of the bid-ask spreads is motivated by the different levels of liquidity in the market. 


\subsection{The European call option in incomplete markets}

In this section, we derive closed-form solutions for the upper and lower bound of a European call option written on an infrequently traded asset and we look at the implications of incomplete markets on these prices. We compare our results to the Black-Scholes (1973) complete-market case and show that, contrary to standard option pricing theory, an increase in the volatility of the underlying asset does not always lead to an increase in the option value.

\subsubsection{Upper and lower bound closed-form solutions}

The market setting is still an incomplete market, with a traded risky asset $S$, a traded riskless asset $B$ and an infrequently traded asset $V$ correlated with $S$. The dynamics of the assets are the ones in equations (2.1)-(2.3). We assume the existence of a European type of call option written on asset $V$.

We start by reminding the reader of the dynamics of asset $V$ in equation (12) of Section 2.2. An equivalent way of writing equation (2.12) is:

$$
d V_{t}=\left(r-q_{1}\right) V_{t} d t+\sigma_{V} V_{t}\left(\rho d \widehat{W}_{1}+\sqrt{1-\rho^{2}} d \widehat{W}_{1}\right)
$$

where: $\quad q_{1}=r-\mu_{V}+\sigma_{V} \rho \frac{\mu_{S}-r}{\sigma_{S}}+\sigma_{V} \sqrt{1-\rho^{2}} \kappa_{2}$

If $\mu_{V}, \sigma_{V}$ and $\kappa_{2}$ are constants, then $V$ follows a lognormal distribution. The process for $V$ now resembles the process for a stock paying a dividend yield equal to $q_{1}$, so we can express the time zero option price as the Black-Scholes (1973) price of a call option on a dividend paying stock:

$$
\begin{aligned}
& C_{0}=V_{0} e^{-q_{1} T} N\left(d_{1}\right)-K e^{-r T} N\left(d_{2}\right) \\
& C_{0}=e^{-r T}\left[V_{0} e^{\left[\mu_{V}-\sigma_{V} \rho\left(\frac{\mu_{S}-r}{\sigma_{S}}\right)-\sigma_{V} \sqrt{1-\rho^{2}} \kappa_{2}\right] T} N\left(d_{1}\right)-K N\left(d_{2}\right)\right]
\end{aligned}
$$

where: $\quad N($.$) - cumulative normal distribution function$

$$
\begin{aligned}
& d_{1}=\frac{\ln \left(\frac{V_{0}}{K}\right)+\left[\mu_{V}-\sigma_{V} \rho\left(\frac{\mu_{S}-r}{\sigma_{S}}\right)-\sigma_{V} \sqrt{1-\rho^{2}} \kappa_{2}+\frac{\sigma_{V}^{2}}{2}\right] T}{\sigma_{V} \sqrt{T}} \\
& d_{2}=d_{1}-\sigma_{V} \sqrt{T} \\
& V_{0}-\text { forward value } \\
& \kappa_{2}=-\sqrt{k^{2}-\left(\frac{\mu_{S}-r}{\sigma_{S}}\right)^{2}}, \text { for the upper bound }
\end{aligned}
$$




$$
\kappa_{2}=\sqrt{k^{2}-\left(\frac{\mu_{S}-r}{\sigma_{S}}\right)^{2}}, \text { for the lower bound }
$$

The final option price is a modified version of the Black-Scholes (1973) option pricing formula. The modification reflects exactly the adjusted drift term that was used to describe the process $V$ under the new probability measure $Q_{A}$ and which appears in equation (2.12). The drift is adjusted downwards to reflect the higher degree of uncertainty which exists in an incomplete market compared to a complete market due to the proportion of the total risk which remains unhedged.

Notice that, unlike in the Black-Scholes (1973) option pricing model, in the incomplete market, the expected return $\mu_{V}$ is still present in the expression for the option price (see equation (2.17)). Even if we were able to find a traded asset $S$ that is perfectly correlated with our underlying, making $\rho$ equal to 1 , the pricing formula would still depend on the expected return of the illiquid asset $V$. This is because the underlying and the risky asset correlated with it have different expected returns and both have to be taken into account in the pricing mechanism.

As a final remark, the reader should bear in mind that we are not modeling a market for homogeneous goods for which there are numerous buyers and sellers bidding and asking prices at the same time (like a stock market), but a market for infrequently traded assets, where occasionally there exists an interested buyer or a seller. Under these conditions, we can only specify the likely interval for the price of the option. Eventually, by making additional assumptions about the type of market and about which counterparty we are (the buyer or the seller), we could uniquely determine the price of the option.

\subsubsection{Implications for the European call option}

We continue with a sensitivity analysis for the price of a European call option in incomplete markets. Standard (complete-market) option pricing theory predicts that an increase in the volatility of the underlying asset always leads to an increase in the value of the option. The pricing mechanism presented in Section 2.2, which assumes an incomplete market, implies that this is not always the case. This can best be seen graphically in Figure 2.1, where, all else equal, the volatility of the underlying asset increases from $1 \%$ to as much as $50 \%$, but the option prices on the lower bound no longer follow an increasing pattern. 
Figure 2.1: The sensitivity of the call price with respect to the volatility of the underlying asset (upper and lower bound prices vs. Black-Scholes prices). The parameter values are as follows: $\sigma_{S}=16 \%, \mu_{S}=8 \%, r=4 \%$, Sharpe ratio asset $S=0.25, k=0.5, \rho=0.8, V_{0}=100, K=60, T=1$ year and $\mu_{V}=r+\rho \frac{\sigma_{V}}{\sigma_{S}}\left(\mu_{S}-r\right)$.

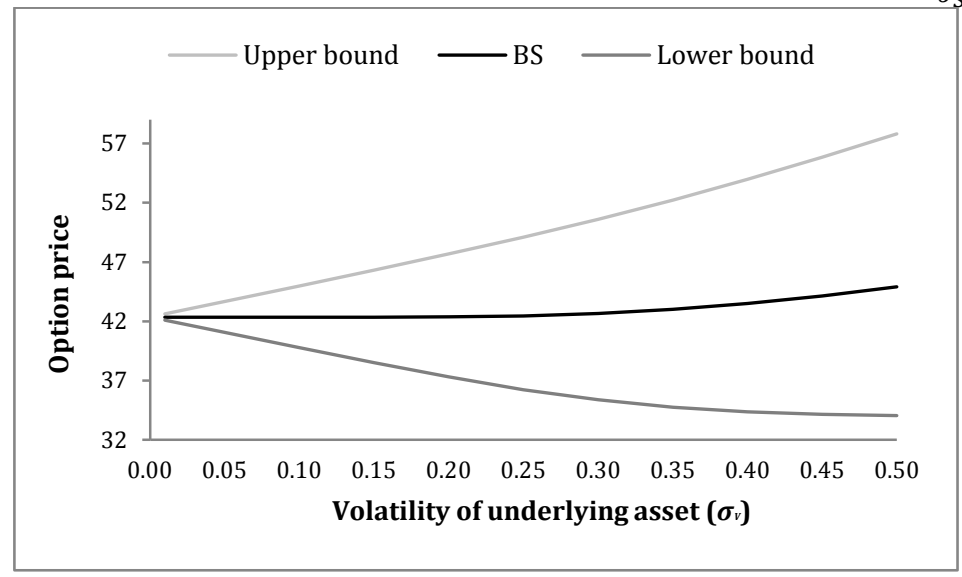

By fixing the market price of risk and all other parameters except for the volatility of the underlying asset, we see that at an increase in the volatility of the underlying both the BlackScholes (1973) option price and the upper bound prices are increasing. However, the lower bound prices display a decreasing pattern, instead of an increasing one as we would expect. This means that we are willing to pay less and less for an asset as uncertainty increases (the lower bound prices are the buyer's reservation prices). This is exactly the feature that cannot be explained by the complete-market models which take into account only the hedgeable sources of risk, not the unhedgeable ones as well. However, the results are consistent with the findings of Henderson (2007) and Miao and Wang (2007), who also conclude via utility indifference pricing that market incompleteness can decrease the option value.

For very low values of $\sigma_{V}$, the prices converge, because, if we eliminate all the uncertainty in the underlying asset (i.e., the infrequently traded asset), the only source of uncertainty left comes from the traded asset and we are back in the Black-Scholes (1973) framework. As $\sigma_{V}$ increases though, the effect of the unhedged risk also increases and that is reflected in the steady widening of the bounds. Note that, for arbitrage reasons, the following CAPM-type of relationship must hold: $\mu_{V}=r+\rho \frac{\sigma_{V}}{\sigma_{S}}\left(\mu_{S}-r\right)$ (see Davis, 2006).

The inverse relationship between the option value and the volatility of the underlying is not independent of the moneyness of the option though. In fact, as Figure 2.2 shows, the more in-themoney the call option is the more pronounced this inverse relationship is. As soon as the option is at-the-money, the negative effect of volatility on option value disappears. 
Figure 2.2: The lower bound prices for different values of the strike price and of the volatility of the underlying asset. The parameter values are as follows: $V_{0}=100, T=1$ year, $r=4 \%, \sigma_{V}=15 \%, \sigma_{S}=16 \%, \mu_{S}=$ $8 \%, \rho=0.8$, Sharpe ratio $S=0.25$. The drift term is still given by: $\mu_{V}=r+\rho \frac{\sigma_{V}}{\sigma_{S}}\left(\mu_{S}-r\right)$.

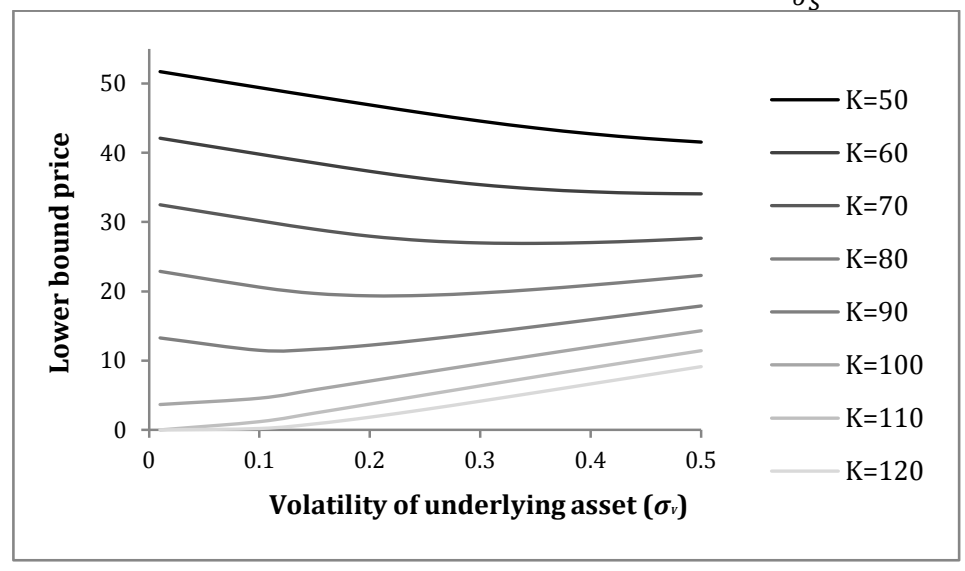

A very important parameter for the option price is the restriction $k$ on the total volatility of the stochastic discount factor. We know that the stochastic discount factor is the product of a riskfree discount factor and a Radon-Nikodym derivative (Björk, 2009). Its expected value is a constant and it is equal to the risk-free discount factor. It is the variance of the stochastic discount factor that changes and that we restrict via $k$. The variance of the stochastic discount factor shows the "distance" between the physical (real world) probability measure $P$ and the new probability measure $Q_{A}$. When these two probability measures are very close to each other, the variance of the stochastic discount factor is low and the price bounds are tight. The farther the probability measures are from each other, the higher the variance of the stochastic discount factor is and the wider the bounds become.

The effect of the volatility restriction $k$ on the option price is presented in Figure 2.3. When the restriction is exactly equal to the Sharpe ratio of the traded asset, we exit the incomplete market setting and the upper and lower bound prices converge to the Black-Scholes price. Afterwards, as $k$ increases the bounds widen. The prices on the lower bound decrease rapidly and the ones on the upper bound experience a sharp increase. 
Figure 2.3: The sensitivity of the call price with respect to the restriction on the volatility of the stochastic discount factor. The parameter values are as follows: $V_{0}=100, K=70, T=1$ year, $r=4 \%, \sigma_{V}=15 \%, \sigma_{S}=16 \%$, $\mu_{S}=8 \%, \rho=0.8$, Sharpe ratio $S=0.25$ and $\mu_{V}=r+\rho \frac{\sigma_{V}}{\sigma_{S}}\left(\mu_{S}-r\right)$.

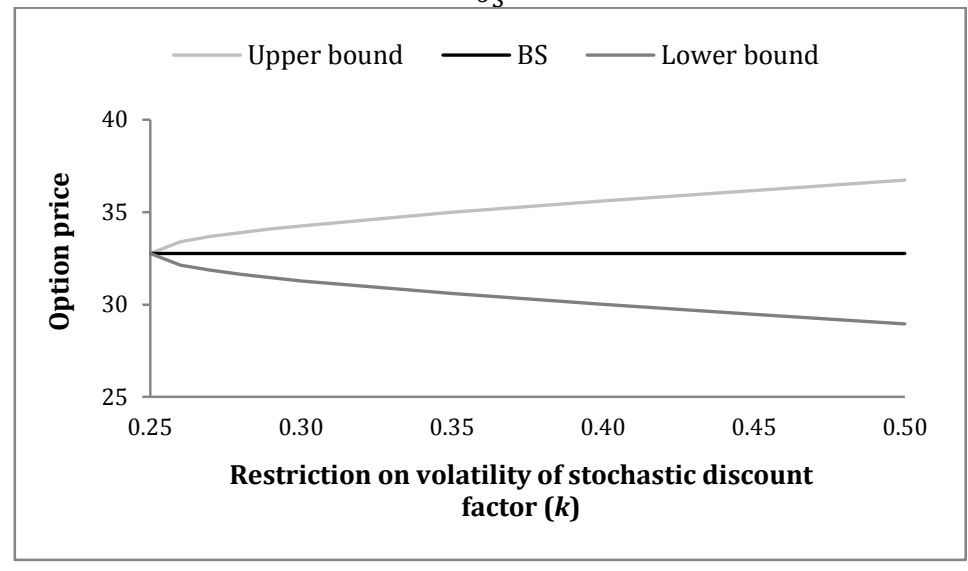

The correlation coefficient $\rho$ between the underlying asset and the traded risky asset also plays a role in determining the behavior of the option prices. Figure 2.4 shows that as the correlation coefficient increases and the partial hedge improves, the upper and lower bound prices approach the Black-Scholes price more and more. In fact, for a perfect (negative or positive) correlation, the upper and the lower bound prices become equal. The largest price difference can be observed at the other extreme, when $\rho=0$, because here we cannot hedge any part of the risk and we deal only with unhedgeable sources of risk.

Figure 2.4: The sensitivity of the call price with respect to the correlation coefficient between the underlying asset and the correlated traded risky asset. The parameter values are as follows: $V_{0}=100, K=70, T=1$ year, $r$ $=4 \%, \sigma_{V}=15 \%, \sigma_{S}=16 \%, \mu_{S}=8 \%$, Sharpe ratio $S=0.25$ and $\mu_{V}=r+\rho \frac{\sigma_{V}}{\sigma_{S}}\left(\mu_{S}-r\right)$.

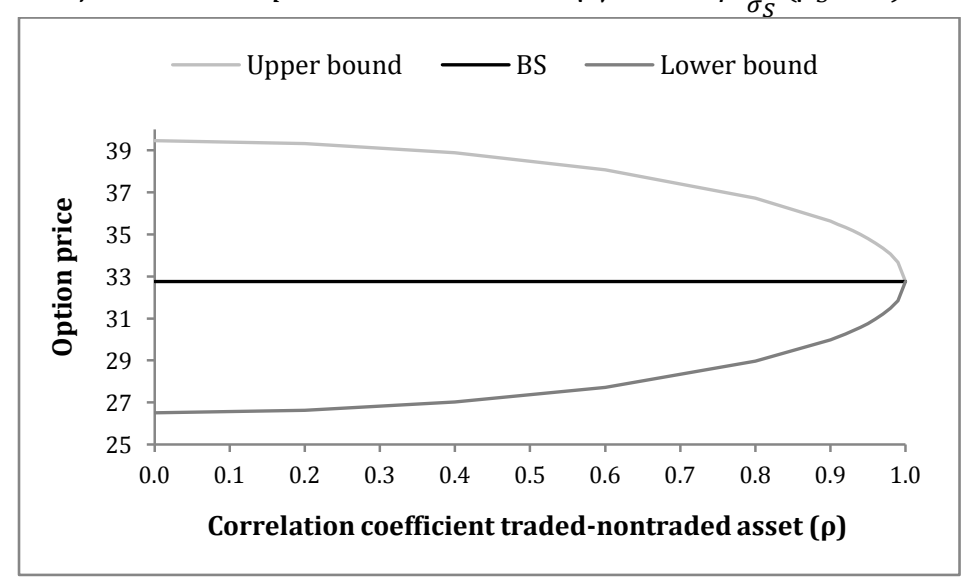

The interesting fact about Figure 2.4 is that there is a large gap between the prices on an almost complete market and the Black-Scholes price at $\rho=1$. In fact, the incomplete market prices approach the Black-Scholes price by $\sqrt{1-\rho^{2}}$. This is consistent with the results of Davis (2006), via a utility indifference approach. 
Following Davis (2006), we make the notation:

$$
\varepsilon=\sqrt{1-\rho^{2}}
$$

in order to perform a Taylor expansion around $\varepsilon=0$ (i.e., for $\rho=1$ ). Knowing that $\mu_{V}=r+$

$\rho \frac{\sigma_{V}}{\sigma_{S}}\left(\mu_{S}-r\right)=r+\frac{\sigma_{V}}{\sigma_{S}}\left(\mu_{S}-r\right) \sqrt{1-\varepsilon^{2}}$, the incomplete market price in equation (2.17) becomes:

$$
\begin{aligned}
C_{0} & =V_{0} N\left(d_{1}\right)-K e^{-r T} N\left(d_{2}\right)-\varepsilon N\left(d_{1}\right) V_{0} \sigma_{V} \kappa_{2} T+O\left(\varepsilon^{2}\right) \\
& =B S \text { price }-\varepsilon N\left(d_{1}\right) V_{0} \sigma_{V} \kappa_{2} T+O\left(\varepsilon^{2}\right)
\end{aligned}
$$

where: $O($.$) - higher order terms$

The incomplete market option price converges to the BS price of a call option on a non-dividend paying asset with $\varepsilon$, where $\varepsilon$ is defined in equation (2.18). Even at a $\rho=0.99, \varepsilon$ is already equal to 0.14 and it has a substantial impact on the BS price. Furthermore, since the incomplete market prices are a modified version of the Black-Scholes (1973) price, the second term of the Taylor expansion in equation (2.19) incorporates a 'delta-effect': $N\left(d_{1}\right)$, the delta measure of a call option written on a non-dividend paying asset, multiplied by additional terms to account for market incompleteness.

\subsection{The American call option in incomplete markets}

In this section, we discuss American-style call options and show that closed-form solutions are available in this case. We emphasize the early exercise feature that the negative relationship between option value and volatility of the underlying adds to an American call option.

The advantage of deriving prices for American type of options is that we are also able to time an investment, not only calculate its value. In a complete market, the price of an American call option coincides with the price of a European call option, because there is no incentive to exercise the option early as long as the underlying asset does not pay any dividends. However, we show that in an incomplete market, where the underlying asset of an option is either infrequently traded or non-traded, the economic agent does have an incentive to exercise an American call option early when he is faced with increasing unhedgeable risk which erodes the option value. Furthermore, Merton (1973) showed that, in a complete market setting, the prices of perpetual American options are closed-form solutions. Hence, we conduct our analysis for a 
perpetual American option, such that we can arrive at analytical formulas comparable to the ones obtained in Section 2.3.

Assume that $F(V)$ is the price of a perpetual American call option written on $V$, where $V$ is the infrequently traded asset described by the stochastic process in equation (2.2). For ease of calculations, we make a notation for the drift term of the stochastic process in equation (2.2): $\tilde{\mu}=\mu_{V}-\sigma_{V} \rho \frac{\mu_{S}-r}{\sigma_{S}}-\sigma_{V} \sqrt{1-\rho^{2}} \kappa_{2}$. According to the Feynman-Kac formula, claim $F$ must satisfy the following PDE:

$$
F_{t}+F_{V} \tilde{\mu} V+\frac{1}{2} F_{V V} \sigma_{V}^{2} V^{2}-r F=0
$$

where: $r$-deterministic short interest rate

Merton (1973) showed that the PDE in equation (2.20) reduces to an ODE, due to the fact that the perpetual option has infinite maturity (i.e., $t \rightarrow \infty$ ). The derivative of $F$ with respect to time drops out and equation $(2.20)$ reduces to:

$$
F_{V} \tilde{\mu} V+\frac{1}{2} F_{V V} \sigma_{V}^{2} V^{2}-r F=0
$$

s.t. $\quad F(0)=0 \quad$ (boundary condition)

$F\left(V_{*}\right)=V_{*}-K$ (value-matching condition)

$F^{\prime}\left(V_{*}\right)=1$ (smooth-pasting condition)

Assume that $F(V)$ is of the form $F(V)=V^{\lambda}$. Then:

$$
\lambda^{2} \frac{1}{2} \sigma_{V}^{2}+\lambda\left(\tilde{\mu}-\frac{1}{2} \sigma_{V}^{2}\right)-r=0
$$

For $V^{\lambda}>0$, the solutions to equation (2.22) are:

$$
\lambda_{1}=-\frac{\sqrt{\sigma_{V}^{4}+(8 r-4 \widetilde{\mu}) \sigma_{V}^{2}+4 \widetilde{\mu}^{2}}-\sigma_{V}^{2}+2 \widetilde{\mu}}{2 \sigma_{V}^{2}} \text { and } \lambda_{2}=\frac{\sqrt{\sigma_{V}^{4}+(8 r-4 \widetilde{\mu}) \sigma_{V}^{2}+4 \widetilde{\mu}^{2}}+\sigma_{V}^{2}-2 \widetilde{\mu}}{2 \sigma_{V}^{2}}
$$

For arbitrary constants $C_{1}$ and $C_{2}$, the general solution to equation (2.21) is:

$$
F(V)=C_{1} V^{\lambda_{1}}+C_{2} V^{\lambda_{2}}
$$


s.t. $F(0)=0$

$$
\begin{aligned}
& V_{*}-K=C_{1} V_{*}^{\lambda_{1}}+C_{2} V_{*}^{\lambda_{2}} \\
& 1=C_{1} \lambda_{1} V_{*}^{\lambda_{1}-1}+C_{2} \lambda_{2} V_{*}^{\lambda_{2}-1}
\end{aligned}
$$

To satisfy the boundary condition $F(0)=0, C_{1}$ must be zero, otherwise $F(V)$ converges to infinity when $V$ goes to zero and $\lambda_{1}$ is negative. $F(V)$ is then simply $F(V)=C_{2} V^{\lambda_{2}}$.

Via the value-matching and smooth-pasting conditions, we are able to determine that the constant $C_{2}$ is given by $C_{2}=\frac{V_{*}^{1-\lambda_{2}}}{\lambda_{2}}$ and that the analytical solutions for the optimal investment threshold and the option value are respectively:

$$
\begin{gathered}
V_{*}=\frac{K \lambda_{2}}{\lambda_{2}-1}, \text { with } \lambda_{2}>1 \text { s.t. } V_{*}>K \\
F\left(V_{*}\right)=V_{*}-K=\frac{K}{\lambda_{2}-1}
\end{gathered}
$$

The early exercise of the perpetual American option can happen once the value $V$ is at least as large as the threshold $V_{*}$, where $V_{*}$ is higher than the strike price $K$.

Similar to the analytical solution for the European call option in equation (2.17), the option value for the perpetual American call is dependent on the drift term of the underlying asset $V, \mu_{V}$, and on the restriction on the volatility of the stochastic discount factor, $k$. Furthermore, the optimal investment threshold and the option value differ for the lower and the upper bound prices, leading to potentially different investment decisions depending on whether we have a long or a short position in the option (i.e., whether we are on the lower bound or on the upper bound).

In a complete market, it is never optimal to exercise an American call option early if the underlying asset is a non-dividend paying asset. In an incomplete market, where the underlying asset of an option is either infrequently traded or non-traded such that we can no longer construct a replicating portfolio to price the option, things change. As Figure 2.5 shows, at the lower bound, the early exercise is triggered by the increase in the volatility of the underlying asset. The option value and the optimal investment threshold for the lower bound prices are both decreasing in the volatility of the underlying. At the upper bound, early exercise is never optimal, because the optimal investment threshold $V_{*}$ is always lower than the strike price $K$. 
Figure 2.5: The lower bound optimal investment threshold and option value for different values of the volatility of the underlying asset. The parameter values are as follows: $\sigma_{S}=16 \%, \mu_{S}=8 \%, r=4 \%$, Sharpe ratio asset $S=0.25, k=0.5, \rho=0.8, V_{0}=100, K=60$ and $\mu_{V}=r+\rho \frac{\sigma_{V}}{\sigma_{S}}\left(\mu_{S}-r\right)$.

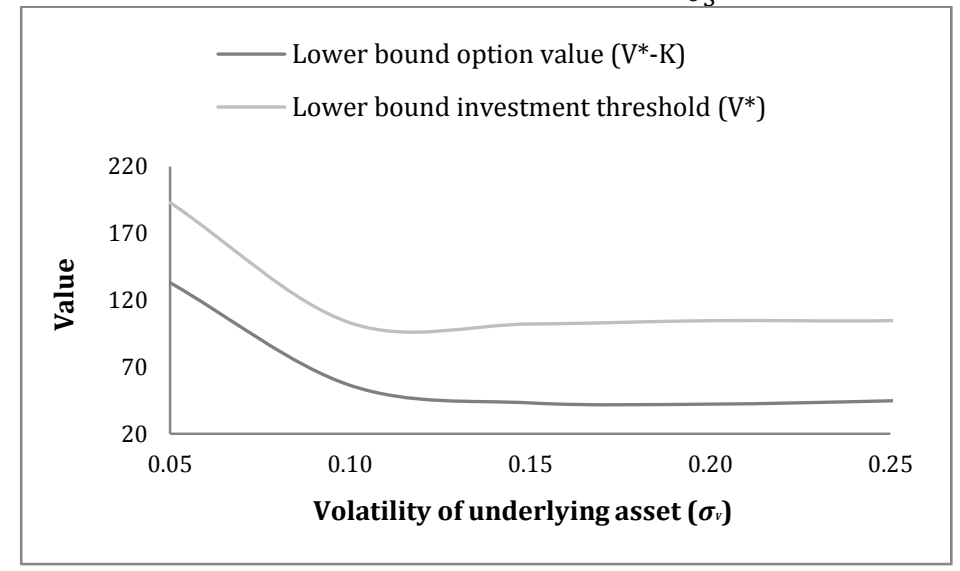

An increase in the volatility of the infrequently traded underlying asset means an increase in the unhedgeable sources of risk. Consequently, the economic agent is willing to pay less and less for the option, which explains the decreasing value, and exercises the option early to lock in value as long as it still exists. This result contradicts the standard options theory, but it is supported by the work of Henderson (2007) and Miao and Wang (2007), who also show via utility indifference pricing that early exercise is possible for an American call option in an incomplete market. However, utility indifference pricing involves more difficult calculations than the ones presented in this paper and, even though Henderson (2007) reaches closed-form solutions, the results of Miao and Wang (2007) are based on numerical methods.

\subsection{Conclusion}

We propose a pricing mechanism for contingent claims in incomplete markets using the model ambiguity concepts put forward by Hansen and Sargent (2001) and Andersen et al. (2003). We continue by analyzing the implications for a special case of a monotonically increasing payoff the call option. We discuss European and American call options in incomplete markets and show that closed-form solutions are available in both cases. We document a negative relationship between the value of a European call option and the volatility of its underlying asset. Furthermore, we emphasize the early exercise feature that this negative relationship adds to an American call option even if the underlying asset is a non-dividend paying asset.

We derive upper and lower bound prices for the option and show that in an incomplete market the lower bound prices (i.e., the buyer's prices) decrease as the volatility of the underlying asset 
increases. This is due to the increase in the unhedgeable sources of risk additional to the hedgeable risk that we find on a complete market and it contradicts standard option pricing theory. Furthermore, in an incomplete market where the underlying asset of an option is either infrequently traded or non-traded, early exercise of an American call option becomes possible at the lower bound. The option value and the optimal investment threshold for the lower bound prices are both decreasing in the volatility of the underlying. The economic agent exercises the option early to lock in value before it disappears as a result of increased unhedgeable risk.

The advantage of the methodology we propose over other incomplete market techniques is that it arrives at closed-form solutions for the option price and, more importantly, comparable to the Black-Scholes (1973) price. Even though it is accessible and easy-to-implement, the difficult part of our approach remains the choice of $k$, which is the exogenous restriction on the total volatility of the stochastic discount factor. 


\section{Chapter 3}

\section{The informational content of infinite maturity bonds ${ }^{2}$}

\subsection{Introduction}

Pricing very long-dated cash flows has direct implications for life insurance companies and pension funds, because these financial institutions have contractual obligations that last far longer than any traded instrument we can find in the market. The purpose of this chapter is to give an answer to the following question: how does the market implicitly price very long-dated cash-flows? We compute theoretical prices for infinite maturity bonds and extract information about the long end of the term structure of interest rates from the difference between the market prices of UK infinite maturity bonds and their analytical prices.

We show that infinite maturity bonds, in particular the War Loan, are a cheap investment. We find that they are generally underpriced, even though such investments should be attractive to large institutional investors. However, if that is indeed the case, then why does the mispricing persist given that this type of investors would be able to correct it? We show that the mispricing is mainly driven by volatility in financial markets and not by expectations of the economic outlook.

The problem with pricing very long-dated cash flows is that the standard pricing method is pricing by replication (i.e., by replicating the cash flows of the asset to be valued with the cash flows of traded assets). However, the longest maturity government bonds traded in the market are 25-year or 30-year bonds. So, how can we then value assets with maturities beyond 30 years? We are in fact in an incomplete market situation, where the presence of non-traded assets gives rise to more sources of randomness than there are traded assets to hedge them with (Björk, 2009).

The focus of this chapter is infinite maturity bonds, or undated gilts, which are still traded in the UK. They were first issued in the $18^{\text {th }}$ century and there are still eight such bonds in issue today,

\footnotetext{
${ }^{2}$ This is joint work with prof. dr. Antoon Pelsser. We are grateful for all the helpful comments we received from our colleagues at Maastricht University and the audience at the 2014 FMA European conference. We also thank NWO (the Netherlands Organization for Scientific Research) for the generous support in the form of a three-year grant via the Graduate Programme 2011 (correspondence number 011/08865/B00).
} 
some of them issued as early as the $19^{\text {th }}$ century. These are the $3^{1 / 2} \%$ Treasury Stock, the $23 / 4 \%$ Annuities, the $4 \%$ Consolidated Loan, the 21/2\% Consolidated Stock, the 21/2\% Treasury Stock, the $2^{1 / 2} \%$ Annuities, the $31 / 2 \%$ Conversion Loan and the $31 / 2 \%$ War Loan. All bonds pay coupons either once, twice or four times per year.

According to the UK Debt Management Office (DMO)3, the undated gilts currently represent less than $1 \%$ of the gilt market, with all but one of the undated gilts being rumps. A rump is a bond with a nominal amount outstanding that is less than $£ 850$ million. The War Loan, which was first issued in 1932, is the only infinite maturity bond considered to be non-rump. It is traded on the London Stock Exchange and it currently has a bit more than $€ 1.9$ billion in issue. Given that it has the largest volume and that it has been traded in the market for over 80 years, we will focus on this particular bond in our analysis.

Our work adds to the literature documenting mispricings in government bond markets. There are two main strands of literature trying to explain this phenomenon. The first strand of literature attributes the mispricing to liquidity effects, which are best visible in off-the-run bonds and government agency bonds.

Krishnamurthy (2002) looks at the difference in yields between on-the-run 30-year Treasury bonds and off-the-run 30-year Treasury bonds. The difference in yields is not negligible, as one would expect for identical bonds, and can best be explained by differences in liquidity. The reason is that 30-year Treasury bonds are auctioned roughly once every 6 months and, once a new bond of this type is issued, it becomes the more liquid one until the next auction when it is replaced by another bond with the same maturity and it will start to be seen as the less liquid one. The findings of Krishnamurthy (2002) are confirmed by Pasquariello and Vega (2009), who develop a theoretical trading model with heterogeneous agents who trade on-the-run and offthe-run Treasury bonds in the presence of public signals (like macroeconomic announcements). Longstaff (2004) reports price differences between seemingly identical bonds in the government agency bond market. He compares the prices of Treasury zero-coupon bonds to the prices of Refcorp (Resolution Funding Corporation) zero-coupon bonds. Refcorp is a government agency created in 1989 to provide funding for the bailout of insolvent institutions after the US savings and loan crisis of the 1980s. Refcorp bonds and Treasury bonds have the same risk profile, because Refcorp bonds are guaranteed by the US Treasury, hence their prices should be equal.

\footnotetext{
3 The DMO is the Government body responsible for the management of cash and sterling debt in the UK.
} 
However, Longstaff (2004) finds a statistically and economically significant yield spread and concludes that it can only be attributed to liquidity.

The second strand of literature explains the mispricing by the presence of slow moving capital (i.e., capital does not flow immediately where the mispricing is, because investors are somehow constrained). Mitchell et al. (2007) study such phenomena in convertible bond markets and in merger markets and find that, due to market frictions, it can take several months until the prices of convertible bonds and target stocks revert to equilibrium. They also conclude that, in markets where it is more difficult to estimate the level of the mispricing, it can take even longer to correct it. Duffie (2010) proposes a theoretical model of asset prices with inattentive investors, who fail to react immediately to demand or supply shocks. He also presents examples of slow moving capital in various markets and, like Mitchell et al. (2007), he concludes that it can take hours, days or even months until prices go back to their equilibrium levels.

Fleckenstein et al. (2014) compare the price of a Treasury bond with the price of a synthetic Treasury bond with matching characteristics, obtained by converting the inflation-linked cash flows of Treasury Inflation-Protected Securities (TIPS) into fixed cash flows using inflation swaps. They find that Treasury bonds are consistently overpriced relative to TIPS and that the mispricing decreases when additional capital flows into the market, consistent with the slowmoving capital explanation. Furthermore, the authors conclude that the Treasury-TIPS price differentials should not be used to imply market expectations of future inflation, as these expectations would be biased downwards, especially when financial markets are very volatile.

Our work investigates the UK government bond market and documents yet another puzzle. Like Fleckenstein et al. (2014), we construct theoretical prices for the War Loan and compare them to the observed prices. We find that the War Loan is generally underpriced. Following Kempf et al. (2012), who determine the drivers of illiquidity premia in the German government bond market, we use economic and financial variables to establish what influences the mispricing in the UK market and conclude that it is mainly financial markets volatility.

The remainder of this chapter is organized as follows. Section 3.2 presents the method we employ, Section 3.3 describes the UK market data used, Section 3.4 presents the results, Section 3.5 continues with robustness checks and Section 3.6 concludes. 


\subsection{Method}

This paper documents a mispricing in the very long-term UK bond market - the infinite maturity bond market. We follow this mispricing from 2000 until 2013 and we show that it persists. The question is why. On the one hand, infinite maturity bonds would be the perfect long-term instrument to invest in for pension funds and insurance companies, but, if these large institutional investors did invest in infinite maturity bonds, the mispricing would disappear. On the other hand, if large institutional investors do not invest in these bonds, then they forgo potential profits. In the remainder of this paper, we first show that a mispricing exists and then we investigate the drivers of this mispricing.

We focus our analysis on one of the eight UK infinite maturity bonds, the $3 \frac{1}{2} \%$ War Loan, because it is the most liquidly traded infinite maturity bond. We start by calculating a theoretical price for a bond with the characteristics of the War Loan: an infinite maturity bond, with a principal of $€ 100$ and which pays a $€ 3.5$ coupon semi-annually (i.e., $€ 1.75$ every 6 months).

In order to determine the theoretical price, we must first extend the term structure of interest rates. Following Nelson and Siegel (1987) and Diebold and Li (2006), we calibrate a NelsonSiegel model to the observed yield curve and then extend the yield curve based on the parameter values resulting from the calibration. The yields of different maturities are computed with the formula:

$$
y_{t}(T)=\beta_{0 t}+\beta_{1 t} \frac{1-e^{-T / \tau_{t}}}{T / \tau_{t}}+\beta_{2 t}\left(\frac{1-e^{-T / \tau_{t}}}{T / \tau_{t}}-e^{-T / \tau_{t}}\right)
$$

Having obtained the yields for all maturities, we then calculate the theoretical price of the infinite maturity bond as the sum of all discounted cash flows. We define the Spread as the difference between the observed price and the theoretical price of the War Loan. We repeat the procedure for every day in the sample and construct a time series of daily spreads for the period $2000-2013$.

We show that the War Loan is consistently mispriced and that there is potential for profits by investing in UK infinite maturity bonds. Following Kempf et al. (2012), we determine what the financial and economic drivers of the Spread are. In particular, we use an error correction model to determine the short-run and long-run effects that stock market, bond market and economic outlook factors have on changes in the mispricing. 


\subsection{Data}

The data used in the analysis comes from four different sources: the $\mathrm{DMO}^{4}$, the Bank of England 5 , Datastream and the London Stock Exchange ${ }^{6}$. It spans over the time period $2000-2013$ and it excludes weekends and holidays.

First, we retrieve daily prices for the eight infinite maturity bonds from the DMO. The prices include the accrued interest and there are no tax benefits from owning these bonds. Second, we retrieve daily UK yield curves and the FTSE100 implied volatility index for maturities of 30 days from the Bank of England. Third, we use swaption volatilities from Datastream. A swaption (or swap option) is an option which gives the right to enter a fixed rate swap agreement at time $T_{n}$. A swaption is normally denoted $T_{n} x\left(T_{N}-T_{n}\right)$, where $T_{n}$ is the expiry date of the option (and the start date of the underlying swap agreement) and $\left(T_{N}-T_{n}\right)$ is the tenor of the underlying swap. The longest maturity swaption volatilities available from 2000 are volatilities from 3 year option contracts on 10 year swap contracts. Last, due to the fact that there are no records of turnover data for any of the undated gilts, we retrieve turnover data for gilts with maturity longer than 15 years from the London Stock Exchange. We use this measure as an indication of the liquidity in the long-term bond market. However, the turnover data is only available at monthly level and starting from 2006.

To reduce the level of noise in the data, we aggregate all series at weekly level. Furthermore, when we introduce information that is available only at monthly level, we aggregate the rest of the data at monthly level as well.

\subsection{Results}

In this section, we discuss the results of our analysis. We argue that the UK infinite maturity bonds, in particular the War Loan, are a good long-term investment for insurance companies and pension funds, which have liabilities extending beyond the longest maturity instruments observed in the market. We show that the War Loan is underpriced compared to its theoretical price, making this bond a cheap long-term investment as well and that the mispricing is mainly driven by the volatility in the stock and in the bond market. Furthermore, we show that the War Loan implies a slightly upward sloping term structure of interest rates. Finally, we investigate

\footnotetext{
${ }^{4}$ http://www.dmo.gov.uk/

5 http://www.bankofengland.co.uk/
} 
how appropriate the use of the Nelson-Siegel (1987) model is in order to extend the term structure of interest rates and conclude that the results are not driven by the choice of termstructure model.

\subsubsection{Calibration results}

We start the analysis by extending the term structure of interest rates in order to calculate theoretical prices for the UK infinite maturity bonds. We use the Nelson-Siegel (1987) specification in equation (3.1) to compute the daily yields needed to discount the cash flows corresponding to each bond. Following Diebold and Li (2006), we impose that $\tau$ is constant throughout the entire sample period and estimate the other three parameters by means of ordinary least squares. We obtain a value of 2.5987 for the constant $\tau$. The results of the NelsonSiegel (1987) procedure are reported in Table 3.1.

Table 3.1: Descriptive statistics of the calibrated parameters and the daily root mean squared errors for $\tau=2.5987$

\begin{tabular}{lccccc}
\hline & Mean & St dev & Min & Median & Max \\
\cline { 2 - 6 }$\beta_{0 \mathrm{t}}$ & 4.58 & 0.51 & 3.13 & 4.58 & 6.04 \\
$\beta_{1 \mathrm{t}}$ & -1.67 & 2.52 & -6.15 & -0.91 & 2.71 \\
$\beta_{2 \mathrm{t}}$ & -0.31 & 2.9 & -7.23 & 0.42 & 7.28 \\
RMSE (in pp) & 0.06 & 0.03 & 0.005 & 0.05 & 0.17 \\
\hline
\end{tabular}

A good check of the proper functioning of the Nelson-Siegel (1987) fit is to plot $\beta_{0 t}$ against the longest-maturity extrapolated yield. According to equation (3.1), we should see that when $T->\infty$ the long yields are approximately equal to $\beta_{0 t}$. This is shown in Figure 3.1. As expected, the values are almost identical throughout our sample period, suggesting that the calibrated value of 2.5987 for the constant parameter $\tau$ is a reasonable value given the observed data.

Having obtained the parameters in equation (3.1), we can calculate daily yields for all maturities, determine the theoretical bond prices and compute the Spread, the difference between the observed price and the theoretical price, for all eight UK undated gilts. Even though the analysis will focus on the War Loan as the most liquidly traded undated gilt, we plot the evolution of the Spread for all eight undated gilts in Figure 3.2. The theoretical price is computed in each case using the corresponding coupon payments and coupon frequencies.

${ }^{6}$ http://www.londonstockexchange.com/home/homepage.htm 
Figure 3.1: The longest-maturity yield extrapolated with Nelson-Siegel (1987) against $\beta_{0 t}$ for each day in the time period $2000-2013$.

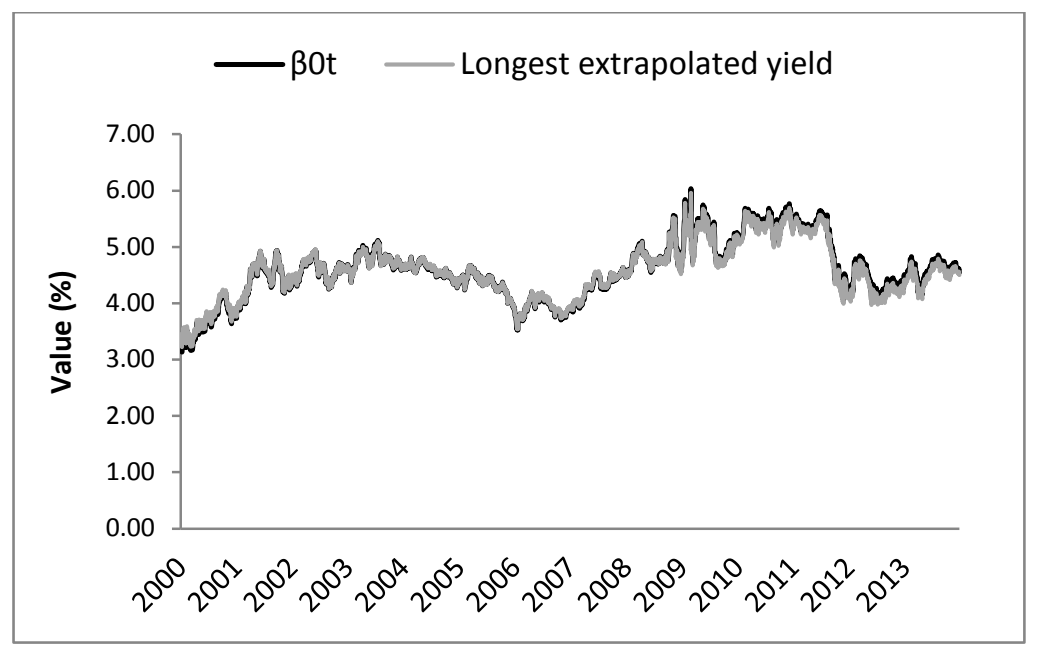

Figure 3.2 reveals similar patterns: the bonds are generally underpriced (a negative value means that the observed price is lower than the theoretical price), with the mispricing being persistent throughout the sample period 2000 - 2013. In fact, the consistent mispricing leads us to believe that there is a potential for profits by investing in these bonds, especially the War Loan, which can be traded on the London Stock Exchange. The question is what drives the mispricing? To answer it, we follow Kempf et al. (2012) and search for economic and financial variables that could influence the Spread.

\subsubsection{The determinants of the mispricing}

In this sub-section, we use an error correction model to disentangle potential short and longterm effects of economic and financial variables on changes in the Spread, which from now on will only refer to the difference between the observed and the theoretical price of the War Loan. We think there are two types of factors that could impact the price of undated gilts: expectations about the economic outlook and financial markets characteristics. We now explain in more detail our choice of independent variables.

First, following Estrella and Hardouvelis (1991) and Estrella and Mishkin (1998), we use the slope of the yield curve, defined as the difference between the 10-year yield and the 3-month yield, as a predictor of future economic activity. We call this variable Slope and convert the daily values into weekly averages.

Second, we use two forward-looking measures of stock market and bond market volatility: the implied volatility from FTSE100 options with 30 days to maturity and the implied volatility from 
Figure 3.2: The evolution of the Spread, the absolute difference between the observed price and the theoretical price, for each of the eight UK infinite maturity bonds. The principal is always £100.
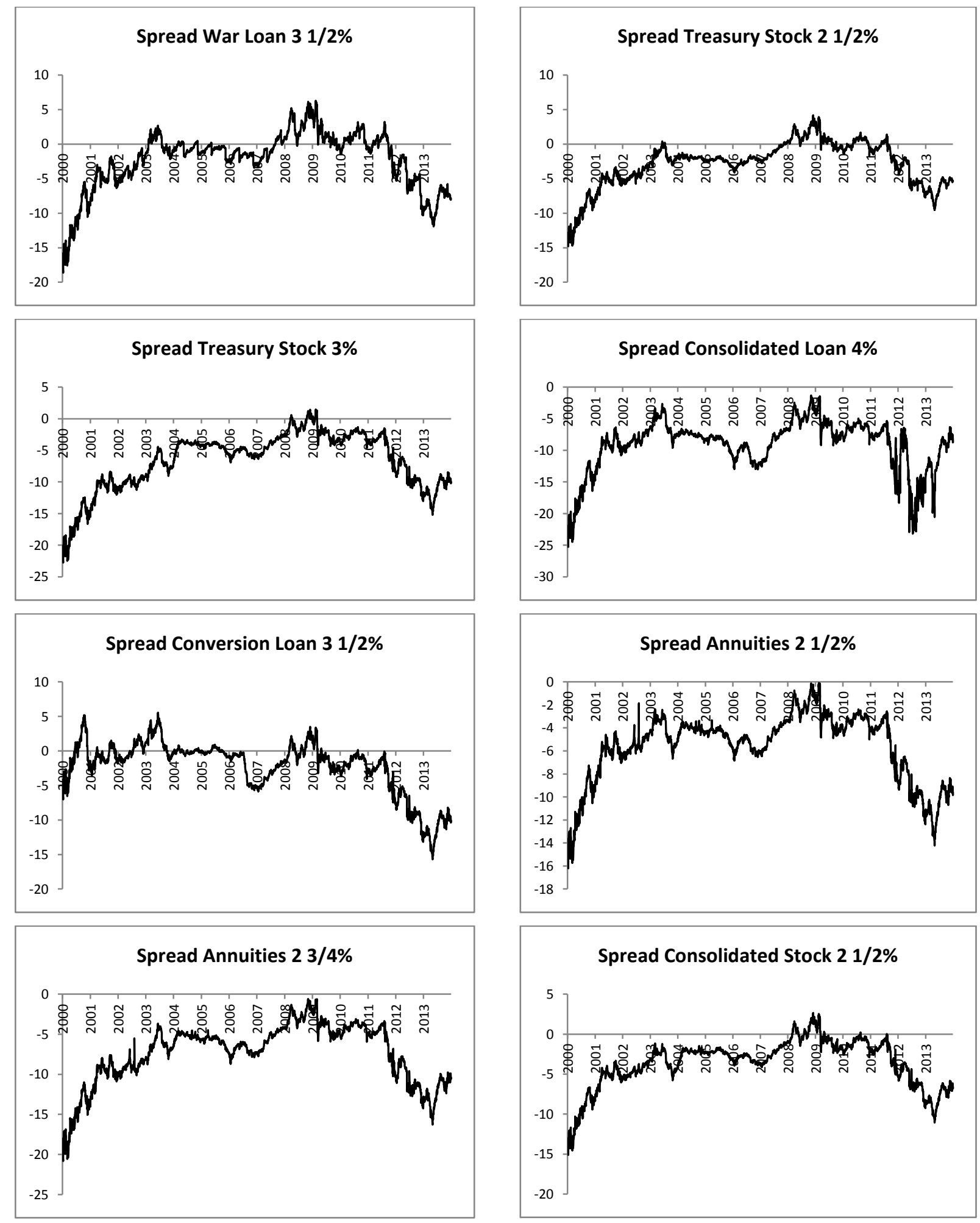
at-the-money swaptions with a 3-year option maturity and a 10-year swap maturity (longer maturity swaption contracts were not available as early as 2000). We call these variables VolStocks and VolBonds, respectively. We average both series of daily values at weekly level.

Third, given that our interest lies in long-maturity bonds, we expect the volatility of the last observed yield to play a role in subsequent changes in the Spread. On the UK market, the last observed yield is the 25-year yield. Hence, we construct weekly standard deviations of this variable and call it VolLastYield.

Last, we need an indication of the liquidity in the infinite maturity bond market. Unfortunately, no such information is available. We do however have access to turnover data for bonds with more than 15 years of maturity. This information is provided by the London Stock exchange on a monthly basis and starting from 2006. We use the natural logarithm of the turnover, which is expressed in €million, and call this series LogTurnover.

Descriptive statistics of all the variables defined above can be found in Table 3.2.

Table 3.2: Descriptive statistics of the series used in the analysis

\begin{tabular}{lllllllll}
\hline & Availability & Frequency & Obs & Mean & Std dev & Min & Median & Max \\
\cline { 2 - 9 } Spread & $2000-2013$ & Weekly & 731 & -2.27 & 4.15 & -17.20 & -1.17 & 6.02 \\
Slope & $2000-2013$ & Weekly & 731 & 0.01 & 0.01 & -0.01 & 0.01 & 0.04 \\
VolStocks & $2000-2013$ & Weekly & 731 & 0.21 & 0.09 & 0.10 & 0.19 & 0.68 \\
VolBonds & $2000-2013$ & Weekly & 731 & 0.16 & 0.05 & 0.10 & 0.15 & 0.30 \\
VolLastYield & $2000-2013$ & Weekly & 731 & 0.04 & 0.02 & 0.01 & 0.03 & 0.27 \\
LogTurnover & $2006-2013$ & Monthly & 96 & 25.12 & 0.49 & 24.29 & 25.02 & 27.94 \\
\hline
\end{tabular}

We start our analysis by regressing changes in Spread on lagged values and changes in the slope of the yield curve, the implied volatilities from FTSE100 options and swaptions and the volatility of the last observed yield. The results are presented in Table 3.3. Columns (1) through (3) progressively introduce more lags and use weekly level data during the time period 2000 2013. The results suggest that the future economic outlook, proxied by the slope of the yield curve, does not have an influence on the mispricing of the War Loan, whereas the volatility on the stock market has a positive impact and the volatility on the bond market, including the volatility in the last observed yield, have a negative impact on the observed mispricing. In the short run, an increase in the stock market volatility leads to an increase in the Spread (or in the mispricing), while an increase in the bond market volatility leads to a decrease in the mispricing. 
Table 3.3: Error correction model explaining changes in Spread. All variables are defined in Section 3.4.2. The $t$-statistics are presented in parentheses. ${ }^{* * *} p<0.01,{ }^{* *} p<0.05,{ }^{*} p<0.1$.

\begin{tabular}{|c|c|c|c|c|}
\hline & \multicolumn{3}{|c|}{$\Delta$ Spread $_{\mathrm{t}}$} & \multirow[b]{2}{*}{ (4) } \\
\hline & (1) & (2) & (3) & \\
\hline Spread $_{\mathrm{t}-1}$ & $\begin{array}{c}-0.024^{* * *} \\
(-4.27)\end{array}$ & $\begin{array}{c}-0.024^{* * *} \\
(-4.16)\end{array}$ & $\begin{array}{c}-0.021^{* * *} \\
(-3.67)\end{array}$ & $\begin{array}{c}-0.202^{* * *} \\
(-2.96)\end{array}$ \\
\hline Slope $_{t-1}$ & $\begin{array}{l}3.201^{*} \\
(1.67)\end{array}$ & $\begin{array}{l}2.790 \\
(1.44)\end{array}$ & $\begin{array}{l}2.715 \\
(1.40)\end{array}$ & $\begin{array}{c}19.134^{*} \\
(1.93)\end{array}$ \\
\hline VolStocks $_{\mathrm{t}-1}$ & $\begin{array}{c}0.670^{* *} \\
(2.58)\end{array}$ & $\begin{array}{c}0.815^{* * *} \\
(2.96)\end{array}$ & $\begin{array}{c}0.643^{* *} \\
(2.23)\end{array}$ & $\begin{array}{c}8.583^{* *} \\
(2.47)\end{array}$ \\
\hline VolBonds $\mathrm{t}_{\mathrm{t}-1}$ & $\begin{array}{c}-1.852^{* * *} \\
(-3.40)\end{array}$ & $\begin{array}{c}-1.703^{* * *} \\
(-3.09)\end{array}$ & $\begin{array}{c}-1.634^{* * *} \\
(-2.95)\end{array}$ & $\begin{array}{c}-11.344^{* * *} \\
(-2.78)\end{array}$ \\
\hline VolLastYield $_{\mathrm{t}-1}$ & $\begin{array}{c}-2.932^{* *} \\
(-2.54)\end{array}$ & $\begin{array}{c}-3.229^{* *} \\
(-2.34)\end{array}$ & $\begin{array}{c}-3.041^{* *} \\
(-1.98)\end{array}$ & $\begin{array}{l}-4.820 \\
(-0.78)\end{array}$ \\
\hline LogTurnover $_{\mathrm{t}-1}$ & & & & $\begin{array}{l}-0.101 \\
(-0.20)\end{array}$ \\
\hline$\Delta$ Slope $_{\mathrm{t}}$ & $\begin{array}{l}-1.930 \\
(-0.08)\end{array}$ & $\begin{array}{l}-0.659 \\
(-0.03)\end{array}$ & $\begin{array}{l}-1.642 \\
(-0.07)\end{array}$ & $\begin{array}{l}-69.603 \\
(-1.00)\end{array}$ \\
\hline$\Delta$ VolStocks $_{\mathrm{t}}$ & $\begin{array}{c}2.271^{* * *} \\
(2.95)\end{array}$ & $\begin{array}{c}2.128^{* * *} \\
(2.75)\end{array}$ & $\begin{array}{c}2.190^{* * *} \\
(2.84)\end{array}$ & $\begin{array}{c}5.807^{* *} \\
(2.01)\end{array}$ \\
\hline$\Delta$ VolBonds $_{\mathrm{t}}$ & $\begin{array}{c}-13.057^{* * *} \\
(-2.67)\end{array}$ & $\begin{array}{c}-10.890^{* *} \\
(-2.18)\end{array}$ & $\begin{array}{c}-10.815^{* *} \\
(-2.14)\end{array}$ & $\begin{array}{c}-28.601^{*} \\
(-1.82)\end{array}$ \\
\hline$\Delta$ VolLastYield $_{\mathrm{t}}$ & $\begin{array}{c}-2.026^{* *} \\
(-2.33)\end{array}$ & $\begin{array}{c}-1.990^{* *} \\
(-2.29)\end{array}$ & $\begin{array}{c}-2.088^{* *} \\
(-2.41)\end{array}$ & $\begin{array}{l}0.689 \\
(0.18)\end{array}$ \\
\hline$\Delta$ LogTurnover $_{\mathrm{t}}$ & & & & $\begin{array}{l}0.147 \\
(0.61)\end{array}$ \\
\hline$\Delta$ Slope $_{\mathrm{t}-1}$ & & $\begin{array}{l}-1.476 \\
(-0.06)\end{array}$ & $\begin{array}{c}-11.409 \\
(-0.45)\end{array}$ & $\begin{array}{l}-6.734 \\
(-0.09)\end{array}$ \\
\hline$\Delta$ VolStocks $_{\mathrm{t}-1}$ & & $\begin{array}{l}-0.443 \\
(-0.57)\end{array}$ & $\begin{array}{l}-0.268 \\
(-0.34)\end{array}$ & $\begin{array}{l}-1.594 \\
(-0.50)\end{array}$ \\
\hline$\Delta$ VolBonds $_{\mathrm{t}-1}$ & & $\begin{array}{c}-10.525^{* *} \\
(-2.10)\end{array}$ & $\begin{array}{c}-12.205^{* *} \\
(-2.39)\end{array}$ & $\begin{array}{c}-26.832^{*} \\
(-1.67)\end{array}$ \\
\hline$\Delta$ VolLastYield $\mathrm{t}_{\mathrm{t}-1}$ & & $\begin{array}{l}0.420 \\
(0.48)\end{array}$ & $\begin{array}{l}-0.036 \\
(-0.03)\end{array}$ & $\begin{array}{c}9.466^{* *} \\
(2.00)\end{array}$ \\
\hline$\Delta$ LogTurnover $_{\mathrm{t}-1}$ & & & & $\begin{array}{l}0.342 \\
(1.00)\end{array}$ \\
\hline$\Delta$ Slope $_{\mathrm{t}-2}$ & & & $\begin{array}{c}27.750 \\
(1.15)\end{array}$ & $\begin{array}{c}-48.967 \\
(-0.73)\end{array}$ \\
\hline$\Delta$ VolStocks $_{\mathrm{t}-2}$ & & & $\begin{array}{l}1.349^{*} \\
(1.74)\end{array}$ & $\begin{array}{l}0.532 \\
(0.18)\end{array}$ \\
\hline$\Delta$ VolBonds $_{\mathrm{t}-2}$ & & & $\begin{array}{c}3.955 \\
(0.79)\end{array}$ & $\begin{array}{l}-3.284 \\
(-0.23)\end{array}$ \\
\hline$\Delta$ VolLastYield $_{\mathrm{t}-2}$ & & & $\begin{array}{l}-0.628 \\
(-0.72)\end{array}$ & $\begin{array}{l}3.854 \\
(1.18)\end{array}$ \\
\hline$\Delta$ LogTurnover $_{\mathrm{t}-2}$ & & & & $\begin{array}{l}0.128 \\
(0.52)\end{array}$ \\
\hline Constant & $\begin{array}{c}0.203^{* *} \\
(2.22)\end{array}$ & $\begin{array}{l}0.166^{*} \\
(1.79)\end{array}$ & $\begin{array}{c}0.187^{* *} \\
(2.00)\end{array}$ & $\begin{array}{l}2.613 \\
(0.21)\end{array}$ \\
\hline $\begin{array}{l}\text { Observations } \\
\mathrm{R}^{2}\end{array}$ & $\begin{array}{c}730 \\
0.064\end{array}$ & $\begin{array}{c}729 \\
0.075\end{array}$ & $\begin{array}{c}728 \\
0.077\end{array}$ & $\begin{array}{c}93 \\
0.358\end{array}$ \\
\hline
\end{tabular}


The effects are not persistent, except for the implied volatility from swaptions, which still influences the Spread up to one lag. The results suggest that, when there is high volatility on the UK stock market, investors prefer bonds, but they only turn to infinite maturity bonds when other type of bonds seem too risky (i.e., when there is high volatility on the bond market). This might explain the plot of the War Loan Spread in Figure 3.2 and why the War Loan was not underpriced during the crisis period 2008-2009 and its aftermath 2010-2011.

We are aware of the fact that low liquidity in the infinite maturity bond market could be the cause of the observed mispricing. Unfortunately, neither bid-ask spreads nor trading volume data are available for the War Loan. Instead, starting from 2006, we have access to monthly level turnover data for gilts with maturity longer than 15 years. Column (4) of Table 3.3 adds the variable LogTurnover to the error correction model of Column (3). It seems that the turnover of long-maturity gilts does not impact our measure of the mispricing at all. However, we cannot rule out liquidity effects from our story, given the rough approximation we employ for the liquidity in the War Loan market.

We continue with a sub-sample analysis of the error correction model in Column (3) of Table 3.3, which is meant to establish whether or not the Spread reacts differently to the chosen economic and financial variables in different time periods. We split our sample into three time periods with equal number of observations and report the results in Table 3.4. We also tried splitting the sample into four equally-spaced time periods and we obtained similar results.

Table 3.4 confirms the previous results of the whole-sample analysis. Most variables retain their signs and statistical significance. The only difference appears in the slope of the yield curve, which is now statistically significant in the short run in the first and last sub-period. Before the financial crisis, an increase in the slope of the yield curve lead to an increase in the mispricing of the War Loan, whereas after the crisis a change in the slope of the yield curve has the opposite effect. An increase in the slope of the yield curve is an indication of improved expectations of future economic activity. We argue that this change in the behavior of the mispricing in response to changes in Slope is due to an increased interest of investors in the War Loan after the financial crisis compared to the period before the crisis, when better economic prospects would prompt one towards the stock market and make them lose interest in the bond market, especially in the infinite maturity bond market.

Overall, our results show that the mispricing of the War Loan is driven by volatility in the financial markets. Another explanation could be though the slow-moving capital hypothesis put 
Table 3.4: Error correction model with weekly level data explaining changes in Spread for sub-samples 20002004, 2004-2009, 2009-2013. All variables are defined in Section 3.4.2. The t-statistics are presented in parentheses. ${ }^{* * *} p<0.01,{ }^{* *} p<0.05,{ }^{*} p<0.1$.

\begin{tabular}{|c|c|c|c|}
\hline & & $\Delta$ Spread $_{\mathrm{t}}$ & \\
\hline & $2000-2004$ & 2004-2009 & $2009-2013$ \\
\hline Spread $_{t-1}$ & $-0.035^{* *}$ & $-0.070^{* * *}$ & $-0.037^{* *}$ \\
\hline & $(-2.45)$ & $(-3.02)$ & $(-2.14)$ \\
\hline Slope $_{\mathrm{t}-1}$ & 2.214 & -13.216 & -20.098 \\
\hline & $(0.30)$ & $(-1.38)$ & $(-1.23)$ \\
\hline VolStockst-1 & 0.311 & $2.065^{* * *}$ & 0.804 \\
\hline & $(0.66)$ & $(3.27)$ & $(0.84)$ \\
\hline VolBonds $\mathrm{t}_{\mathrm{t}-1}$ & 4.672 & 2.934 & $-6.956^{* *}$ \\
\hline & $(1.26)$ & $(0.71)$ & $(-2.18)$ \\
\hline VolLastYield $_{\mathrm{t}-1}$ & $-13.145^{* * *}$ & -0.364 & -0.777 \\
\hline & $(-3.37)$ & $(-0.12)$ & $(-0.28)$ \\
\hline$\Delta$ Slope $_{\mathrm{t}}$ & 87.183* & -23.290 & $-95.740 * *$ \\
\hline & $(1.67)$ & $(-0.66)$ & $(-2.01)$ \\
\hline$\Delta$ VolStocks $_{\mathrm{t}}$ & $4.284^{* * *}$ & 0.679 & $3.235^{* *}$ \\
\hline & $(3.01)$ & $(0.56)$ & $(2.07)$ \\
\hline$\Delta$ VolBonds $_{\mathrm{t}}$ & -16.766 & 6.277 & $-21.990 * * *$ \\
\hline & $(-1.12)$ & $(0.56)$ & $(-3.23)$ \\
\hline$\Delta$ VolLastYield $_{\mathrm{t}}$ & $-7.358^{* * *}$ & -0.562 & -0.071 \\
\hline & $(-3.91)$ & $(-0.38)$ & $(-0.05)$ \\
\hline$\Delta$ Slope $_{\mathrm{t}-1}$ & -59.498 & 7.246 & 21.805 \\
\hline & $(-1.16)$ & $(0.20)$ & $(0.45)$ \\
\hline$\Delta$ VolStocks $_{\mathrm{t}-1}$ & -0.896 & $-3.588^{* * *}$ & 2.499 \\
\hline & $(-0.63)$ & $(-2.83)$ & $(1.52)$ \\
\hline$\Delta$ VolBonds $_{\mathrm{t}-1}$ & 10.846 & $-37.077^{* * *}$ & -9.985 \\
\hline & $(0.72)$ & $(-3.49)$ & $(-1.47)$ \\
\hline$\Delta$ VolLastYield $_{\mathrm{t}-1}$ & $4.655^{*}$ & -3.052 & 2.568 \\
\hline & $(1.70)$ & $(-1.47)$ & (1.33) \\
\hline$\Delta$ Slope $_{\mathrm{t}-2}$ & 25.430 & 20.892 & 72.315 \\
\hline & $(0.52)$ & $(0.59)$ & $(1.52)$ \\
\hline$\Delta$ VolStocks $_{\mathrm{t}-2}$ & $3.734^{* * *}$ & 1.853 & -2.533 \\
\hline & $(2.63)$ & $(1.44)$ & $(-1.62)$ \\
\hline$\Delta$ VolBonds $_{\mathrm{t}-2}$ & 2.007 & -6.814 & 10.125 \\
\hline & $(0.14)$ & $(-0.65)$ & (1.49) \\
\hline$\Delta$ VolLastYield $_{\mathrm{t}-2}$ & 0.773 & $-3.991^{* * *}$ & $2.451^{*}$ \\
\hline & $(0.40)$ & $(-2.75)$ & $(1.80)$ \\
\hline Constant & -0.344 & -0.753 & $1.779 *$ \\
\hline & $(-0.70)$ & $(-1.34)$ & $(1.74)$ \\
\hline Observations & 241 & 241 & 240 \\
\hline $\mathrm{R}^{2}$ & 0.168 & 0.223 & 0.190 \\
\hline
\end{tabular}


forward by Mitchell et al. (2007), Duffie (2010) and Fleckenstein et al. (2014). However, we are confident we can reject this explanation. Investor under-reaction seems very unlikely given that we observe the mispricing for much longer periods of time (i.e., years) than ever documented in any of the previous literature.

We also consider the possibility of measurement error introduced with the use of the NelsonSiegel (1987) fit. However, as Diebold and Li (2006) suggest, such pricing errors are persistent and, even though the prices constructed using a term structure model will never be exactly equal to the observed bond prices due to tax and liquidity effects, they will disappear when using price changes. We conduct our analysis with changes in the mispricing, which will no longer contain any measurement error, but only the actual mispricing.

\subsubsection{Implied long-term discount rate}

Apart from providing a good long-term investment at a cheap price, the War Loan could also be a source of valuable information regarding the long end of the term structure of interest rates. In particular, this infinite maturity bond could give an indication of how the market implicitly prices cash flows beyond traded maturities.

We conduct the following exercise. Using the observed term structure, we subtract the present value of the first 25 years of cash flows from the observed War Loan price. We then assume a constant long-term discount rate and imply this discount rate from the remaining value, which is always a positive value. The result of this exercise can be seen in Figure 3.3, where we plot the implied long-term discount rate against the 25 -year rate, which is the last observed interest rate. The War Loan tells us that the long-term discount rate tracks the evolution of the last observed rate very closely. Furthermore, it implies a slightly upward sloping term structure of interest rates beyond traded maturities, given that the long-term discount rate is always above the 25year rate. We should bear in mind though that our long-term discount rate is generally overstated due to the tendency of the War Loan to be underpriced.

We are now also presented with the opportunity to test the existence and the determinants of the mispricing in the War Loan without the influence of the Nelson-Siegel (1987) model. Without making any assumptions about the extension of the term structure of interest rates, the difference between the 25-year rate and the implied long-term discount rate is another representation of the Spread presented in the upper left corner of Figure 3.1. We call this difference YieldSpread and re-run the error correction model in Column (3) of Table 3.3 in order 
to explain changes in the YieldSpread instead of the Spread variable. We present the results in Table 3.5.

Figure 3.3: The implied long-term discount rate against the 25-year interest rate

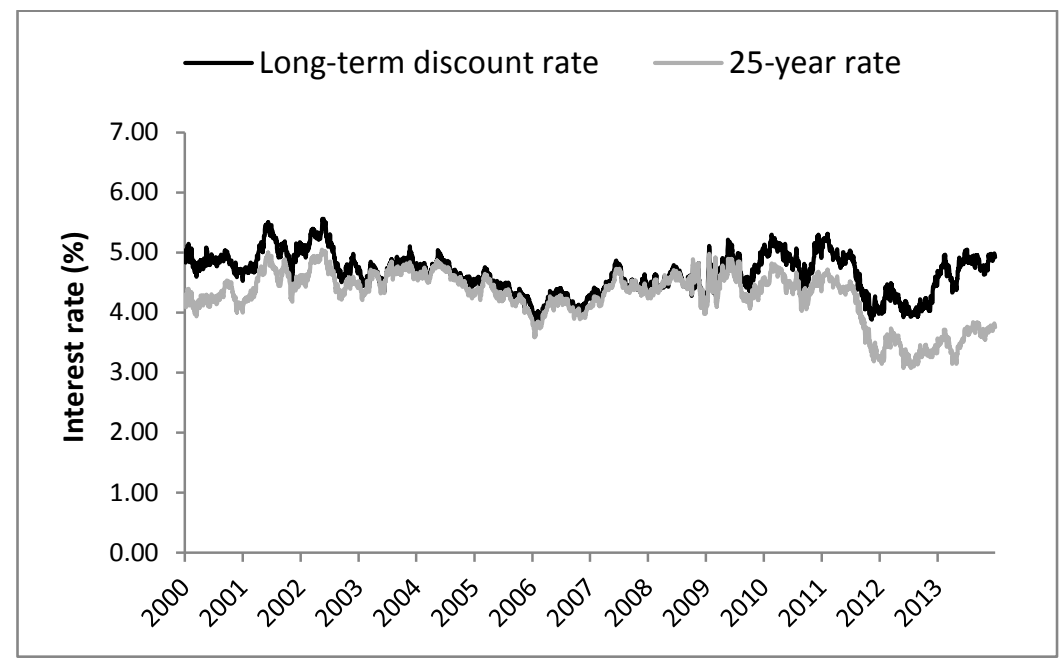

Similar to the Spread, the YieldSpread is positively influenced by the volatility in the stock market and negatively influenced by the volatility in the bond market, with the effect of the implied volatility on the bond market persisting up to one lag. However, the volatility in the last observed yield is statistically insignificant. The results in Table 3.5 coincide with our previous findings, but, most importantly, they show that the mispricing of the War Loan and its determinants are not an artifact of the Nelson-Siegel (1987) model. The mispricing of the War Loan is indeed a result of a series of financial variables and it is not triggered by the future economic prospects.

\subsection{Mispricing or option value?}

The UK undated gilts have two unique features: they have infinite maturity and they can be redeemed by the issuer (i.e., the Government) at any point in time, meaning that these gilts have an embedded American option feature. Some of the undated gilts can be redeemed on a payment date, while others, like the War Loan, require at least three months' notice in the London Gazette.

We acknowledge the fact that a component of the observed mispricing is the embedded option value of the War Loan. The methodology of how one could calculate the price of the bond with 
Table 3.5: Error correction model with weekly level data explaining changes in YieldSpread. YieldSpread is the difference between the last observed yield and the implied long-term discount rate. All other variables are defined in Section 3.4.2. The t-statistics are presented in parentheses. ${ }^{* *} p<0.01,{ }^{* *} p<0.05,{ }^{*} p<0.1$.

\begin{tabular}{|c|c|}
\hline & $\Delta$ YieldSpread $_{\mathrm{t}}$ \\
\hline YieldSpread $_{\mathrm{t}-1}$ & $\begin{array}{c}-0.019 * * * \\
(-3.21)\end{array}$ \\
\hline Slope $_{t-1}$ & $\begin{array}{c}-0.00002 \\
(-0.02)\end{array}$ \\
\hline VolStocks $\mathrm{t}_{\mathrm{t}-1}$ & $\begin{array}{c}0.0004^{* *} \\
(2.24)\end{array}$ \\
\hline VolBonds $_{\mathrm{t}-1}$ & $\begin{array}{c}-0.001^{* * *} \\
(-3.09)\end{array}$ \\
\hline VolLastYield $_{\mathrm{t}-1}$ & $\begin{array}{l}-0.002 \\
(-1.58)\end{array}$ \\
\hline$\Delta$ Slope $_{\mathrm{t}}$ & $\begin{array}{l}-0.018 \\
(-1.15)\end{array}$ \\
\hline$\Delta$ VolStocks $_{\mathrm{t}}$ & $\begin{array}{c}0.001^{* * *} \\
(2.66)\end{array}$ \\
\hline$\Delta$ VolBonds $_{\mathrm{t}}$ & $\begin{array}{l}-0.004 \\
(-1.24)\end{array}$ \\
\hline$\Delta$ VolLastYield $_{\mathrm{t}}$ & $\begin{array}{c}-0.002^{* * *} \\
(-2.65)\end{array}$ \\
\hline$\Delta$ Slope $_{\mathrm{t}-1}$ & $\begin{array}{l}-0.014 \\
(-0.83)\end{array}$ \\
\hline$\Delta$ VolStocks $_{\mathrm{t}-1}$ & $\begin{array}{c}0.0004 \\
(0.78)\end{array}$ \\
\hline$\Delta$ VolBonds $_{\mathrm{t}-1}$ & $\begin{array}{c}-0.006^{*} \\
(-1.79)\end{array}$ \\
\hline$\Delta$ VolLastYield $_{\mathrm{t}-1}$ & $\begin{array}{c}-0.0003 \\
(-0.45)\end{array}$ \\
\hline$\Delta$ Slope $_{\mathrm{t}-2}$ & $\begin{array}{l}0.005 \\
(0.33)\end{array}$ \\
\hline$\Delta$ VolStocks $_{\mathrm{t}-2}$ & $\begin{array}{c}-0.0001 \\
(-0.32)\end{array}$ \\
\hline$\Delta$ VolBonds $_{\mathrm{t}-2}$ & $\begin{array}{l}0.001 \\
(0.25)\end{array}$ \\
\hline$\Delta$ VolLastYield $_{\mathrm{t}-2}$ & $\begin{array}{c}-0.0001 \\
(-0.21)\end{array}$ \\
\hline Constant & $\begin{array}{c}0.0001^{* *} \\
(2.02)\end{array}$ \\
\hline $\begin{array}{l}\text { Observations } \\
\mathrm{R}^{2}\end{array}$ & $\begin{array}{c}728 \\
0.056 \\
\end{array}$ \\
\hline
\end{tabular}


the embedded American option is presented in the Appendix. However, the option value cannot account for the entire magnitude of the effect.

All eight undated gilts differ only by coupon rate and liquidity. In a low interest rate environment, the option value of a $3 \frac{1}{2} \%$ infinite maturity coupon bond is higher than the option value of a $2 \frac{1}{2} \%$ infinite maturity coupon bond, making the higher-coupon bond less valuable than the lower-coupon bond and its underpricing less severe. Based on the data in Figure 3.2, the left panel of Figure 3.4 shows that this is not always the case, for instance in the beginning and end periods of our time series when long-term interest rates are at relatively low levels. Similarly, infinite maturity bonds with the same coupon rate should have the same option value, but the right panel of Figure 3.4 shows that the level of mispricing differs for two bonds with the same coupon rate. Furthermore, the presence of the embedded option value does not explain why the War Loan is sometimes overpriced compared to the theoretical price. When the option value is low, as in the time period 2008-2010 when long-term interest rates are at relatively high levels, the theoretical price should be a good approximation of the observed market price and no mispricing should be visible anymore.

Figure 3.4: Comparison of the different Spread measures among undated gilts
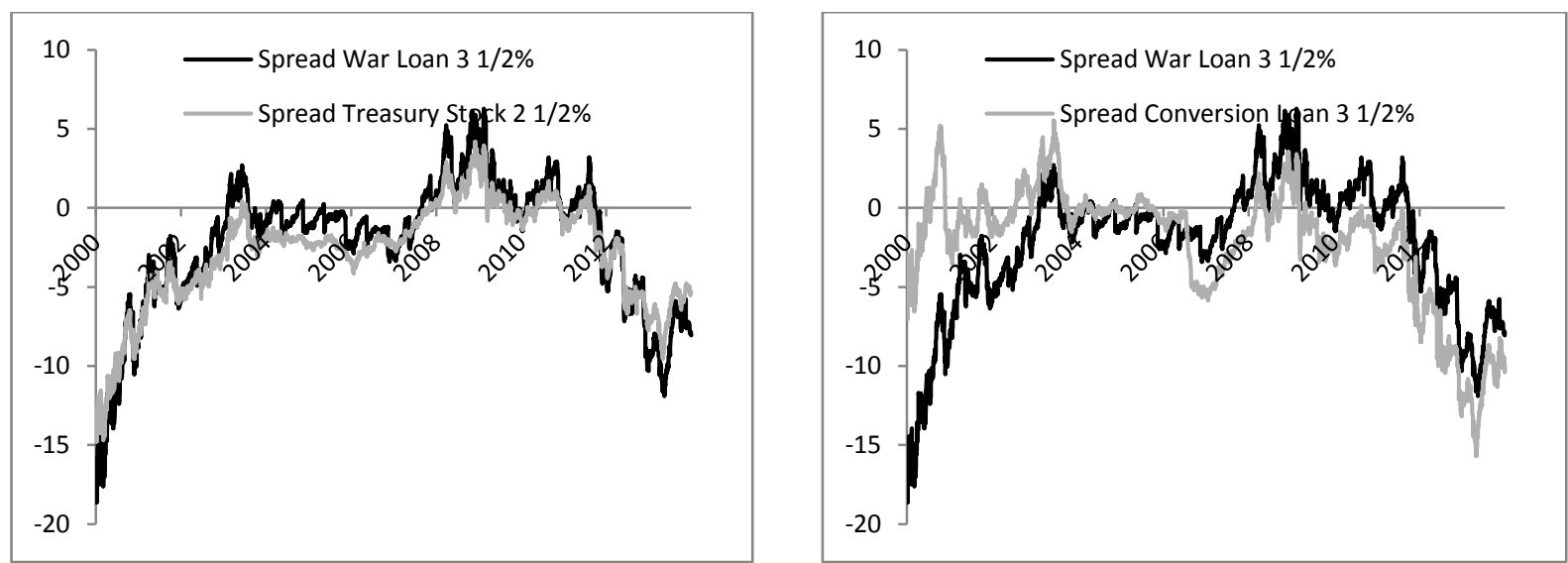

The level of the long-term interest rates can be seen as a proxy for option value: the lower the interest rates fall the higher the option value becomes. We add the level of the last observed yield, which we denote by LastYield, to the specification in Column (3) of Table 3.3 and present the results in Table 3.6. The results show that indeed the level of the last observed yield has a positive effect on the Spread in the short run, suggesting that the option value explains part of the mispricing, but it does not eliminate the influence of the volatility on the stock market and on the bond market nor does it invalidate our previous findings. 
Table 3.6: Error correction model explaining changes in Spread. LastYield is the level of the last observed yield (i.e., the 25-year yield). All other variables are defined in Section 3.4.2. The t-statistics are presented in parentheses. ${ }^{* * *} p<0.01,{ }^{* *} p<0.05,{ }^{*} p<0.1$.

\begin{tabular}{|c|c|}
\hline & $\Delta$ Spread $_{\mathrm{t}}$ \\
\hline Spreadt $-1_{1}$ & $\begin{array}{c}-0.021^{* * *} \\
(-3.65)\end{array}$ \\
\hline Slope $_{t-1}$ & $\begin{array}{l}3.637 \\
(1.46)\end{array}$ \\
\hline VolStockst-1 & $\begin{array}{c}0.866^{* * *} \\
(2.90)\end{array}$ \\
\hline VolBondst-1 & $\begin{array}{c}-2.143^{* *} \\
(-2.04)\end{array}$ \\
\hline VolLastYield $_{\mathrm{t}-1}$ & $\begin{array}{c}-3.501^{* *} \\
(-2.29)\end{array}$ \\
\hline LastYield $\mathrm{t}_{\mathrm{t}-1}$ & $\begin{array}{l}-0.067 \\
(-0.68)\end{array}$ \\
\hline$\Delta$ Slope $_{\mathrm{t}}$ & $\begin{array}{c}-83.720^{* * *} \\
(-2.67)\end{array}$ \\
\hline$\Delta$ VolStocks $_{\mathrm{t}}$ & $\begin{array}{c}2.226^{* * * *} \\
(2.90)\end{array}$ \\
\hline$\Delta$ VolBondst & $\begin{array}{l}-3.667 \\
(-0.68)\end{array}$ \\
\hline$\Delta$ VolLastYield $_{\mathrm{t}}$ & $\begin{array}{c}-2.306^{* * *} \\
(-2.68)\end{array}$ \\
\hline$\Delta$ LastYield $_{\mathrm{t}}$ & $\begin{array}{c}1.628^{* * *} \\
(4.09)\end{array}$ \\
\hline$\Delta$ Slope $_{\mathrm{t}-1}$ & $\begin{array}{c}-11.331 \\
(-0.34)\end{array}$ \\
\hline$\Delta$ VolStocks $_{\mathrm{t}-1}$ & $\begin{array}{l}-0.582 \\
(-0.75)\end{array}$ \\
\hline$\Delta$ VolBonds $\mathrm{t}_{\mathrm{t}-1}$ & $\begin{array}{c}-9.648^{*} \\
(-1.78)\end{array}$ \\
\hline$\Delta$ VolLastYield $_{\mathrm{t}-1}$ & $\begin{array}{l}0.060 \\
(0.05)\end{array}$ \\
\hline$\Delta$ LastYield $_{\mathrm{t}-1}$ & $\begin{array}{l}0.207 \\
(0.52)\end{array}$ \\
\hline$\Delta$ Slope $_{\mathrm{t}-2}$ & $\begin{array}{l}43.921 \\
(1.41)\end{array}$ \\
\hline$\Delta$ VolStockst-2 & $\begin{array}{l}1.443^{*} \\
(1.87)\end{array}$ \\
\hline$\Delta$ VolBondst $\mathrm{s}_{\mathrm{t}-2}$ & $\begin{array}{l}3.972 \\
(0.74)\end{array}$ \\
\hline$\Delta$ VolLastYield $_{\mathrm{t}-2}$ & $\begin{array}{l}-0.596 \\
(-0.69)\end{array}$ \\
\hline$\Delta$ LastYield $_{\mathrm{t}-2}$ & $\begin{array}{l}-0.022 \\
(-0.06)\end{array}$ \\
\hline Constant & $\begin{array}{l}0.523 \\
(0.96)\end{array}$ \\
\hline $\begin{array}{l}\text { Observations } \\
\mathrm{R}^{2}\end{array}$ & $\begin{array}{c}728 \\
0.101\end{array}$ \\
\hline
\end{tabular}


Given all the reasons mentioned above, we conclude that, even though the option value can partly explain the documented mispricing in the War Loan, it cannot account for the patterns entirely.

\subsection{Robustness test}

As a robustness test, we search for a different measure to proxy for the economic outlook instead of the slope of the term structure of interest rates. We use the Economic Sentiment Indicator, a monthly indicator provided by Eurostat 7 . We retrieve the Economic Sentiment Indicator data both at EU and UK level for the time period 2000 - 2013.

The Economic Sentiment Indicator is a survey-based measure of economic prospects. It is comprised of five confidence indicators with different weights: the industrial confidence indicator, the services confidence indicator, the consumer confidence indicator, the construction confidence indicator and the retail trade confidence indicator. The Economic Sentiment Indicator is calculated as an index with mean value of 100 and standard deviation of 10 over a fixed standardized sample period.

We re-run the error correction model in Column (3) of Table 3.3, this time replacing the Slope variable first with the Economic Sentiment at EU level and then with the Economic Sentiment at UK level. We aggregate all data on a monthly basis and present the results in Table 3.7.

Similar to the findings in Section 3.4.2., the economic prospects have no influence on the mispricing of the War Loan. Furthermore, the use of the Economic Sentiment Indicator does not change the impact the volatility of the stock market and of the bond market has on the Spread. We still observe a positive relationship between VolStocks and Spread and a negative relationship between VolBonds and Spread. Similar to the results in Table 3.3, the implied volatility from swaptions is persistent and influences the Spread up to one lag. However, the volatility of the last observed yield, VolLastYield, becomes insignificant.

We conclude that Table 3.7 supports the previous evidence, leading us to believe that our results are not driven by the particular choice of variables and that we indeed capture the drivers of the mispricing we document for the War Loan.

\footnotetext{
7 http://epp.eurostat.ec.europa.eu/portal/page/portal/eurostat/home/
} 
Table 3.7: Error correction model with monthly level data explaining changes in Spread during the time period 2000 - 2013. EcSentEU and EcSentUK are the Economic Sentiment Indicators at EU and UK level respectively, provided by Eurostat. All other variables are defined in Section 3.4.2. The t-statistics are presented in parentheses. ${ }^{* * *} p<0.01,{ }^{* *} p<0.05,{ }^{*} p<0.1$

\begin{tabular}{|c|c|c|}
\hline & \multicolumn{2}{|l|}{$\Delta$ Spread $_{\mathrm{t}}$} \\
\hline & $(1)$ & $(2)$ \\
\hline Spread $_{t-1}$ & $\begin{array}{c}-0.078 * * * \\
(-3.19)\end{array}$ & $\begin{array}{c}-0.081^{* * *} \\
(-3.44)\end{array}$ \\
\hline EcSentEU $_{\mathrm{t}-1}$ & $\begin{array}{c}0.008 \\
(0.63)\end{array}$ & \\
\hline EcSentUK $_{\mathrm{t}-1}$ & & $\begin{array}{c}0.003 \\
(0.22)\end{array}$ \\
\hline VolStocks $_{\mathrm{t}-1}$ & $\begin{array}{c}3.827^{* *} \\
(2.57)\end{array}$ & $\begin{array}{c}3.557^{* *} \\
(2.46)\end{array}$ \\
\hline VolBonds $_{\mathrm{t}-1}$ & $\begin{array}{c}-4.188^{*} \\
(-1.90)\end{array}$ & $\begin{array}{c}-4.826^{* *} \\
(-2.46)\end{array}$ \\
\hline VolLastYield $_{\mathrm{t}-1}$ & $\begin{array}{l}-3.765 \\
(-0.87)\end{array}$ & $\begin{array}{l}-4.287 \\
(-0.94)\end{array}$ \\
\hline$\Delta \mathrm{EcSentEU}_{\mathrm{t}}$ & $\begin{array}{l}0.023 \\
(0.40)\end{array}$ & \\
\hline$\Delta \mathrm{EcSentUK}_{\mathrm{t}}$ & & $\begin{array}{l}0.024 \\
(0.96)\end{array}$ \\
\hline$\Delta$ VolStocks $_{\mathrm{t}}$ & $\begin{array}{c}6.326^{* * *} \\
(3.36)\end{array}$ & $\begin{array}{c}6.250^{* * *} \\
(3.36)\end{array}$ \\
\hline$\Delta$ VolBonds $_{\mathrm{t}}$ & $\begin{array}{c}-17.148^{*} \\
(-1.78)\end{array}$ & $\begin{array}{c}-17.686^{*} \\
(-1.88)\end{array}$ \\
\hline$\Delta$ VolLastYield $_{\mathrm{t}}$ & $\begin{array}{c}0.419 \\
(0.16)\end{array}$ & $\begin{array}{l}0.201 \\
(0.08)\end{array}$ \\
\hline$\Delta \mathrm{EcSentEU}_{\mathrm{t}-1}$ & $\begin{array}{l}0.055 \\
(1.03)\end{array}$ & \\
\hline$\Delta \mathrm{EcSentUK}_{\mathrm{t}-1}$ & & $\begin{array}{l}0.012 \\
(0.47)\end{array}$ \\
\hline$\Delta$ VolStocks $_{\mathrm{t}-1}$ & $\begin{array}{l}0.546 \\
(0.29)\end{array}$ & $\begin{array}{l}0.167 \\
(0.09)\end{array}$ \\
\hline$\Delta$ VolBonds $_{\mathrm{t}-1}$ & $\begin{array}{c}-17.468^{*} \\
(-1.80)\end{array}$ & $\begin{array}{c}-17.309^{*} \\
(-1.82)\end{array}$ \\
\hline$\Delta$ VolLastYield $_{\mathrm{t}-1}$ & $\begin{array}{l}6.860^{*} \\
(1.86)\end{array}$ & $\begin{array}{l}6.690^{*} \\
(1.81)\end{array}$ \\
\hline$\Delta \mathrm{EcSentEU}_{\mathrm{t}-2}$ & $\begin{array}{l}-0.037 \\
(-0.69)\end{array}$ & \\
\hline$\Delta \mathrm{EcSentUK}_{\mathrm{t}-2}$ & & $\begin{array}{l}-0.019 \\
(-0.78)\end{array}$ \\
\hline$\Delta$ VolStocks $_{\mathrm{t}-2}$ & $\begin{array}{l}-1.106 \\
(-0.60)\end{array}$ & $\begin{array}{l}-1.437 \\
(-0.78)\end{array}$ \\
\hline$\Delta$ VolBonds $_{\mathrm{t}-2}$ & $\begin{array}{l}9.931 \\
(1.02)\end{array}$ & $\begin{array}{l}10.013 \\
(1.07)\end{array}$ \\
\hline$\Delta$ VolLastYield $_{\mathrm{t}-2}$ & $\begin{array}{l}2.924 \\
(1.15)\end{array}$ & $\begin{array}{l}2.906 \\
(1.14)\end{array}$ \\
\hline Constant & $\begin{array}{l}-0.745 \\
(-0.43)\end{array}$ & $\begin{array}{l}-0.057 \\
(-0.03)\end{array}$ \\
\hline $\begin{array}{l}\text { Observations } \\
\mathrm{R}^{2}\end{array}$ & $\begin{array}{c}165 \\
0.294 \\
\end{array}$ & $\begin{array}{c}165 \\
0.294 \\
\end{array}$ \\
\hline
\end{tabular}




\subsection{Conclusion}

We document a mispricing in the UK infinite maturity bond market. We compare observed market prices to theoretical bond prices in order to extract information about the long end of the term structure of interest rates. We show that UK infinite maturity bonds and in particular the War Loan are generally underpriced and that the mispricing is mainly driven by volatility in the financial markets. Furthermore, we show that the War Loan implies a slightly upward term structure of interest rates.

The question remains though: why does the mispricing persist? One would expect that large institutional investors like pension funds and insurance companies would be interested in such long-term investments, eliminating the mispricing. However, it seems that they in fact do not invest in these instruments given the persistent mispricing, in which case they leave money on the table.

\subsection{Appendix}

The War Loan can be redeemed by the government at any point in time. If the issuer decides to buy back the War Loan, the bond holders receive $€ 100$ plus the value of the coupon. To incorporate this American option feature in the pricing mechanism, we can calibrate a 1-factor Hull-White (1990) model to market swaption prices. The parameter values resulting from the calibration can then be used as inputs for a finite difference pricing method in order to price the bond option.

In the Hull-White (1990) model, the dynamics of the short interest rate under the risk-neutral measure $Q$ are given by:

$$
d r=[\theta(t)-a r] d t+\sigma d w
$$

$\theta$ is a deterministic function of time, $a$ is a constant mean-reversion parameter and $\sigma$ is a constant volatility parameter.

There is no closed-form solution for the price of a swaption in the Hull-White (1990) model. In the absence of an analytical formula, the Jamshidian (1989) decomposition can be used to 
compute the price of a swaption, by writing the option on a coupon bond as a sum of $N$ options on the underlying zero-coupon bonds ${ }^{8}$. This decomposition can be applied, because the price of a swaption is equivalent to the price of a put option on a coupon bond with strike price equal to 1 .

Given that there is no analytical formula for an American bond option, the calibrated parameters $a$ and $\sigma$ are used as inputs for an explicit finite difference method to calculate the price of an infinite maturity bond with the characteristics of the War Loan. The time-zero price of the bond option is computed via a backwards recursive procedure, knowing that at every node of the grid there is a trade-off between the continuation value and the prepayment value of the bond. If market interest rates are low, it is cheaper for the government to prepay the bond. However, if market interest rates are high, it is better for the government to continue paying the semiannual coupons to the bond holders. The early exercise of the American option takes place only at the time points when coupon payments are made. Details of the finite difference method can be found in Pelsser (2000).

\footnotetext{
${ }^{8}$ This holds for all one-factor term structure models and for all applications where the components of the portfolio are monotonic functions of the same state variable.
} 


\section{Chapter 4}

\section{The role of corporate political contributions in the allocation of government procurements 9}

\subsection{Introduction}

There is growing concern that politics and business are becoming more and more intertwined, to the point that political decisions are not made in the interest of the voters anymore but in the interest of the most well-connected company. For instance, in the beginning of September 2014, the media was reporting that former US Republican Congressman Eric Cantor will join Wall Street boutique investment bank Moelis \& Co. as vice chairman and board member for a compensation of $\$ 3.4$ million in order to help Moelis \& Co. navigate difficult terrain in Washington. Cantor was House Majority Leader from 2011 until his resignation from Congress in August 2014, after having lost the Republican primary election. According to the Center for Responsive Politics ${ }^{10}$, during his political career, Cantor raised most contributions money from companies in the securities and investment industry.

Is this example a mere coincidence or does it hint at the nature of the relationship between politicians and the private sector? Does Moelis \& Co. stand to gain anything from the government by hiring someone with inside knowledge of Washington? It could be that the company is seeking easier access to government contracts. Alternatively, Moelis \& Co. might be hoping for increased support when lobbying for favorable legislation. This is another example of an incomplete market situation. The activity of companies is affected by the political decisions made in the country they operate in. However, one cannot trade in political decisions hence the market for political risk is incomplete.

The purpose of this chapter is to determine the connection between corporate political contributions and the allocation of government procurement contracts. We compile comprehensive information on all S\&P500 companies in the time span $1993-2010$ and provide

\footnotetext{
9 This is joint work with prof. dr. Piet Eichholtz. We are thankful to our colleagues at Maastricht University for valuable feedback and to NWO (the Netherlands Organization for Scientific Research) for the generous support in the form of a three-year grant via the Graduate Programme 2011 (correspondence number 2011/08865/B00).

$10 \mathrm{http}: / /$ www.opensecrets.org/
} 
an overview of the contributing behavior around congressional election campaigns and the implications on the subsequent allocation of procurement contracts.

We find that making a contribution can increase the chances of receiving a procurement contract in the next period. To maximize the future procurement value, companies should contribute to a large number of candidates taking part in Congressional races and preferably to candidates of the Republican Party. Furthermore, we show that the effects of contributions vary depending on the industry the company belongs to. In some industries, companies can use contributions as a tool in the competition for government contracts, while in others contributions have no effect on the subsequent procurement value, suggesting that the contributions' purpose is different there, perhaps directed at insuring against unfavorable legislation.

Our work is closely related to the work of Witko (2011), Goldman et al. (2013) and Tahoun (2014), who relate political affiliations to the allocation of government procurement contracts. Witko (2011) tracks all PACs in continuous existence between 1979 - 2006, regardless of whether the affiliated company is public or private, and relates their contributing behavior to the number of government contracts received. He finds that the more money a company contributes the more government contracts the company receives. Goldman et al. (2013) look at the effects of the change in control in the House and the Senate after the 1994 election and find that companies with boards politically connected to the winning party experience an increase in the value of the procurement contracts after the election. However, contributions made by firms to the 1994 election campaign do not have a significant effect in this setting. Tahoun (2014) relates the shares of S\&P500 firms held by members of Congress in the time frame $2004-2007$ to the corporate political contributions made by these firms - as gains for the politicians - and the government contracts received by these firms - as gains for the firms. He finds that US members of Congress invest more in firms which contribute to election campaigns compared to the rest and that firms which exhibit this type of associations receive more government contracts.

This chapter contributes to the work of Witko (2011), Goldman et al. (2013) and Tahoun (2014) by establishing a clear relationship between political contributions and the allocation of procurement contracts. As opposed to Tahoun (2014), who analyzes the politician-firm relationship from the perspective of the politician, we focus on the firm as the decision maker and, contrary to the results of Goldman et al. (2013), we find that contributions play a central role in the allocation of procurement contracts. We ask the question whether or not it is worthwhile for firms to contribute and how exactly they stand to gain from it. We find that firms 
can benefit from contributing to election campaigns by increasing their chances to be awarded a procurement contract in the next period. The difference in results compared to Goldman et al. (2013) is likely driven by the fact that we use a much longer time span to capture these effects. Even though the literature related to the allocation of procurement contracts is limited, the literature on political contributions is quite extensive and it spans two main strands. The first strand of literature documents the process of contributing to election campaigns via political action committees (PACs). Grier and Munger (1991) and Stratmann (1992) find that PACs target congressional committees that they believe might serve their interests and that incumbents, especially in close election races, are most receptive to these contributions. Additionally, Kroszner and Stratmann (2005) find that congressional committee members receive more contributions when they are higher ranked in the committee and make clear which interests they support.

Stratmann (1995) finds that contributions made around the time of a vote are more important than contributions received at the last election. Snyder (1990) documents the fact that candidates in election races try to attract as many contributions from PACs as possible, even though Ansolabehere et al. (2003) show that most contributions come from individuals and not from PACs, while Milyo et al. (2000) show that corporate PACs in particular spend more money on lobbying activities than on campaign contributions. Bombardini and Trebbi (2011) show that PACs interact with politicians by promising not only monetary contributions for election campaigns but also votes. If the size of the interest group the PAC represents is large enough, then the voter representation can be quite significant. The authors find a concave relationship between monetary contributions and votes: once the votes promised by a PAC to a legislator are numerous enough, the contribution value needed to ensure the future support of the legislator starts to decrease.

Contribution limits in place during the sample period affect both the election races and the PACs themselves. Stratmann et al. (2006) show that these limits lead to increased competition and closer races with less of an advantage for incumbents. Drazen et al. (2007) talk about a reduced advantage of richer PACs over poorer PACs, even though the exact opposite could also happen: richer PACs increase their bargaining power even more.

The second strand of literature relates political contributions to firm performance. Claessen et al. (2008) use a panel of Brazilian election data to show that firms which contribute to election campaigns benefit from easier subsequent access to bank finance. Goldman et al. (2009) and Cooper et al. (2010) show that firms can experience positive abnormal returns either by having 
politically connected board members or by making contributions to election campaigns, especially if they contribute to candidates located in the same state as the firm. Ovtchinnikov and Pantaleoni (2012) find that even individual contributions to election campaigns are beneficial for firms, especially in difficult economic times, if individuals target legislators who can influence the economic well-being in a certain area or industry. Hong and Kostovetsky (2012) and Di Giuli and Kostovetsky (2014) show that more support to the Democrat party is associated with lower investments by mutual funds in stocks of socially irresponsible companies and with higher corporate social responsibility ratings, respectively.

The remainder of this chapter is organized as follows. Section 4.2 describes the data used. Section 4.3 presents the empirical analysis and the results. Section 4.4 discusses the findings and concludes.

\subsection{Data and descriptive statistics}

Our aim is to find the effect that campaign contributions made by S\&P500 companies have on the probability that these companies receive government contracts in the following period and, if there is indeed an effect, we want to know how large it is. To this end, we compile company level data from three different sources: political contributions during congressional elections from the Federal Election Commission (FEC), government procurements data from the Federal Procurement Data System - Next Generation (FPDS-NG) and company financials from COMPUSTAT. We obtain yearly information on S\&P500 companies from these sources for the time period 1993 - 2010. Our sample starts in 1993, when the congressional committees (i.e., the committees making up the US House of Representatives and the Senate) in their current form were established, and it ends in 2010, when the Citizens United act was passed, eliminating some of the restrictions on the amounts of contributions and potentially modifying the contributing behavior.

The Federal Election Commission (FEC) is an independent regulatory agency whose role is to enforce the Federal Election Campaign Act (FECA) of 1971, in particular to disclose all information on campaign finance during federal elections and to ensure that the limits on contributions imposed by law are not broken. The FEC gathers information from all federal elections for the US Congress as well as presidential elections and it reports contributions made by both individuals and political action committees. A political action committee (PAC) is an entity organized for the specific purpose of raising and spending money in order to elect or 
defeat candidates. According to the FEC, a PAC can be affiliated to a corporation, a labor organization, a membership organization, a trade association, a cooperative or a corporation without capital stock.

We focus on the activity of corporate PACs during congressional elections. Congressional elections take place every two years, which means that an election cycle, which is the period of time during which an elected candidate exerts his term and contributions can be made for the next election, lasts for two years. Corporations are not allowed to make contributions to election campaigns, but their PACs are. According to the FEC rules, a PAC can receive repeated contributions for the same candidate or for multiple candidates, as long as the contributions do not exceed $\$ 5,000$ per year from one contributor. Furthermore, a PAC can contribute a maximum of $\$ 5,000$ per candidate per election, where each primary, general, runoff and special election in House and Senate races is treated as a separate election with separate contribution limits. A corporate PAC can only accept contributions from managers and stockholders and their families and it is not allowed to seek contributions from other employee categories. We aggregate all the reported contributions at company level.

The Federal Procurement Data System - Next Generation (FPDS-NG) is a government database that comprises information on all procurements, with a value higher than $\$ 3,000$, contracted by the US Government. A procurement contract is a contract to sell goods and services to the government. The information in this database is public and it refers to the name of the company providing the goods and services, the total value of the procurement and the contracting agency of the US Government.

The company financials are retrieved from COMPUSTAT. We use yearly information on total assets (including cash holdings), the book-to-market ratio (measured as the book value per share divided by the end-of-year market price per share), total debt (measured as the sum of long term debt and debt in current liabilities), total dividends (i.e. common and preferred), capital expenditures (or Capex) and the cost of goods sold (or Cogs).

The data gathering process is carried out as follows. First, we identify all the names of the S\&P500 companies in the time span 1993-2010. We track company name changes using the EDGAR online database provided by the US Securities and Exchange Commission (SEC). Second, we match the company names to the names listed in the political contributions files of the FEC, such that we identify which S\&P500 companies made contributions, to which candidates and what the contribution values were. We use exact name matching. Third, we manually search for 
each S\&P500 company name in the FPDS-NG database, in order to obtain information on the dollar amounts received in procurements by these companies. Again, we use exact name matching. We do not include subsidiary level data in our sample.

The resulting sample consists of 911 unique S\&P500 companies or 8,359 observations. The descriptive statistics are reported in Table 4.1. We deleted 2 observations that reported negative dividends, 4 observations that reported negative sales, 325 observations that reported negative equity and 51 observations that reported total dividends higher than total assets.

Table 4.1: Descriptive statistics for the sample of 911 unique S\&P500 companies in the time frame 1993-2010

\begin{tabular}{llllll}
\hline & Mean & Min & Median & Max & St dev \\
\hline Procurement & $85,200,000$ & 0 & 0 & $33,600,000,000$ & $973,000,000$ \\
Procurement (\% of Assets) & 0.52 & 0 & 0 & 107.31 & 4.18 \\
Log(1+Procurement) & 5.92 & 0 & 0 & 24.24 & 7.42 \\
Contribution & 49,593 & 0 & 0 & $2,186,800$ & 121,710 \\
Contribution (\% of Assets) & 0.0003 & 0 & 0 & 0.04 & 0.001 \\
Log(1+Contribution) & 5.14 & 0 & 0 & 14.60 & 5.44 \\
No. supported candidates & 26.86 & 0 & 0 & 513 & 50.44 \\
\% Democrats & 17.72 & 0 & 0 & 100 & 23.10 \\
\% Republicans & 30.32 & 0 & 0 & 100 & 34.47 \\
& & & & & \\
LogAssets & 22.91 & 18.21 & 22.80 & 28.45 & 1.41 \\
LogBM & -1.00 & -6.72 & -0.95 & 12.21 & 0.82 \\
Debt/Assets & 0.24 & 0 & 0.24 & 0.96 & 0.16 \\
Dividends/Assets & 0.02 & 0 & 0.01 & 0.61 & 0.03 \\
Capex/Sales & 0.08 & 0 & 0.05 & 1.69 & 0.11 \\
Cogs/Sales & 0.61 & 0.01 & 0.65 & 10.52 & 0.24 \\
\hline
\end{tabular}

Table 4.1 shows that, on average, the S\&P500 companies in our sample contribute to 27 candidates or approximately $\$ 50,000$, meaning that on average they contribute $\sim \$ 1,852$ per candidate (i.e., below the limit of $\$ 5,000$ per candidate per election) and they receive approximately $\$ 85$ million in procurements. Predominantly, they support the Republican Party.

In Figure 4.1, we display the evolution of the average procurement value and the average contribution value per year during the time period 1993-2010. The vertical lines mark the twoyear periods of the election cycles. Both the contribution values and the procurement values show strongly increasing trends, especially after 1999. It seems that the contributions follow the pattern of the election cycles: they decrease in the first year of an election cycle and then they 
spike in the year right before the election, suggesting that contributions are essential close to the actual election. From 2005 onwards, the values track each other very closely.

Figure 4.1: The evolution of the average procurement value and the average contribution value per company per year from 1993 until 2010; the vertical lines mark election dates

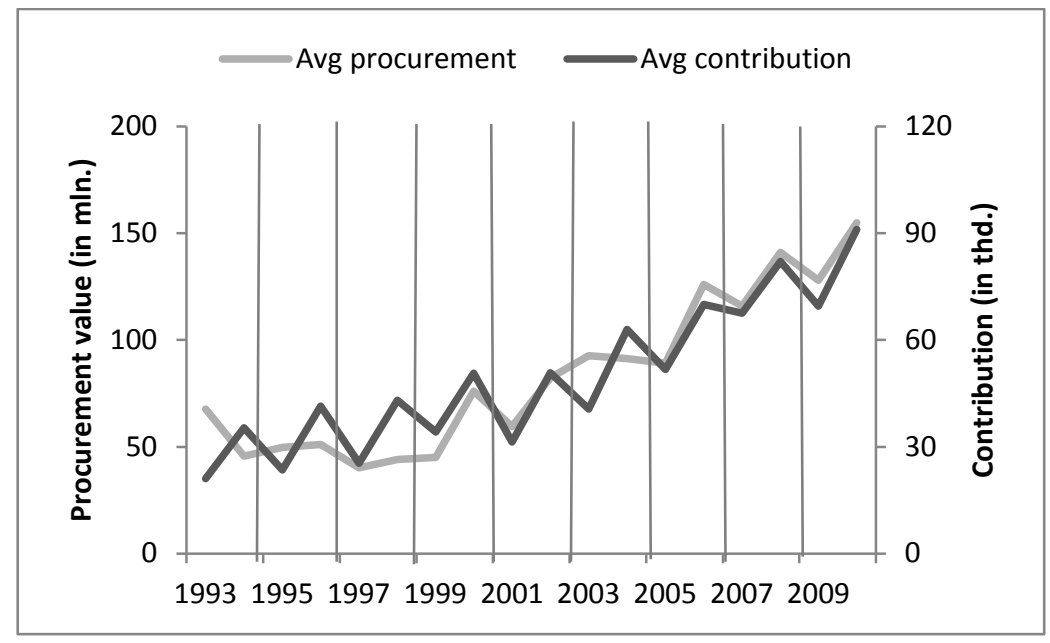

Since 1999, both the average procurement and the average contribution per company almost doubled in value, suggesting that S\&P500 companies invest more in election campaigns, but they also gain more in government contracts. However, the increase in procurements obtained by the S\&P500 companies is not nearly as spectacular as the increase in the total procurements awarded at federal level. Figure 4.2 plots this increase on a yearly basis from 1993 until 2010. From 1999 until 2010, the total procurements awarded by the US government almost tripled in value. In 1993, the procurements awarded to S\&P500 companies alone represented 19\% of the total. Throughout the years, the percentage decreased, ending up at 15\% in 2010.

Figure 4.2: The evolution of the total procurement value at national level and the total procurement value allocated to S\&P500 companies per year from 1993 until 2010

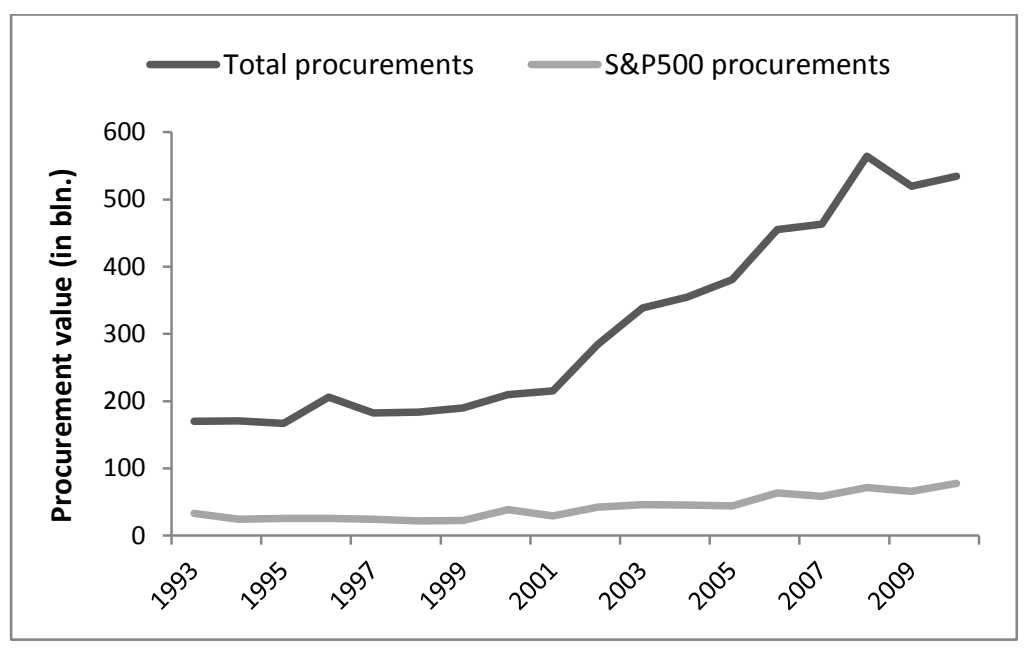


We continue the description of data with Figure 4.3, which shows the percentage of S\&P500 companies contributing to election campaigns and the percentage of S\&P500 companies actually receiving procurement contracts. It seems that roughly $50 \%$ of the sample makes contributions every year, with the overwhelming majority of contributors giving to both the Democrats and the Republicans. Approximately $40 \%$ of the sample receives procurement contracts every year.

Figure 4.3: The evolution of the percentage of S\&P500 companies contributing to congressional elections, contributing to both Democrats and Republicans and receiving procurement contracts from 1993 until 2010

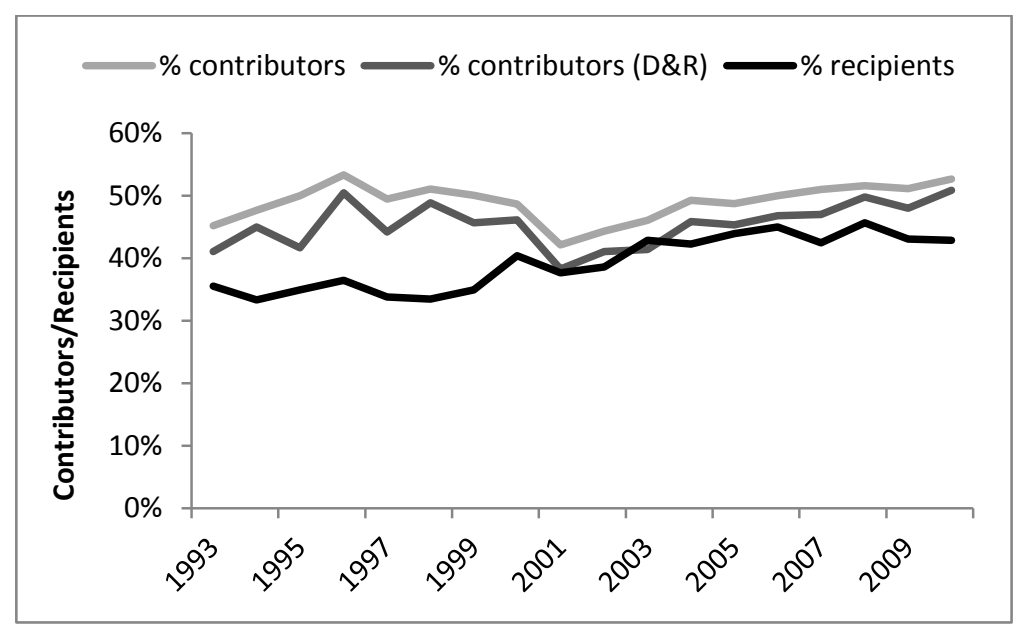

We use the Fama-French 10 industry classification to learn more about the type of companies in our sample. Details of the Fama-French 10 industry classification can be found in Appendix Table 4.1. In the entire sample, on average $22 \%$ of companies contribute to election campaigns and receive procurement contracts. The vast majority of the companies with these characteristics belong to the Manufacturing industry. $17 \%$ of the companies in our sample receive government contracts without making any contribution, in particular companies from the HiTech industry. $27 \%$ contribute but do not receive procurements, while $34 \%$ do not engage in contributing nor do they contract procurements. These last two categories belong to the industry denoted Other in the Fama-French classification, which includes activities such as mining, constructions, transportation, bus services, entertainment or finance.

\subsection{Empirical analysis and results}

In this section we show that corporate political contributions have an influence on the subsequent procurement values that S\&P500 companies receive and that these effects are persistent over time. Furthermore, we show that the effects vary across industries, suggesting 
that in some industries contributions are indeed a tool in the competition among firms for procurements, while in others, they serve a different purpose, which could be for instance a type of insurance against unfavorable legislation.

\subsubsection{Corporate political contributions and subsequent procurement contracts}

We start our analysis by investigating the general relationship between corporate political contributions and procurement contracts. Even though it is difficult to disentangle the timing of contributions and procurements (i.e., whether a contribution is followed by a procurement or the other way around), we argue that the only reason a firm would contribute after receiving procurements is to secure future benefits. Thus, our main interest is not whether a firm received procurements in the past or not, but whether or not continuing to contribute affects future procurements.

First, we determine how a contribution in the previous time period influences the likelihood of receiving a procurement contract in the current time period. To this end, we run a pooled Logit model. We are aware of potential endogeneity issues, which is why we instrument the contributions variable with lagged contributions (where one lag represents one year) and we try to limit the possibility of an omitted variable bias by controlling for industry differences and company characteristics.

All regressions include industry dummies, constructed with the Fama-French 10 industries classification, and year dummies. Furthermore, the control variables used are in line with previous literature, such as Di Giuli and Kostovetsky (2014), Goldman et al. (2013) or Tahoun (2014). In unreported results, we try three different proxies for the size of a company: the logarithm of total assets, the logarithm of total sales and the logarithm of market capitalization. The results remain the same regardless of the specification. We also include changes from period $t-1$ to period $t$ in total assets, total sales and total market capitalization instead of the values at a given time point, without it altering our results in any way. Given that the key results are not influenced by the choice of size proxy, we use only the logarithm of total assets in subsequent analyses. Finally, we construct a Herfindhal-Hirschman Index ranging from 0 to 1 based on the total sales of all firms in industry $j$ at time $t$, but the index coefficient is statistically insignificant in all regressions and we remove it from subsequent analyses.

The results are displayed in Table 4.2. In Column (1), we regress Dproc $i$, , a dummy variable which takes the value 1 if firm $i$ receives a procurement contract in time period $t$ and 0 
Table 4.2: Pooled Logit regressions with industry and year dummies.

\begin{tabular}{|c|c|c|c|c|}
\hline & \multicolumn{3}{|c|}{ DProc $_{\mathrm{i}, \mathrm{t}}$} & \multirow[b]{2}{*}{ (4) } \\
\hline & (1) & $(2)$ & (3) & \\
\hline DContrib $_{\mathrm{i}, \mathrm{t}-1}$ & $\begin{array}{c}0.676^{* * *} \\
(5.76)\end{array}$ & & & \\
\hline DRepublican $_{\mathrm{i}, \mathrm{t}-1}$ & & $\begin{array}{c}0.605^{* * *} \\
(4.73)\end{array}$ & $\begin{array}{l}-0.108 \\
(-0.87)\end{array}$ & \\
\hline DRepublicans\&Democrats $_{\mathrm{i}, \mathrm{t}-1}$ & & $\begin{array}{c}0.704^{* * *} \\
(5.79)\end{array}$ & & \\
\hline DDemocrat $_{\mathrm{i}, \mathrm{t}-1}$ & & & $\begin{array}{c}-0.730^{* * *} \\
(-5.94)\end{array}$ & \\
\hline $\log (1+\text { Contrib })_{\mathrm{i}, \mathrm{t}-1}$ & & & & $\begin{array}{c}0.066^{* * *} \\
(5.98)\end{array}$ \\
\hline LogAssets $_{i, t}$ & $\begin{array}{c}0.031 \\
(0.55)\end{array}$ & $\begin{array}{l}0.036 \\
(0.65)\end{array}$ & $\begin{array}{l}0.031 \\
(0.55)\end{array}$ & $\begin{array}{r}0.008 \\
(0.14)\end{array}$ \\
\hline $\operatorname{LogBM}_{i, t}$ & $\begin{array}{l}-0.190^{* *} \\
(-2.31)\end{array}$ & $\begin{array}{c}-0.193^{* *} \\
(-2.35)\end{array}$ & $\begin{array}{c}-0.191^{* *} \\
(-2.33)\end{array}$ & $\begin{array}{c}-0.188^{* *} \\
(-2.29)\end{array}$ \\
\hline Debt/Assets $s_{i, t}$ & $\begin{array}{l}0.209 \\
(0.52)\end{array}$ & $\begin{array}{l}0.203 \\
(0.51)\end{array}$ & $\begin{array}{l}0.211 \\
(0.53)\end{array}$ & $\begin{array}{l}0.233 \\
(0.58)\end{array}$ \\
\hline Dividends/Assets $_{\mathrm{i}, \mathrm{t}}$ & $\begin{array}{l}-3.389 \\
(-1.34)\end{array}$ & $\begin{array}{l}-3.420 \\
(-1.37)\end{array}$ & $\begin{array}{l}-3.508 \\
(-1.40)\end{array}$ & $\begin{array}{l}-3.764 \\
(-1.45)\end{array}$ \\
\hline Capex/Sales $_{\mathrm{i}, \mathrm{t}}$ & $\begin{array}{l}-2.023^{* * *} \\
(-2.70)\end{array}$ & $\begin{array}{c}-1.974^{* * *} \\
(-2.62)\end{array}$ & $\begin{array}{c}-1.989 * * * \\
(-2.63)\end{array}$ & $\begin{array}{l}-2.050^{* * *} \\
(-2.71)\end{array}$ \\
\hline Cogs/Sales ${ }_{i, t}$ & $\begin{array}{l}-0.039 \\
(-0.13)\end{array}$ & $\begin{array}{l}-0.018 \\
(-0.06)\end{array}$ & $\begin{array}{l}-0.021 \\
(-0.06)\end{array}$ & $\begin{array}{l}-0.055 \\
(-0.18)\end{array}$ \\
\hline Constant & $\begin{array}{l}-0.936 \\
(-0.68)\end{array}$ & $\begin{array}{l}-0.918 \\
(-0.68)\end{array}$ & $\begin{array}{l}-0.076 \\
(-0.05)\end{array}$ & $\begin{array}{l}-0.402 \\
(-0.29)\end{array}$ \\
\hline FF 10 industry dummies & Yes & Yes & Yes & Yes \\
\hline Year dummies & Yes & Yes & Yes & Yes \\
\hline Observations & 7,368 & 7,368 & 7,368 & 7,368 \\
\hline Pseudo-R ${ }^{2}$ & 0.114 & 0.112 & 0.113 & 0.115 \\
\hline $\begin{array}{l}\text { Odds of a procurement due to } \\
\text { a contribution }\end{array}$ & 1.966 & $\begin{array}{l}1.830 \\
2.022 \\
\end{array}$ & $\begin{array}{l}0.897 \\
0.482 \\
\end{array}$ & 1.068 \\
\hline
\end{tabular}

Note: DProci,t is a dummy variable which takes the value 1 if company i receives a procurement contract at time $t$ and 0 otherwise. DContrib $b_{i-1}$ is a dummy variable which takes the value 1 if company i makes a contribution at time $t-1$ and 0 otherwise. DRepublican $n_{i, t-1}$ is a dummy variable which takes the value 1 if firm $i$ makes at least $61 \%$ of contributions to the Republican Party and the rest to the Democratic Party and 0 otherwise. DRepublicans\&Democrats ${ }_{i, t-1}$ is a dummy variable which takes the value 1 if firm $i$ contributes between $40 \%$ and $60 \%$ to the Republicans and the rest to the Democrats and 0 otherwise. DDemocrat $t_{i, t-1}$ is a dummy variable which takes the value 1 if firm i contributes less than $40 \%$ to the Republicans and the rest to the Democrats and 0 otherwise. Log $(1+\text { Contrib })_{i, t-1}$ is the logarithm of 1 plus the total contribution value of firm $i$ at time t-1. The control variables are defined in Appendix Table 4.2. The z-statistics are in parentheses. We cluster the standard errors at the firm level ${ }^{11}{ }^{* * *} p<0.01,{ }^{* *} p<0.05,{ }^{*} p<0.1$.

\footnotetext{
${ }^{11}$ Following Petersen (2009), we correct the standard errors for clustering effects. We cluster the standard errors at firm level and include time dummies as an alternative to double-clustering, as suggested by Thompson (2011).
} 
otherwise, on Dcontrib $b_{i, t-1}$, a dummy variable which takes the value 1 if firm $i$ makes a political contribution in time period $t-1$ and 0 otherwise, and a set of control variables. The coefficient on the lagged dummy variable for having made a contribution is positive and statistically significant. We interpret odds ratios and conclude that making a contribution in the previous time period almost doubles a company's chances of receiving a procurement contract in the current time period.

In Columns (2) and (3), we decompose the contributions variable depending on the allocation of contributions between the Republican Party and the Democratic Party. DRepublican $_{i, t-1}$ is a dummy variable which takes the value 1 if firm $i$ makes at least $61 \%$ of contributions to the Republican Party and the rest to the Democratic Party and 0 otherwise. DRepublicans\&Democrats $_{i, t-1}$ is a dummy variable which takes the value 1 if firm $i$ contributes between $40 \%$ and $60 \%$ to the Republicans and the rest to the Democrats and 0 otherwise. This dummy variable captures in fact the firms contributing almost equally to both parties. DDemocrat $_{i,-1}$ is a dummy variable which takes the value 1 if firm $i$ contributes less than $40 \%$ to the Republicans and the rest to the Democrats and 0 otherwise.

Column (2) of Table 4.2 shows that, relative to making most contributions to the Democrats, contributing to the Republican Party or approximately equal to both parties doubles the chances a company has to receive a procurement contract in the future. Similarly, Column (3) shows that, relative to contributing equal to both parties, contributing to the Republicans is not statistically different, but making most contributions to the Democrats actually decreases a company's chances of receiving a government contract in the future. We know from Figure 4.2 that the vast majority of contributing S\&P500 companies actually contributes to both parties, but it seems that they would be equally well-off by just contributing to the Republican Party.

In Column (4) of Table 4.2, we investigate how the actual amount an S\&P500 company contributes to an election campaign in the previous time period influences the likelihood of that company receiving a procurement contract in the current time period. We regress PProc $_{i, t}$ on $\log (1+\text { Contrib })_{i, t-1}$, which is the logarithm of 1 plus the total contribution value per firm. The coefficient of $\log (1+\text { Contrib })_{i, t-1}$ is positive and statistically significant, but when we look at the odds ratio we realize that a higher amount does not considerably increase the chances of receiving a procurement in the future. If we compare this result to the result in Column (1) of Table 4.2, we can say that it is not how much but the mere fact that it contributes to election campaigns, which increases a company's chances of receiving a government contract in the future. Given that contributions are limited to a maximum of $\$ 5,000$ per candidate per election 
and companies cannot compete in contribution amounts, it is possible that contributions act only as a signal that companies send to the government to express their interest in the process of allocating procurements.

The statistically significant control variables in Table 4.2 are $\operatorname{LogBM}_{i, t}$ and Capex/Sales $i, t$, both with a negative sign, suggesting that mature, overvalued companies, with less potential for future benefits from capital expenditures are more likely to receive government contracts. These results are in line with previous literature, such as Di Giuli and Kostovetsky (2014), Goldman et al. (2013) or Tahoun (2014), and they are consistent throughout the remainder of the paper. Unlike previous literature, the size variable LogAssets $_{i, t}$ is insignificant in our analysis, but this is likely due to the fact that all the companies in our sample are S\&P500 companies, hence large companies.

Second, we quantify the relationship between making a corporate political contribution and the subsequent dollar amount received in the form of a procurement contract. We do this using a Tobit model, because the dependent variable is censored at zero (a company receives either a positive value in the form of a procurement contract or zero). We regress the logarithm of 1 plus the total value of the procurement contract on three different measures of political contributions and a set of control variables.

The results are presented in Table 4.3. In Columns (1) through (3), we use as contribution variables the logarithm of 1 plus the total contribution value per firm, the logarithm of 1 plus the number of candidates and the logarithm of 1 plus the total company contribution value per candidate, respectively. The coefficients of all these variables are positive and statistically significant. To interpret the magnitude of the effects, we compute marginal effects at the mean, which show that a $1 \%$ increase in the total contribution value a firm makes leads to a $0.239 \%$ increase in the total procurement value the firm subsequently receives. This means that, for a hypothetical firm with contributions and procurements equal to the sample average, an extra $\$ 495.93(1 \% * 49,593)$ in average contribution brings an extra $\$ 203,628(0.239 \% * 85,200,000)$ in average procurement value. Similarly, a $1 \%$ increase in the supported number of candidates or in the contribution value per candidate leads to a $0.721 \%$ and a $0.331 \%$ increase in the subsequent procurement value, respectively. Contributing to 1 extra candidate, which is roughly a $4 \%$ increase in the average number of candidates a company supports ( $4 \% * 26.86)$, brings an extra $\sim \$ 2.5$ million in average procurement value $(0.721 \% * 4 * 85,200,000)$. These procurement values seem very large, but one must take into account the fact that they represent revenues, not profits. 
Table 4.3: Pooled Tobit regressions with industry and year dummies.

\begin{tabular}{|c|c|c|c|}
\hline & \multicolumn{3}{|c|}{$\log (1+\text { Proc })_{i, t}$} \\
\hline & $(1)$ & $(2)$ & (3) \\
\hline $\log (1+\text { Contrib })_{\mathrm{i}, \mathrm{t}-1}$ & $\begin{array}{l}0.522^{* * *} \\
(6.37)\end{array}$ & & \\
\hline $\log (1+\text { Candidates })_{\mathrm{i}, \mathrm{t}-1}$ & & $\begin{array}{l}1.576^{* * *} \\
(6.69)\end{array}$ & \\
\hline $\log (1+\text { Contrib/Candidates })_{\mathrm{i}, \mathrm{t}-1}$ & & & $\begin{array}{l}0.724^{* * *} \\
(6.03)\end{array}$ \\
\hline LogAssets $_{\mathrm{i}, \mathrm{t}}$ & $\begin{array}{l}0.264 \\
(0.62)\end{array}$ & $\begin{array}{l}0.033 \\
(0.08)\end{array}$ & $\begin{array}{l}0.439 \\
(1.03)\end{array}$ \\
\hline $\operatorname{LogBM}_{i, t}$ & $\begin{array}{c}-1.481^{* * *} \\
(-2.78)\end{array}$ & $\begin{array}{c}-1.431^{* * *} \\
(-2.69)\end{array}$ & $\begin{array}{c}-1.516^{* * *} \\
(-2.83)\end{array}$ \\
\hline Debt/Assets $_{i, t}$ & $\begin{array}{l}2.983 \\
(0.98)\end{array}$ & $\begin{array}{l}3.314 \\
(1.09)\end{array}$ & $\begin{array}{l}2.781 \\
(0.90)\end{array}$ \\
\hline 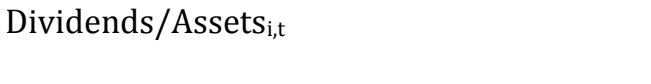 & $\begin{array}{l}-27.857 \\
(-1.51)\end{array}$ & $\begin{array}{c}-31.660^{*} \\
(-1.70)\end{array}$ & $\begin{array}{l}-25.383 \\
(-1.39)\end{array}$ \\
\hline Capex/Sales $i, t$ & $\begin{array}{c}-16.680^{* * *} \\
(-2.97)\end{array}$ & $\begin{array}{c}-16.727^{* * *} \\
(-2.95)\end{array}$ & $\begin{array}{c}-16.547^{* * *} \\
(-2.95)\end{array}$ \\
\hline Cogs/Sales $_{\mathrm{i}, \mathrm{t}}$ & $\begin{array}{l}1.581 \\
(0.81)\end{array}$ & $\begin{array}{l}1.565 \\
(0.81)\end{array}$ & $\begin{array}{l}1.647 \\
(0.84)\end{array}$ \\
\hline Constant & $\begin{array}{l}-7.094 \\
(-0.69)\end{array}$ & $\begin{array}{l}-1.315 \\
(-0.13)\end{array}$ & $\begin{array}{c}-11.209 \\
(-1.09)\end{array}$ \\
\hline FF 10 industry dummies & Yes & Yes & Yes \\
\hline Year dummies & Yes & Yes & Yes \\
\hline Observations & 7,368 & 7,368 & 7,368 \\
\hline Pseudo- $\mathrm{R}^{2}$ & 0.042 & 0.043 & 0.042 \\
\hline $\begin{array}{l}\text { Marginal effect at the mean of contribution } \\
\text { variables on procurement value }\end{array}$ & 0.239 & 0.721 & 0.331 \\
\hline
\end{tabular}

Note: $\log (1+\text { Proc })_{i, t}$ is the logarithm of 1 plus the total procurement value of firm $i$ at time $t$. $\log (1+\text { Contrib })_{i, t-1}$ is the logarithm of 1 plus the total contribution value of firm $i$ at time $t-1$. $\log (1+\text { Candidates })_{i, t-1}$ is the logarithm of 1 plus the total number of candidates company $i$ supports at time $t$ 1. $\log (1+\text { Contrib/Candidates })_{i, t-1}$ is the logarithm of 1 plus the total contribution value per candidate of company $i$ at time $t$-1. The control variables are defined in Appendix Table 4.2. The t-statistics are in parentheses. We cluster the standard errors at firm level. ${ }^{* * *} p<0.01,{ }^{* *} p<0.05,{ }^{*} p<0.1$ 
Third, we look at the evolution of the relationship between making a contribution and receiving procurement contracts throughout the election cycles. We re-run the specification in Column (1) of Table 4.3 per election cycle and present the results in Table 4.4. The effect of contributions on the subsequent procurement value is positive and statistically significant in all election cycles. There appears to be a persistent reciprocal relationship between contributing S\&P500 companies and the government in its capacity to allocate procurement contracts.

The marginal effect at the mean progressively decreases in value until election cycle 1999-2000 and afterwards it becomes increasingly more economically significant, a pattern which coincides with the evolution of the average procurement value in Figure 4.1 and the total procurement value in Figure 4.2. The year 2000 seems to represent a structural break in the data, but it is unclear why. In unreported results, we test for this by splitting the sample in two time periods: 1993-2000 and 2001-2010. However, the effect contributions have on the subsequent procurement value is the same in both time periods.

So far, the results suggest that the most profitable strategy for companies (i.e., the strategy that maximizes the future procurement value) is to contribute to a large number of candidates taking part in Congressional races and preferably to candidates of the Republican Party. It must be noted though that our sample is characterized by a large percentage of repeat contributors. One reason could be that they are driven by ideological beliefs. However, the vast majority of the contributing firms contribute to both the Democratic and the Republican Party, ruling out the political convictions hypothesis. In fact, the act of contributing to both parties could be assimilated to an imperfect hedge against political decisions. We argue that the S\&P500 companies contribute repeatedly with the intention to secure future benefits, either in the shape of government contracts or as favorable legislation. We also argue that the decision to contribute with the intention to receive government contracts and the decision to contribute with the intention to ensure against unfavorable legislation are two distinct choices, which depend on the type of industry the firm belongs to. The next subsection will go more into detail with this issue and will show that this is likely to be the case. 
Table 4.4: Pooled Tobit regressions with industry dummies by election cycle.

\begin{tabular}{|c|c|c|c|c|c|c|c|c|c|}
\hline \multicolumn{10}{|c|}{$\log (1+\text { Proc })_{\mathrm{i}, \mathrm{t}}$} \\
\hline & 1993-1994 & 1995-1996 & 1997-1998 & 1999-2000 & $2001-2002$ & $2003-2004$ & $2005-2006$ & $2007-2008$ & $2009-2010$ \\
\hline $\log (1+\text { Contrib })_{\mathrm{i}, \mathrm{t}-1}$ & $\begin{array}{c}0.806^{* * *} \\
(4.40)\end{array}$ & $\begin{array}{c}0.707^{* * *} \\
(4.67)\end{array}$ & $\begin{array}{c}0.600^{* * *} \\
(3.98)\end{array}$ & $\begin{array}{c}0.343^{* *} \\
(2.47)\end{array}$ & $\begin{array}{c}0.431^{* * *} \\
(3.07)\end{array}$ & $\begin{array}{c}0.388^{* * *} \\
(3.10)\end{array}$ & $\begin{array}{c}0.526^{* * *} \\
(4.17)\end{array}$ & $\begin{array}{c}0.653^{* * *} \\
(5.17)\end{array}$ & $\begin{array}{c}0.498^{* * *} \\
(3.89)\end{array}$ \\
\hline LogAssets $_{i, t}$ & $\begin{array}{l}0.493 \\
(0.67)\end{array}$ & $\begin{array}{l}0.051 \\
(0.08)\end{array}$ & $\begin{array}{l}-0.283 \\
(-0.42)\end{array}$ & $\begin{array}{l}-0.140 \\
(-0.21)\end{array}$ & $\begin{array}{l}0.142 \\
(0.22)\end{array}$ & $\begin{array}{l}0.368 \\
(0.59)\end{array}$ & $\begin{array}{l}-0.338 \\
(-0.53)\end{array}$ & $\begin{array}{l}0.347 \\
(0.61)\end{array}$ & $\begin{array}{l}0.762 \\
(1.20)\end{array}$ \\
\hline $\operatorname{LogBM}_{i, t}$ & $\begin{array}{c}-4.276^{* *} \\
(-2.27)\end{array}$ & $\begin{array}{c}-5.075^{* * *} \\
(-3.32)\end{array}$ & $\begin{array}{l}-1.014 \\
(-0.85)\end{array}$ & $\begin{array}{c}-2.817^{* * *} \\
(-2.79)\end{array}$ & $\begin{array}{c}-1.843^{*} \\
(-1.77)\end{array}$ & $\begin{array}{l}-1.656 \\
(-1.44)\end{array}$ & $\begin{array}{l}-0.098 \\
(-0.08)\end{array}$ & $\begin{array}{l}-0.539 \\
(-1.06)\end{array}$ & $\begin{array}{c}-2.510^{* *} \\
(-2.03)\end{array}$ \\
\hline Debt/Assets $\mathrm{i}_{\mathrm{i}, \mathrm{t}}$ & $\begin{array}{l}8.283 \\
(1.33)\end{array}$ & $\begin{array}{l}2.507 \\
(0.45)\end{array}$ & $\begin{array}{l}4.573 \\
(0.82)\end{array}$ & $\begin{array}{l}7.664 \\
(1.50)\end{array}$ & $\begin{array}{l}7.362 \\
(1.49)\end{array}$ & $\begin{array}{l}2.394 \\
(0.51)\end{array}$ & $\begin{array}{l}-3.949 \\
(-0.88)\end{array}$ & $\begin{array}{l}4.952 \\
(1.33)\end{array}$ & $\begin{array}{l}5.347 \\
(1.10)\end{array}$ \\
\hline Dividends/Assets $_{\mathrm{i}, \mathrm{t}}$ & $\begin{array}{c}-57.860 \\
(-1.46)\end{array}$ & $\begin{array}{c}-49.712 \\
(-1.35)\end{array}$ & $\begin{array}{c}-42.638 \\
(-1.18)\end{array}$ & $\begin{array}{c}-79.909^{* *} \\
(-2.02)\end{array}$ & $\begin{array}{c}-69.216 \\
(-1.38)\end{array}$ & $\begin{array}{c}18.748 \\
(0.43)\end{array}$ & $\begin{array}{c}-10.212 \\
(-0.29)\end{array}$ & $\begin{array}{l}-7.339 \\
(-0.49)\end{array}$ & $\begin{array}{c}-52.381 \\
(-1.63)\end{array}$ \\
\hline Capex/Sales ${ }_{i, t}$ & $\begin{array}{c}-31.282^{* *} \\
(-2.29)\end{array}$ & $\begin{array}{c}-23.046^{*} \\
(-1.80)\end{array}$ & $\begin{array}{c}-27.173^{* * *} \\
(-2.63)\end{array}$ & $\begin{array}{l}-4.161 \\
(-0.49)\end{array}$ & $\begin{array}{c}-19.704^{* *} \\
(-2.07)\end{array}$ & $\begin{array}{l}-9.408 \\
(-0.73)\end{array}$ & $\begin{array}{c}-18.809^{*} \\
(-1.66)\end{array}$ & $\begin{array}{c}-18.388^{* *} \\
(-2.31)\end{array}$ & $\begin{array}{c}-11.003 \\
(-1.09)\end{array}$ \\
\hline Cogs/Sales ${ }_{\mathrm{i}, \mathrm{t}}$ & $\begin{array}{l}-1.518 \\
(-0.24)\end{array}$ & $\begin{array}{l}2.557 \\
(0.44)\end{array}$ & $\begin{array}{l}2.153 \\
(0.43)\end{array}$ & $\begin{array}{l}8.483^{*} \\
(1.70)\end{array}$ & $\begin{array}{l}7.526^{*} \\
(1.81)\end{array}$ & $\begin{array}{l}6.971^{*} \\
(1.71)\end{array}$ & $\begin{array}{l}4.060 \\
(1.10)\end{array}$ & $\begin{array}{l}-2.112 \\
(-0.77)\end{array}$ & $\begin{array}{l}-4.445 \\
(-1.21)\end{array}$ \\
\hline Constant & $\begin{array}{c}-12.218 \\
(-0.69)\end{array}$ & $\begin{array}{l}-7.571 \\
(-0.48)\end{array}$ & $\begin{array}{l}6.638 \\
(0.41)\end{array}$ & $\begin{array}{l}-2.688 \\
(-0.17)\end{array}$ & $\begin{array}{c}-13.934 \\
(-0.90)\end{array}$ & $\begin{array}{c}-16.394 \\
(-1.12)\end{array}$ & $\begin{array}{l}4.886 \\
(0.31)\end{array}$ & $\begin{array}{c}-13.150 \\
(-0.94)\end{array}$ & $\begin{array}{c}-23.653 \\
(-1.45)\end{array}$ \\
\hline FF 10 industry dummies & Yes & Yes & Yes & Yes & Yes & Yes & Yes & Yes & Yes \\
\hline Observations & 427 & 853 & 826 & 809 & 838 & 869 & 917 & 900 & 929 \\
\hline Pseudo- $\mathrm{R}^{2}$ & 0.080 & 0.068 & 0.053 & 0.038 & 0.038 & 0.038 & 0.045 & 0.050 & 0.036 \\
\hline $\begin{array}{l}\text { Marginal effect at the } \\
\text { mean of contributions } \\
\text { on procurement value }\end{array}$ & 0.310 & 0.283 & 0.229 & 0.148 & 0.191 & 0.194 & 0.263 & 0.329 & 0.241 \\
\hline
\end{tabular}

Note: $\log (1+\text { Proc })_{i, t}$ is the logarithm of 1 plus the total procurement value of firm $i$ at time $t$. Log(1+Contrib $)_{i, t-1}$ is the logarithm of 1 plus the total contribution value of firm $i$ at time $t$-1. The control variables are defined in Appendix Table 4.2. The $t$-statistics are in parentheses. We cluster the standard errors at firm level. *** $p<0.01$,

** $p<0.05, * p<0.1$ 


\subsubsection{Industry-specific effects}

We learned from the results in the previous subsection that the level of corporate political contributions influences the size of procurement contracts and that the effects are persistent over time. We now argue that the importance of contributions in obtaining procurement contracts is different from one industry to another.

Before formally testing our hypothesis, we analyze some descriptive statistics at the industry level. Table 4.5 shows the percentage of S\&P500 companies that on average participate in the contributions process (i.e., Contributors) and whether or not these companies receive procurement contracts (i.e., Recipients). We use the Fama-French 10 industry classification as described in Appendix Table 4.1. The reference point of the table is the column Recipients Contributors, where the values are ranked from highest to lowest.

In line with our previous results, Table 4.5 shows that in all industries, except for HiTech and Shops, contributors receive on average more procurements than non-contributors, suggesting that contributions could play a role in the allocation of government contracts. However, when comparing the Recipients Contributors and the Non-recipients Contributors columns of Table 4.5 , we observe some heterogeneity at the contributions/procurements level. In industries such as Utilities, Shops, Energy and Other, the percentage of contributors which do not receive procurements is higher than the percentage of contributors which receive procurements, suggesting that in these industries the purpose of contributions is not necessarily the maximization of the future procurement value. This leads us to believe that the firms in these industries could be receiving another type of benefit out of their political contributions instead of procurement contracts.

We now test our hypothesis that the effects of corporate political contributions vary from one industry to another by running the pooled Tobit model of Table 4.3 for each industry in the Fama-French 10 industry classification. The results are displayed in Table 4.6. The industries are ordered from highest to lowest based on the magnitude of the marginal effect at the mean of contributions on procurement values. 
Table 4.5: The percentages of S\&P500 companies contributing to election campaigns (i.e., Contributors) and receiving procurement contracts (i.e., Recipients) in each of the Fama-French 10 industries

\begin{tabular}{lcccc}
\hline & \multicolumn{2}{c}{ Recipients } & \multicolumn{2}{c}{ Non-recipients } \\
\cline { 2 - 5 } Fama French 10 industries & Contributors & Non-contributors & Contributors & Non-contributors \\
\hline Healthcare & $38 \%$ & $20 \%$ & $22 \%$ & $20 \%$ \\
Durables & $35 \%$ & $13 \%$ & $24 \%$ & $27 \%$ \\
Manufacturing & $34 \%$ & $21 \%$ & $18 \%$ & $27 \%$ \\
Telecommunications & $29 \%$ & $20 \%$ & $19 \%$ & $31 \%$ \\
HiTech & $25 \%$ & $39 \%$ & $8 \%$ & $28 \%$ \\
Nondurables & $23 \%$ & $15 \%$ & $18 \%$ & $44 \%$ \\
Utilities & $20 \%$ & $5 \%$ & $40 \%$ & $35 \%$ \\
Shops & $14 \%$ & $16 \%$ & $29 \%$ & $41 \%$ \\
Energy & $14 \%$ & $12 \%$ & $39 \%$ & $36 \%$ \\
Other & $12 \%$ & $9 \%$ & $38 \%$ & $40 \%$ \\
\hline
\end{tabular}

As expected, the magnitudes of the effects differ across industries. The largest marginal effect at the mean is in the Durables industry. There, contributions seem to be most effective in increasing the procurement value in the next period. In some industries we find no effect at all. In the industries classified as Healthcare, Shops and Energy the effect of corporate political contributions on the subsequent value of government procurements is statistically insignificant, suggesting that, if contributions are made, their purpose is not to increase the procurement value in the next period. We think that the more likely explanation is that contributions are meant to ensure that politicians will not adopt any unfavorable changes in legislation.

This is also in line with the findings of Table 4.5, which shows that in some industries there are more contributors who do not receive procurements than there are contributors successful at being awarded procurements. The best example is the Energy sector, which is highly regulated in the US. In the entire sample, $53 \%$ of all the companies in this industry contribute to election campaigns, but only $14 \%$ receive government contracts, the remaining $39 \%$ perhaps making sure that they have a politician's ear when it comes to regulation in the field. It is surprising though that in the Healthcare industry the result is statistically insignificant, considering the numbers in Table 4.5. However, it could be argued that, if as many as $60 \%$ of the companies in the industry contribute to election campaigns and 38\% of those receive procurements even though past contributions do not have any influence on procurements, then the contributions must be meant for a different purpose. As stated earlier, we argue that this purpose is most likely favorable legislation and not ideological beliefs otherwise the vast majority of S\&P500 companies would not be consistently contributing to both the Republicans and the Democrats. 
Table 4.6: Pooled Tobit regressions with year dummies per industry.

\begin{tabular}{|c|c|c|c|c|c|c|c|c|c|c|}
\hline & \multicolumn{10}{|c|}{$\log (1+\text { Proc })_{i, t}$} \\
\hline & Durables & HiTech & Telecom & Manufacturing & Nondurables & Utilities & Other & Healthcare & Shops & Energy \\
\hline $\log (1+\text { Contrib })_{\mathrm{i}, \mathrm{t}-1}$ & $\begin{array}{c}0.901^{* *} \\
(2.28)\end{array}$ & $\begin{array}{c}0.548^{* * *} \\
(2.88)\end{array}$ & $\begin{array}{c}0.586^{* * *} \\
(3.23)\end{array}$ & $\begin{array}{c}0.536^{* * *} \\
(2.90)\end{array}$ & $\begin{array}{c}0.814^{* * *} \\
(3.06)\end{array}$ & $\begin{array}{c}1.067^{* * *} \\
(3.38)\end{array}$ & $\begin{array}{c}0.508^{* *} \\
(2.42)\end{array}$ & $\begin{array}{l}0.131 \\
(0.58)\end{array}$ & $\begin{array}{l}-0.091 \\
(-0.39)\end{array}$ & $\begin{array}{l}-0.321 \\
(-0.71)\end{array}$ \\
\hline LogAssets $_{\mathrm{i}, \mathrm{t}}$ & $\begin{array}{c}4.277^{* *} \\
(2.45)\end{array}$ & $\begin{array}{l}0.155 \\
(0.17)\end{array}$ & $\begin{array}{l}1.748 \\
(1.31)\end{array}$ & $\begin{array}{c}2.450^{* *} \\
(2.42)\end{array}$ & $\begin{array}{l}-0.106 \\
(-0.08)\end{array}$ & $\begin{array}{l}0.396 \\
(0.14)\end{array}$ & $\begin{array}{c}-2.131^{* *} \\
(-2.09)\end{array}$ & $\begin{array}{l}0.619 \\
(0.53)\end{array}$ & $\begin{array}{l}2.510 \\
(1.64)\end{array}$ & $\begin{array}{c}6.451^{* *} \\
(2.23)\end{array}$ \\
\hline $\operatorname{LogBM}_{\mathrm{i}, \mathrm{t}}$ & $\begin{array}{l}-1.510 \\
(-0.52)\end{array}$ & $\begin{array}{l}0.175 \\
(0.24)\end{array}$ & $\begin{array}{l}-0.257 \\
(-0.32)\end{array}$ & $\begin{array}{c}-2.259^{*} \\
(-1.75)\end{array}$ & $\begin{array}{c}-8.533^{* * *} \\
(-4.67)\end{array}$ & $\begin{array}{l}1.177 \\
(1.17)\end{array}$ & $\begin{array}{l}-3.136^{*} \\
(-1.92)\end{array}$ & $\begin{array}{l}0.379 \\
(0.19)\end{array}$ & $\begin{array}{l}-0.987 \\
(-0.55)\end{array}$ & $\begin{array}{l}-2.193 \\
(-0.51)\end{array}$ \\
\hline Debt/Assets ${ }_{i, t}$ & $\begin{array}{c}-17.814 \\
(-1.31)\end{array}$ & $\begin{array}{l}4.983 \\
(0.87)\end{array}$ & $\begin{array}{c}16.078^{*} \\
(1.77)\end{array}$ & $\begin{array}{l}-8.900 \\
(-1.16)\end{array}$ & $\begin{array}{l}9.420 \\
(0.95)\end{array}$ & $\begin{array}{c}-29.717 \\
(-1.26)\end{array}$ & $\begin{array}{l}9.525 \\
(1.48)\end{array}$ & $\begin{array}{l}2.109 \\
(0.21)\end{array}$ & $\begin{array}{l}-0.520 \\
(-0.06)\end{array}$ & $\begin{array}{c}-36.985^{* *} \\
(-2.18)\end{array}$ \\
\hline Dividends/Assets $_{\mathrm{i}, \mathrm{t}}$ & $\begin{array}{l}11.171 \\
(0.06)\end{array}$ & $\begin{array}{c}-60.699 \\
(-1.18)\end{array}$ & $\begin{array}{l}95.581 \\
(1.51)\end{array}$ & $\begin{array}{c}-174.206^{* *} \\
(-2.36)\end{array}$ & $\begin{array}{c}-137.166^{* * *} \\
(-3.79)\end{array}$ & $\begin{array}{l}4.173 \\
(0.02)\end{array}$ & $\begin{array}{c}-24.309 \\
(-0.54)\end{array}$ & $\begin{array}{l}4.799 \\
(0.15)\end{array}$ & $\begin{array}{c}63.554 \\
(0.93)\end{array}$ & $\begin{array}{c}-405.981 \\
(-1.30)\end{array}$ \\
\hline Capex/Sales ${ }_{\mathrm{i}, \mathrm{t}}$ & $\begin{array}{c}-163.794^{* * *} \\
(-3.12)\end{array}$ & $\begin{array}{c}-37.299 * * * \\
(-2.73)\end{array}$ & $\begin{array}{c}-12.356 \\
(-0.61)\end{array}$ & $\begin{array}{c}-42.886 \\
(-1.47)\end{array}$ & $\begin{array}{c}63.922 \\
(0.76)\end{array}$ & $\begin{array}{c}28.227^{*} \\
(1.67)\end{array}$ & $\begin{array}{l}13.614 \\
(0.95)\end{array}$ & $\begin{array}{c}13.900 \\
(0.46)\end{array}$ & $\begin{array}{c}-160.256^{* * *} \\
(-3.07)\end{array}$ & $\begin{array}{c}-47.892^{* * *} \\
(-3.62)\end{array}$ \\
\hline Cogs/Sales ${ }_{i, t}$ & $\begin{array}{l}-9.543 \\
(-0.38)\end{array}$ & $\begin{array}{l}-6.535^{*} \\
(-1.77)\end{array}$ & $\begin{array}{c}-26.472^{* *} \\
(-2.17)\end{array}$ & $\begin{array}{l}-1.583 \\
(-0.18)\end{array}$ & $\begin{array}{c}46.046^{* * *} \\
(5.45)\end{array}$ & $\begin{array}{l}20.317 \\
(1.11)\end{array}$ & $\begin{array}{l}-3.473 \\
(-0.63)\end{array}$ & $\begin{array}{c}-12.581 \\
(-1.57)\end{array}$ & $\begin{array}{l}16.689 \\
(1.24)\end{array}$ & $\begin{array}{c}10.040 \\
(0.67)\end{array}$ \\
\hline Constant & $\begin{array}{c}-93.075^{* *} \\
(-2.34)\end{array}$ & $\begin{array}{l}5.836 \\
(0.28)\end{array}$ & $\begin{array}{c}-37.054 \\
(-1.16)\end{array}$ & $\begin{array}{c}-49.586^{* *} \\
(-2.07)\end{array}$ & $\begin{array}{c}-33.226 \\
(-1.17)\end{array}$ & $\begin{array}{c}-39.869 \\
(-0.52)\end{array}$ & $\begin{array}{c}37.710 \\
(1.50)\end{array}$ & $\begin{array}{l}-4.650 \\
(-0.16)\end{array}$ & $\begin{array}{c}-68.123^{*} \\
(-1.96)\end{array}$ & $\begin{array}{c}-155.637^{* *} \\
(-2.47)\end{array}$ \\
\hline Year dummies & Yes & Yes & Yes & Yes & Yes & Yes & Yes & Yes & Yes & Yes \\
\hline Observations & 201 & 1,139 & 246 & 1,327 & 587 & 573 & 1,573 & 494 & 845 & 383 \\
\hline Pseudo-R ${ }^{2}$ & 0.073 & 0.017 & 0.066 & 0.029 & 0.099 & 0.032 & 0.024 & 0.016 & 0.064 & 0.103 \\
\hline $\begin{array}{l}\text { Marginal effect of } \\
\text { contributions on } \\
\text { procurement value }\end{array}$ & 0.531 & 0.416 & 0.353 & 0.339 & 0.325 & 0.269 & 0.112 & 0.089 & -0.028 & -0.057 \\
\hline
\end{tabular}

Note: $\log (1+\text { Proc })_{i, t}$ is the logarithm of 1 plus the total procurement value of firm $i$ at time $t$. Log(1+Contrib $)_{i, t-1}$ is the logarithm of 1 plus the total contribution value of firm i at time $t-1$. The control variables are defined in Appendix Table 4.2. The $t$-statistics are in parentheses. The standard errors clustered at firm level. *** $p<0.01$,

** $p<0.05, * p<0.1$. 


\subsection{Conclusion}

This paper establishes a clear connection between corporate political contributions and the allocation of government procurement contracts. We gather information on all S\&P500 companies, the contributions they make to Congressional election campaigns and the government procurements they receive in the time period 1993 - 2010, covering full Congressional election cycles.

We find that making a contribution can increase a firm's chances of subsequently receiving a procurement contract, with a larger contribution leading to a larger procurement value. To maximize the future procurement value, companies should contribute to a large number of candidates taking part in Congressional races, preferably from the Republican Party. Furthermore, we find that the effects of contributions are persistent over time and that they vary depending on the industry a firm belongs to.

A most interesting finding is that contributions influence procurements differently in different industries. For the industries where we find a positive and statistically significant effect, we argue that firms can indeed use contributions as a tool in the competition with other firms for government contracts. For the industries where we find no effect on the subsequent procurement value, we propose the alternative explanation that perhaps the contributions act as insurance against unfavorable legislation. 


\subsection{Appendix}

Appendix Table 4.1: The composition of the Fama-French 10 industries

\begin{tabular}{ll}
\hline Industry & Composition \\
\hline Durables & Cars, TV's, furniture, household appliances \\
Energy & Oil, gas and coal extraction and products \\
Health & Healthcare, medical equipment and drugs \\
HiTech & Computers, software and electronic equipment \\
Manufacturing & Machinery, trucks, planes, chemicals, furnaces, paper, printing \\
Nondurables & Food, tobacco, textiles, apparel, leather, toys \\
Other & Mines, constructions, building materials, transportation, hotels, bus services, entertainment, finance \\
Shops & Wholesale, retail and some services (laundries, repair shops) \\
Telecom & Telephone and television transmission \\
Utilities & Electric, gas and water services \\
\hline
\end{tabular}

Appendix Table 4.2: The description of the control variables used in Tables 4.2 - 4.4 and 4.6.

\begin{tabular}{ll}
\hline Variable & Description \\
\hline LogAssets $_{\mathrm{i}, \mathrm{t}}$ & The logarithm of the total assets of company $i$ at time $t$. Source: Compustat. \\
LogBM $_{\mathrm{i}, \mathrm{t}}$ & The logarithm of the book-to-market ratio of company $i$ at time $t$. Source: Compustat. \\
Debt/Assets & The total debt value of company $i$ scaled by the company's total assets at time $t$. Source: \\
& Compustat. \\
Dividends/Assets & The total dividends paid by company $i$ scaled by the company's total assets at time $t$. \\
& Source: Compustat. \\
Capex/Sales & The capital expenditures of company $i$ scaled by the company's total sales at time $t$. \\
& Source: Compustat. \\
Cogs/Sales & The cost of goods sold of company $i$ scaled by the company's total sales at time $t$. \\
& Source: Compustat.
\end{tabular}




\section{Chapter 5}

\section{Concluding remarks}

This dissertation is a collection of studies in the framework of incomplete markets. Most markets can be characterized as incomplete, at least at certain points in time, and this dissertation presents three different situations in which the market becomes incomplete due to the presence of nontraded or infrequently traded assets.

Chapter 2 discusses the modifications to the Black-Scholes (1973) option pricing model needed in order to obtain closed-form solutions for European and American call options in incomplete markets, where the market is incomplete due to the presence of a non-traded or infrequently traded asset as the underlying asset of the option. The results show that there exists a negative relationship between the value of a European call option and the volatility of its underlying asset. Furthermore, this negative relationship adds an early exercise feature to an American call option even if the underlying asset is a non-dividend paying asset. This is due to the presence of unhedgeable sources of risk, additional to the hedgeable risk that we find on a complete market, eroding the option value.

Chapter 3 explores the problem of pricing very long-dated cash flows, when the market is incomplete due to the presence of non-traded government bonds beyond maturities of 25 or 30 years. In particular, chapter 3 documents a mispricing in the UK government bond market, the infinite maturity bond market, and shows that UK infinite maturity bonds are a cheap investment. These bonds are generally underpriced. The mispricing persists throughout the time period 20002013 and it is mainly driven by volatility in the financial markets. Furthermore, the UK infinite maturity bonds can be a source of additional information regarding the term structure of interest rates as they imply a slightly upward term structure of interest rates beyond traded maturities.

Chapter 4 analyzes the market for political risk. In this case, the fact that the market is incomplete determines a certain behavior in S\&P500 companies. They make political contributions to the Democratic Party or to the Republican Party or to both in order to increase their chances of receiving benefits from the government either in the form of procurement contracts or potentially as favorable legislation. 
Historical data shows that both campaign contributions and procurement values related to S\&P500 companies have an increasing trend in the time frame 1993-2010, suggesting that an investigation of the matter is not unwarranted. Furthermore, the documented effects of contributions vary depending on the industry the company belongs to. In some industries, for instance Telecommunications or HiTech, it appears that companies can use contributions as a tool in the competition for government contracts, while in others, for instance in Healthcare or Energy, contributions have no statistically significant effect, suggesting that the contributions' purpose might be different in this case. An alternative explanation for the companies in the latter category might be that the political contributions are in fact directed at insuring against unfavorable legislation.

All in all, the chapters in this dissertation analyze problems that are specific to incomplete markets and put forward potential solutions to these problems. They show that, in this situation, the prices of assets are no longer unique and that the best one can do is narrow down the possible solutions to a price interval. However, in order to derive closed-form solutions, one must accept the fact that these solutions are dependent on an exogenous restriction for which there are no clear guidelines on how to set it. Furthermore, the absence of certain traded assets, like government bonds, makes the discounting of long-dated cash flows very difficult and one must try to imply the necessary information from other traded long-dated financial instruments. However, if such instruments exist, they are usually characterized by a high degree of illiquidity. And, since incomplete markets are practically ubiquitous, one can also treat the market for political risk as an incomplete market. Here, the economic agents engage in a type of partial hedge in the hope of insuring against political risk by contributing to the election campaigns of candidates belonging to both the Democratic and the Republican parties, but unfortunately the result is the subsequent allocation of government money to the highest bidder and not necessarily the allocation of government money in the interests of the voters. 


\section{References}

Anderson, E., Hansen, L.P., Sargent, T.J., 2003. A quartet of semigroups for model specification, robustness, prices of risk and model detection. Journal of the European Economic Association 1(1), 68-123.

Ansolabehere, S., Figueiredo J. M., Snyder, J. M., 2003. Why is there so little money in US politics?. Journal of Economic Perspectives. 17(1), 105-130.

Artzner, P., Delbaen, F., Eber, J.M., Heath, D., 1999. Coherent measures of risk. Mathematical Finance 9(3), 203-228.

Black, F., Scholes, M., 1973. The pricing of options and corporate liabilities. Journal of Political Economy 81(3), 637-654.

Björk, T., 2009. Arbitrage theory in continuous time. Oxford University Press.

Björk, T., Slinko, I., 2006. Towards a general theory of good-deal bounds. Review of Finance 10(2), 221-260.

Bombardini, M., Trebbi, F., 2011. Votes or money? Theory and evidence from the US Congress. Journal of Public Economics 95(7-8), 587-611.

Carr, P., German, H., Madan, D. B., 2001. Pricing and hedging in incomplete markets. Journal of Financial Economics 62(1), 131-167.

Černý, A., 2003. Generalized Sharpe ratios and asset pricing in incomplete markets. European Finance Review 7(2), 191-233.

Cherny, A., Madan, D. B., 2010. Markets as a counterparty: an introduction to conic finance. International Journal of Theoretical and Applied Finance 13(8), 1149-1177.

Claessens, S., Feijen, E., Laeven, L., 2008. Political connections and preferential access to finance: the role of campaign contributions. Journal of Financial Economics 88(3), 554-580.

Cochrane, J.H., Saa-Requejo, J., 2000. Beyond arbitrage: good-deal asset price bounds in incomplete markets. Journal of Political Economy 108(1), 79-119.

Cochrane, J.H., 2005. Asset pricing (revised edition). Princeton University Press.

Cooper, M. J., Gulen, H., Ovtchinnikov, A. V., 2010. Corporate political contributions and stock returns, Journal of Finance 65(2), 687-724.

Davis, M.H.A., 2006. Optimal hedging with basis risk. In Kabanov, Y., Liptser, R., Stoyanov, J., From stochastic calculus to mathematical finance. Springer-Verlag.

Delbaen, F., 2002. Coherent risk measures on general probability spaces. In Sandmann, K., Schönbucher, P. J., Advances in finance and stochastics. Springer-Verlag. 
Diebold, F. X., Li, C., 2006. Forecasting the term structure of government bond yields. Journal of Econometrics 130(2), 337-364.

Di Giuli, A., Kostovetsky, L., 2014. Are red or blue companies more likely to go green? Politics and corporate social responsibility. Journal of Financial Economics 111(1), 158-180.

Drazen, A., Limao, N., Stratmann, T., 2007. Political contribution caps and lobby formation: theory and evidence. Journal of Public Economics 91(3-4), 723-754.

Duffie, D., 1987. Stochastic equilibria with incomplete financial markets. Journal of Economic Theory 41(2), 405-416.

Duffie, D., 2010. Presidential address: asset price dynamics with slow-moving capital. Journal of Finance 65(4), 1237-1267.

Duffie, D., Fleming, W., Soner, H. M., Zariphopoulou, T., 1997. Hedging in incomplete markets with HARA utility. Journal of Economic Dynamics and Control 21(4-5), 753-782.

Estrella, A., Hardouvelis, G. A., 1991. The term structure as a predictor of real economic activity. Journal of Finance 46(2), 555-576.

Estrella, A., Mishkin, F. S., 1998. Predicting U.S. recessions: financial variables as leading indicators. Review of Economics and Statistics 80(1), 45-61.

Fleckenstein, M., Longstaff, F. A., Lustig, H., 2014. The TIPS-Treasury Bond Puzzle. Journal of Finance 69(5), 2151-2197.

Goldman, E., Rocholl, J., So, J., 2009. Do politically connected boards affect firm value?. Review of Financial Studies 22(6), 2331-2360.

Goldman, E., Rocholl, J., So, J., 2013. Politically connected boards of directors and the allocation of procurement contracts. Review of Finance 17(5), 1617-1648.

Grier, K. B., Munger, M. C., 1991. Committee assignments, constituent preferences and campaign contributions. Economic Inquiry 29(1), 24-43.

Hansen, L. P., Jagannathan, R., 1991. Implications of security market data for models of dynamic economies. Journal of Political Economy 99(2), 225-262.

Hansen, L. P., Sargent, T. J., 2001. Robust control and model uncertainty. American Economic Review 91(2), 60-66.

Henderson, V., 2002. Valuation of claims on nontraded assets using utility maximization. Mathematical Finance 12(4), 351-373.

Henderson, V., 2007. Valuing the option to invest in an incomplete market. Mathematics and Financial Economics 1(2), 103-128. 
Henderson, V., Hobson, D., 2002. Real options with constant relative risk aversion. Journal of Economic Dynamics and Control 27(2), 329-355.

Henderson, V., Hobson, D., 2004. Utility indifference pricing - an overview. In Carmona, R., Indifference pricing - theory and applications. Princeton University Press.

Hodges, S., 1998. A generalization of the Sharpe ratio and its application to valuation bounds and risk measures. FORC. University of Warwick.

Hong, H., Kostovetsky, L., 2012. Red and blue investing: values and finance. Journal of Financial Economics 103(1), 1-19.

Hull, J. C., White, A. D., 1990. Pricing interest-rate derivative securities. Review of Financial Studies 3(4), 573-592.

Hull, J. C., 2012. Options, futures and other derivatives (8 ${ }^{\text {th }}$ edition). Prentice Hall.

Jamshidian, F., 1989. An exact bond option formula. Journal of Finance 44(1), 205-209.

Jaschke, S., Küchler, U., 2001. Coherent risk measures and good-deal bounds. Finance and Stochastics 5(2), 181-200.

Kempf, A., Korn, O., Uhrig-Homburg, M., 2012. The term structure of illiquidity premia. Journal of Banking and Finance 36(5), 1381-1391.

Krishnamurthy, A., 2002. The bond/old-bond spread. Journal of Financial Economics 66(2-3), 463506.

Kroszner, R. S., Stratmann, T., 2005. Corporate campaign contributions, repeat giving and the rewards to legislator reputation. Journal of Law and Economics 48(1), 41-71.

Longstaff, F. A., 2004. The flight-to-liquidity premium in US Treasury bond prices. Journal of Business 77(3), 511-526.

MacKenzie, D., 2009. Material markets: how economic agents are constructed. Oxford University Press.

Merton, R., 1973. Theory of rational option pricing. Bell Journal of Economics and Management Science 4(1), 141-183.

Miao, J., Wang, N., 2007. Investment, consumption, and hedging under incomplete markets. Journal of Financial Economics 86(3), 608-642.

Milyo, J., Primo, D., Groseclose, T., 2000. Corporate PAC campaign contributions in perspective. Business and Politics 2(1), 75-88.

Mitchell, M., Pedersen, L. H., Pulvino, T., 2007. Slow moving capital. American Economic Review, American Economic Association papers and proceedings 97(2), 215-220. 
Nelson, C. R., Siegel, A. F., 1987. Parsimonious modeling of yield curves. Journal of Business 60(4), 473-489.

Ovtchinnikov, A. V., Pantaleoni, E., 2012. Individual political contributions and firm performance. Journal of Financial Economics 105(2), 367-392.

Pasquariello, P., Vega, C., 2009. The on-the-run liquidity phenomenon. Journal of Financial Economics 92(1), 1-24.

Pelsser, A., 2000. Efficient methods for valuing interest rate derivatives. Springer-Verlag.

Petersen, M. A., 2009. Estimating standard errors in finance panel data sets: comparing approaches. The Review of Financial Studies 22(1), 435-480.

Snyder, J. M., 1990. Campaign contributions as investments: the US House of Representatives, 1980 - 1986. Journal of Political Economy 98(6), 1195-1227.

Stratmann, T., 1992. Are contributors rational? Untangling strategies of political action committees. Journal of Political Economy 100(3), 647-664.

Stratmann, T., 1995. Campaign contributions and congressional voting: does the timing of contributions matter?. Review of Economics and Statistics 77(1), 127-136.

Stratmann, T., Aparicio-Castillo, F. J., 2006. Competition policy for elections: do campaign contribution limits matter?. Public Choice 127(1-2), 177-206.

Tahoun, A., 2014. The role of stock ownership by US members of Congress on the market for political favors. Journal of Financial Economics 111(1), 86-110.

Titman, S., 1985. Urban land prices under uncertainty. Economic Review 75(3), 505-514.

Thompson, S. B., 2011. Simple formulas for standard errors that cluster by both firm and time. Journal of Financial Economics 99(1), 1-10.

Witko, C., 2011. Campaign contributions, access, and government contracting. Journal of Public Administration Research and Theory 21(4), 761-778. 


\section{Knowledge valorization}

This section is an addendum to the dissertation, a collection of the author's reflections regarding the topic of incomplete markets. In particular, this addendum discusses knowledge valorization (or the process of creating value from knowledge) in the context of the current dissertation.

Academic work can be considered to be value adding if, apart from being scientifically relevant, it is also of social and/or economic relevance. Where finance is concerned, this means that the work is targeted at various stakeholders, from individuals and households to corporations and the society as a whole, in such a way that it highlights either shortcomings or opportunities not considered before, which would make these stakeholders significantly alter their course of action. Therefore, in order to discuss how this dissertation creates value from knowledge we must identify both the shortcomings or opportunities of each market setting presented and the corresponding stakeholders.

Chapters 2 and 3 of this dissertation have asset pricing implications for various types of investors. Chapter 2 describes a pricing mechanism in incomplete markets that is particularly interesting for retail or institutional investors who want to value real options. Real options represent future opportunities and are an important part of the capital budgeting decisions that firms are faced with. Better valuation techniques for real options can help a firm identify valuable projects and in turn lead to a better allocation of resources among projects. Ultimately, such decisions can be vital for the survival of a firm.

Chapter 3 deals with the issue of discounting very long dated cash-flows. It brings into attention perhaps one of the most peculiar UK debt instruments: infinite maturity callable government bonds. The underlying problem is the discounting of cash flows with maturities longer than the longest maturity of traded instruments and the prices of bonds with infinite maturity could reveal valuable information on this matter. The stakeholders in this case are institutional investors, such as pension funds and insurance companies, because these are the type of investors with contractual obligations that last longer than any traded instrument in the market.

The implications of Chapter 3 are of both economic and social nature and are relevant for the society as a whole, because the problem of discounting long-dated cash flows in fact extends to an 
even bigger problem, that of the current pension crisis. Pension funds all over the world currently fear that they will soon not be able to meet their obligations. Apart from the social policies that governments must devise in order to improve the ratio of workers per retiree, this problem must also be tackled from a finance perspective by understanding exactly how underfunded pension funds are. To this end, one must discount the future obligations at the correct discount rate, which is something that is not known with certainty but that can be inferred for instance from market prices of instruments like the UK infinite maturity bonds.

Chapter 4 targets the general public and it has both social and economic relevance. The chapter investigates whether or not the contributions that S\&P500 companies make to election campaigns can increase their chances of subsequently receiving benefits from the government either in the form of procurement contracts or potentially as favorable legislation. There are several stakeholders in this case: various companies, the government, tax payers and their interests are not always aligned. The economic relevance of this topic lies in the fact that it opens up the discussion about whether or not the allocation of tax payer money is efficient and value adding given the increase in election campaign contributions over the years. The social aspect is represented by the fact that the topic questions whether or not an important part of how our society functions - the election system - was corrupted by the process of raising campaign contributions in the sense that contributors expect some form of compensation in return. The purpose of the chapter is not to give a definitive answer to these questions, but to raise awareness of the phenomenon among the general public and to encourage further research in the area.

The topics in this dissertation are diverse and they open up many avenues for further research, especially since the related literature is not so vast. The ideas have already been shared with the general public at international conferences, like the 2012 World Congress of the Bachelier Finance Society in Sydney, the 2012 AsRES - AREUEA Joint International Conference in Singapore, the 2013 ASTIN Colloquium of the International Actuarial Association in The Hague and the 2014 FMA Doctoral Student Consortium in Maastricht. It is the author's hope that these ideas will materialize into academic journal publications. 


\section{Biography}

Oana Floroiu was born on the 20 $0^{\text {th }}$ of September 1986 in Galati, Romania. She completed her undergraduate studies at the Academy of Economic Studies in Bucharest and received a Bachelor's degree in Economics, specialization Finance and Banking.

She subsequently pursued a Master's in Financial Economics, the Asset Pricing track, and a Master's in Economic and Financial Research, specialization Financial Economics, both at Maastricht University.

Oana worked for one year as a Research Assistant at the Finance Department of Maastricht University, before she joined as a PhD Candidate in 2011. Her three-year PhD position was financed by NWO (the Netherlands Organization for Scientific Research) via the Graduate Program 2011.

The work collected in this dissertation has been presented at international conferences like the 2012 World Congress of the Bachelier Finance Society in Sydney, the 2012 AsRES - AREUEA Joint International Conference in Singapore, the 2013 ASTIN Colloquium of the International Actuarial Association in The Hague and the 2014 FMA Doctoral Student Consortium in Maastricht. Oana visited the School of Banking and Finance of the University of New South Wales in Sydney, whose hospitality during June-July 2012 is highly appreciated.

Since November 2014, Oana has been working at KPMG Netherlands in the Financial Risk Management Department. 